UNIVERSIDADE DE SÃO PAULO

ESCOLA DE ENGENHARIA DE SÃO CARLOS

DEPARTAMENTO DE ENGENHARIA ELÉTRICA

PROGRAMA DE PÓS-GRADUAÇÃO EM ENGENHARIA ELÉTRICA

ANDERSON OLIVEIRA SILVA

\title{
MODELAGEM DE CRISTAIS FOTÔNICOS TRIDIMENSIONAIS PELO MÉTODO DAS DIFERENÇAS FINITAS NO DOMÍNIO DO TEMPO (FDTD)
}

São Carlos - SP

2008 
UNIVERSIDADE DE SÃO PAULO

ESCOLA DE ENGENHARIA DE SÃO CARLOS

DEPARTAMENTO DE ENGENHARIA ELÉTRICA

PROGRAMA DE PÓS-GRADUAÇÃO EM ENGENHARIA ELÉTRICA

ANDERSON OLIVEIRA SILVA

\section{MODELAGEM DE CRISTAIS FOTÔNICOS TRIDIMENSIONAIS PELO MÉTODO DAS DIFERENÇAS FINITAS NO DOMÍNIO DO TEMPO (FDTD)}

Dissertação apresentada à Escola de Engenharia de São Carlos (USP/SC) como parte dos requisitos para a obtenção do título de Mestre em Engenharia Elétrica.

Área de concentração: Telecomunicações

Orientador: Prof. Dr. Murilo Araujo Romero

São Carlos - SP

2008 


\section{DEDICATÓRIA}

A Arlete Oliveira da Silva e Raimundo Nazareno Mesquita da Silva, meus pais, pelo incansável apoio despendido ao longo de minha educação. 


\section{AGRADECIMENTOS}

Ao grupo de Telecomunicações da Escola de Engenharia de São Carlos, pelo apoio logístico à realização deste trabalho.

Ao Conselho Nacional de Desenvolvimento Científico e Tecnológico (CNPq) pelo apoio financeiro à realização do curso de mestrado. 
"A Ciência não é luxo, é necessidade. Quando esta idéia estiver difundida o bastante para ser aceita pelas sociedades humanas como um legado tão legítimo e profundo quanto valores religiosos, haverá razões para confiança no futuro.

Caso contrário estaremos sempre à mercê da sorte."

Ulisses Capozzoli, doutor em Astronomia pela USP e editor da Scientific American Brasil. 


\section{SUMÁRIO}

LISTA DE SIGLAS .......................................................................... 1

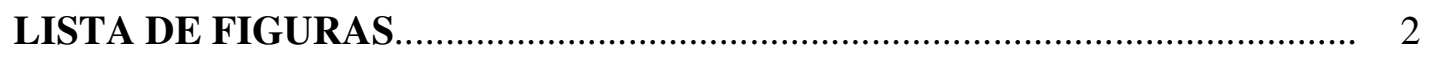

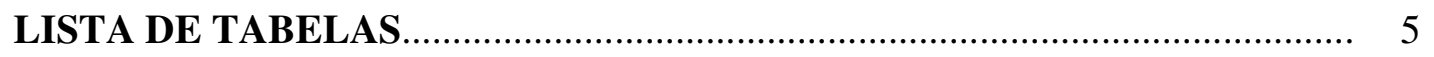

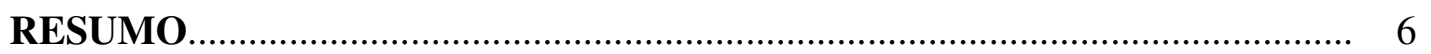

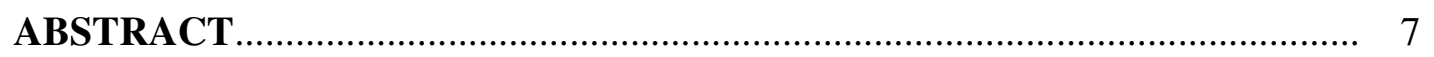

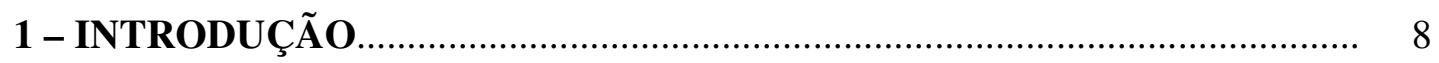

1.1 - Histórico sobre cristais fotônicos.............................................................. 11

1.2 - Dificuldades envolvidas na simulação computacional da propagação eletromagnética por cristais fotônicos 3D ................................................ 17

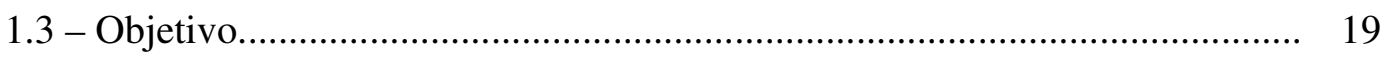

\section{2 - MODELAGEM DE CRISTAIS FOTÔNICOS PELO MÉTODO DAS} DIFERENÇAS FINITAS NO DOMÍNIO DO TEMPO (FDTD)...................... 21

2.1 - Eletromagnetismo de estruturas periódicas............................................... 22

2.1.1 - O método da expansão em ondas planas (PWEM - plane wave expansion method)........................ 25

2.2 - O método FDTD - características gerais............................................... 28

2.2.1 - As expressões para as componentes de campo elétrico e magnético em FDTD.......................................................................... $\quad 30$

2.3 - A modelagem da excitação eletromagnética pelo método FDTD................ 37

2.3.1 - Superposição de ondas planas....................................................... 38

2.3.2 - O pulso senoidal de envoltória gaussiana......................................... 39

2.4 - Condições de contorno - modelagem das terminações do domínio computacional.. 
2.4.1 - Condição de contorno periódica.

2.4.2 - Condição de camada perfeitamente casada - PML............................ 44

2.5 - Análise no domínio espectral................................................................ 48

2.6 - Fluxograma do algoritmo baseado em FDTD.......................................... 50

\section{3 - DIAGRAMA DE BANDAS DO CRISTAL FOTÔNICO}

TRIDIMENSIONAL COMPOSTO POR OPALAS DE LÁTEX ....................... 52

3.1 - Técnicas de preparação de cristais fotônicos tridimensionais......................... 53

3.1.1 - Preparação do cristal FCC constituído por opalas de látex................. 55

3.2 - Definição da malha computacional............................................................ 57

3.2.1 - Suporte computacional utilizado................................................... 59

3.2.2 - Nomenclatura empregada nesta dissertação...................................... 61

3.3 - Cristal formado por opalas inversas - Aferição do algoritmo FDTD para o cálculo de diagrama de bandas.

3.3.1 - Comparação entre o diagrama de bandas e a curva de dispersão do ar - modos radiados e modos confinados no cristal fotônico tridimensional.

3.4 - Cristal auto-organizado formado por opalas de látex.

3.4.1 - Modos radiados e modos confinados do cristal formado por opalas de látex

3.5 - Diagrama de bandas do cristal formado por opalas de látex para $f p=54 \% \ldots \ldots$.

\section{4 - ESPECTROS DE REFLETÂNCIA ASSOCIADOS AO CRISTAL} COMPOSTO POR OPALAS DE LÁTEX.

4.1 - Espectros de Refletância associados à família de planos (111) do cristal de látex.

4.1.1 - Procedimento de cálculo do comprimento de onda de Bragg $\left(\lambda_{M}\right)$ pelo método FDTD.

4.1.2 - Variação do comprimento de onda de Bragg à medida que o ângulo de incidência é aumentado. 
4.2 - Variação da largura do espectro de refletância com o ângulo de incidência.. 88 5 - CONCLUSÃO

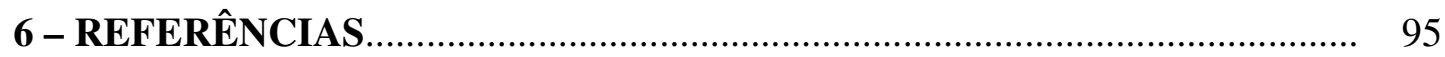




\section{LISTA DE SIGLAS}

PBG

FDTD

FCC

PWEM

FEM.

TEM.

PML

$\mathrm{ABC}$

DFT.

FFT.

LBL

$f p$
Photonic band gap

Finite difference time domain

Face-centered-cubic

Plane wave expansion method

Finite element method

Transverso eletromagnético

Perfectly matched layer

Absorbing boundary condition

Discrete Fourier transform

Fast Fourier transform

Layer-by-layer

Fator de empacotamento 


\section{LISTA DE FIGURAS}

Fig 1.1 - Exemplos de cristais fotônicos naturais: (a) opalas, minerais constituídos por microestruturas esféricas de sílica responsáveis pelo efeito iridescente, (b) morpho menelaus, borboleta cujas asas são formadas por uma rede periódica porosa que confere a elas um tom azulado.

Fig 1.2 - (a) Cristal fotônico 1D, (b) cristal fotônico 2D e (c) cristal fotônico 3D....

Fig 1.3 - Esquema de fabricação do cristal Yablonovite [8]-[9]

Fig 1.4 - Em (a) é mostrada uma visualização esquemática de um cristal tridimensional tipo woodpile [10], (b) corresponde à fotomicrografia de opalas monodispersas de látex em um cristal coloidal [11].

Fig 1.5 - Guia de onda implementado em photonic crystal slab

Fig 1.6 - Exemplos de dispositivos ópticos baseados em slabs de cristal fotônico: (a) guia de onda com curvatura de $90^{\circ}$; (b) divisor de potência óptica; (c) microcavidade ressonante.

Fig 2.1 - Célula de Yee tridimensional. As componentes de campo magnético estão deslocadas das componentes de campo elétrico por meio incremento espacial. O índices $i, j$ e $k$ referem-se aos passos espaciais nas direções $x$, $y$ e $z$, respectivamente.

Fig 2.2 - Molécula computacional para o arranjo leapfrog. A circuferência indica o valor desconhecido da função $u$ e os quadrados referem-se aos valores armazenados na memória computacional.

Fig 2.3 - Propagação de uma onda TEM em um cristal fotônico unidimensional perfeito de período $a$ na direção $z$

Fig 2.4 - Convergência da autofreqüência como uma função do número de ondas planas usadas em (2.24). Este gráfico refere-se à vigésima banda da zona de Brillouin do cristal mostrado na Fig. 2.3.

Fig 2.5 - (a) Sinal senoidal $f(t)$ modulado por uma envoltória gaussiana. (b) Módulo da transformada de Fourier do sinal $f(t)$.....

Fig 2.6 - Supercélula de um cristal bidimensional com célula unitária quadrada. Observa-se que a supercélula contém o defeito do cristal.

Fig 2.7 - Parte superior direita da camada PML. As demais regiões são similares às correspondentes nesta figura 
Fig 2.8 - Fluxograma do algoritmo baseado em FDTD aplicado a cristais fotônicos. $\mathrm{O}$ critério de parada $\mathrm{N}_{\max }$ corresponde ao maior passo de tempo definido no algoritmo.

Fig 3.1 - Fotomicrografias das amostras cristalinas formadas por opalas de látex em uma rede FCC: (A) látex-250, (B) látex-300, (C) látex-350 e (D) látex-400 [32].....

Fig 3.2 - Célula unitária de um cristal FCC implementado em uma malha de diferenças finitas. As coordenadas espaciais são especificadas em termos dos passos de discretização espacial da malha computacional.

Fig 3.3 - Visualização do cristal fotônico FCC considerado infinito apenas nas direções $x$ e $y$. O comprimento de $5 a$ corresponde ao tamanho completo da malha computacional na direção $z$, englobando a altura de $3 a$ do cristal e $2 a$ relativamente ao espaço livre.

Fig 3.4 - Cluster do grupo de telecomunicações da Escola de Engenharia de São Carlos/USP.

Fig 3.5 - Diagrama de bandas do cristal formado por opalas inversas. A faixa em preto corresponde ao PBG completo

Fig 3.6 - Distribuição de densidade de fluxo elétrico para os pontos (a) $\mathbf{X}$ e (b) $\mathbf{K}$ pertencentes à zona irredutível de Brillouin do cristal formado por opalas inversas. As coordenadas $x$ e $y$ indicam os passos discretização espacial...

Fig 3.7 - Modos radiados e modos confinados do cristal fotônico formado por opalas inversas. Os modos acima da curva de dispersão do ar (linha em vermelho) correspondem aos modos radiados. Os modos abaixo da curva de dispersão do ar são os modos confinados do cristal

Fig 3.8 - Diagrama de bandas obtido por FDTD para o cristal formado por opalas de látex.

Fig 3.9 - Variação do PBG relativo em função do índice de refração para a direção $\mathbf{X}$ da zona irredutível de Brillouin; $\omega_{0}$ corresponde à frequiência central do band gap

Fig 3.10 - Distribuição da densidade de fluxo elétrico para os pontos (a) $\mathbf{X}$ e (b) $\mathbf{K}$ pertencentes à zona irredutível de Brillouin do cristal formado por opalas de látex. As coordenadas $x$ e $y$ indicam os passos de discretização espacial.

Fig 3.11 - Modos radiados e modos confinados do cristal fotônico formado por opalas de látex. Os modos acima da curva de dispersão do ar (linha em vermelho) correspondem aos modos radiados. Os modos abaixo da curva de dispersão do ar são os modos confinados do cristal. 
Fig 3.12 - Diagrama de bandas do cristal de látex $\operatorname{com} f p=54 \%$. A faixa em preto corresponde ao PBG completo.

Fig 4.1 - Espectros de refletância obtidos experimentalmente sob diferentes ângulos de incidência: (A) látex-250, (B) látex-300, (C) látex-350, (D) látex-400 [32].....

Fig 4.2 - Visualização esquemática dos pontos onde é tomada a sequiência temporal dos campos incidente e refletido. A linha tracejada é normal à fronteira da estrutura modelada. A linha em cinza delimita o domínio computacional.

Fig 4.3 - Variação do comprimento de onda de Bragg com $\operatorname{sen}^{2} \theta$. Os diagramas correspondem às quatro amostras fabricadas: (a) látex-250, (b) látex-300, (c) látex-350 e (d) látex-400

Fig 4.4 - Espectros de refletância para ângulos de incidência (a) $\theta=2^{\circ}$, (b) $\theta=10^{\circ}$, (c) $\theta=15^{\circ}$ e (d) $\theta=20^{\circ}$ no plano (111) obtidos por FDTD

Fig 4.5 - Variação do comprimento de onda de Bragg à medida que a distância interplanar $d_{111}$ é aumentada. O valor do ângulo de incidência está fixado em $\theta=38^{\circ}$

Fig 4.6 - A definição de FWHM compreende o intervalo espectral no qual a intensidade cai à metade do valor de pico.

Fig 4.7 - Variação do FWHM calculada por FDTD à medida que o ângulo de incidência é aumentado, o valor percentual é tomado em relação ao comprimento de onda do pico de refletância. 


\section{LISTA DE TABELAS}

Tabela I - Valores das autofreqüências normalizadas que delimitam o PBG no cristal formado por opalas inversas. Comparação entre os resultados deste trabalho e aqueles

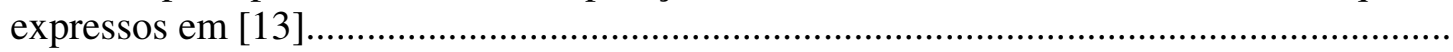

Tabela II - Valores das autofreqüências normalizadas que delimitam o PBG no cristal formado por opalas inversas. Comparação entre os resultados deste trabalho e aqueles expressos em [31]....

Tabela III - Valores de fator de empacotamento, diâmetro das opalas e índice de refração efetivo das amostras de cristal fotônico fabricadas. 


\section{RESUMO}

A modelagem numérica de cristais fotônicos tridimensionais é o objeto de estudo deste trabalho. Especificamente, o método das diferenças finitas no domínio do tempo (FDTD) é utilizado para a modelagem de um cristal FCC (face-centered-cubic) formado por opalas de látex imersas em ar. Por meio de uma análise comparativa com o cristal formado por opalas inversas (opalas de ar incrustadas em uma matriz dielétrica com alto índice de refração), é mostrado que o baixo contraste de índice de refração do cristal de látex é característica preponderante para a inexistência de uma banda proibida completa. No entanto, podem ser observadas bandas fotônicas proibidas ao longo de algumas direções de propagação, como é evidenciado através da investigação da difração de Bragg relativa à família de planos cristalinos (111). Sempre que possível os resultados numéricos são comparados com os dados experimentais disponíveis.

Palavras-chave: diferenças finitas, cristais fotônicos, difração de Bragg. 


\begin{abstract}
The numerical modeling of tridimensional photonic crystals is the object of study in this work. Especifically, the finite difference time domain method (FDTD) is used for the modeling of a FCC (face-centered-cubic) crystal composed by latex opals immersed in air. Through a comparative analysis to a crystal composed by inverse opals (close-packed air opals in a dielectric matrix with high refractive index), it is shown that the low contrast of the latex crystal is the crucial characteristic to prevent the rising of a complete photonic band gap. However, photonic band gaps can be observed for certain directions of propagation, as it is demonstrated by the investigation of Bragg diffraction related to the (111) crystalline planes. Wherever possible, the numerical results are compared to available experimental data.
\end{abstract}




\section{1 - INTRODUÇÃO}

Desde a década de 80 , passou a haver um progressivo avanço no desenvolvimento de dispositivos capazes de controlar a propagação de fótons em escalas micrométricas e nanométricas. A motivação para a fabricação destes dispositivos reside na implementação de chips totalmente ópticos com escala de integração comparável a dos modernos circuitos eletrônicos. Isto torna possível superar limitações encontradas pelo transporte e processamento de dados empregando elétrons e, por conseqüência, permite atender a crescente demanda por um tráfego de informações cada vez mais intenso no mundo globalizado. Cristais fotônicos têm contribuído consideravelmente para a evolução deste contexto. Estes materiais possibilitam manipular a emissão e propagação luminosa a graus elevados de confinamento e guiamento, exercendo papel crucial na implementação, miniaturização e aumento da densidade de integração de circuitos ópticos.

Cristais fotônicos são estruturas que apresentam variação periódica de um índice de refração e possuem constante de rede comparável a comprimentos de onda da faixa espectral óptica, afetando a propagação de fótons de uma maneira similar ao que ocorre com elétrons em cristais semicondutores. Isto significa que a rede cristalina leva à inibição de emissão luminosa espontânea em determinadas faixas espectrais, as quais são denominadas PBGs (photonic band gaps), não apresentando assim um continuum de energias permitidas para propagação fotônica em todas as direções.

Um proeminente exemplo de cristal fotônico são as opalas encontradas na natureza (Fig. 1.1 (a)), minerais compostos por cristais de sílica, os quais são responsáveis pela iridescência característica destas pedras. Outro interessante exemplo é encontrado nas asas de 
borboletas do gênero morpho, cuja coloração provém da difração da luz por uma rede periódica porosa (Fig. $1.1(b))$.

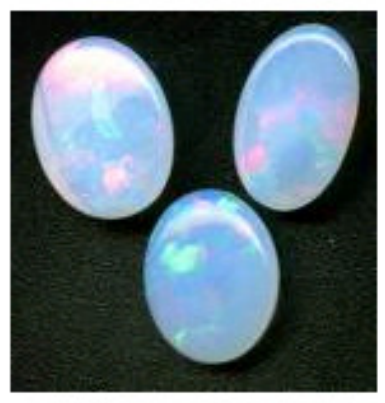

(a)

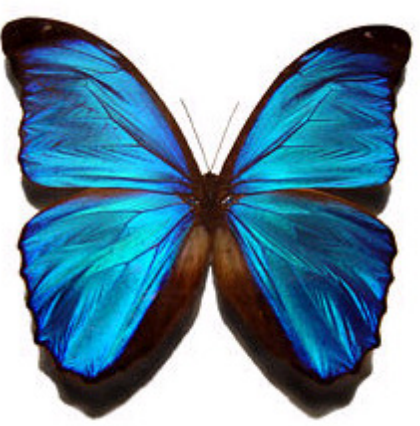

(b)

Fig. 1.1 - Exemplos de cristais fotônicos naturais: (a) opalas, minerais constituídos por microestruturas esféricas de sílica responsáveis pelo efeito iridescente; (b) morpho menelaus, borboleta cujas asas são formadas por uma rede periódica porosa que confere a elas um tom azulado.

Cristais fotônicos podem ser classificados em três tipos, de acordo com a variação espacial da rede periódica [1]-[2]. No caso em que esta variação ocorre apenas ao longo de uma única direção, o cristal é denominado unidimensional (1D). Caso a periodicidade ocorra ao longo de um plano, o cristal é denominado bidimensional (2D) e, se a rede periódica se estender ao longo de todas as direções espaciais, o cristal fotônico é dito ser tridimensional (3D). A Fig. 1.2 mostra exemplos de redes cristalinas unidimensionais, bidimensionais e tridimensionais.

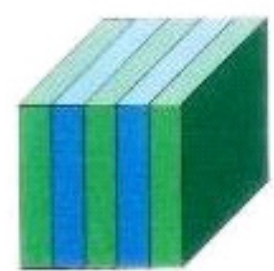

(a)

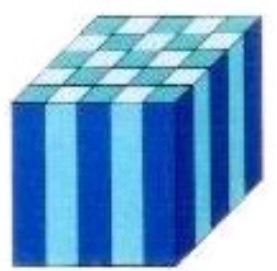

(b)

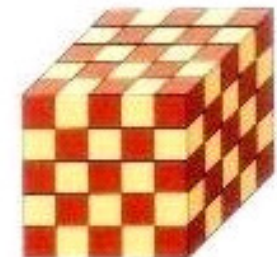

(c)

Fig. 1.2 - (a) Cristal fotônico 1D; (b) cristal fotônico 2D e (c) cristal fotônico 3D. 
Os avanços das técnicas de fabricação, auxiliados pelo incremento do suporte a simulações computacionais, estimulou consideravelmente o interesse da comunidade científica na implementação de cristais fotônicos. Isto, por seu turno, tornou possível investigações das propriedades ópticas de diversas configurações de redes cristalinas, englobando desde espelhos de Bragg (cristais fotônicos 1D), até redes cuja periodicidade se estende ao longo das três dimensões espaciais [1]-[2].

Partindo do que foi acima descrito, chega-se ao atual estágio da tecnologia de dispositivos baseados em cristais fotônicos, em que guias de onda, nanolasers, filtros e chaveadores ópticos propiciam alta escala de integração em circuitos optoeletrônicos e possibilitam tornar realidade a implementação de circuitos totalmente ópticos [1]-[2].

Este trabalho motiva-se no cenário supracitado para abordar a modelagem numérica de cristais fotônicos com periodicidade tridimensional. Esta modelagem utiliza o método das diferenças finitas no domínio do tempo (finite differrence time domain - FDTD) como ferramenta numérica, a qual é aplicada à investigação das propriedades ópticas de um cristal formado por opalas de látex organizadas em um arranjo FCC (face-centered-cubic).

Com a finalidade de fundamentar cronologicamente este trabalho, a seção seguinte dedica-se a apresentar um histórico sobre a evolução das pesquisas científicas no campo de cristais fotônicos. Posteriormente, especial atenção é dada às dificuldades envolvidas na simulação computacional da propagação da luz por cristais 3D. Esta seção tem por finalidade justificar o objetivo deste trabalho, o qual é apresentado ao final deste capítulo. 


\section{1 - Histórico sobre cristais fotônicos}

Nos últimos anos, o incremento nos estudos sobre as propriedades de cristais fotônicos possibilitou significativos avanços no controle do fluxo óptico. Tal avanço tecnológico é descrito a seguir por meio de um histórico sobre a evolução nas pesquisas acerca de cristais fotônicos, com especial atenção para o desenvolvimento das configurações tridimensionais.

As propriedades eletromagnéticas de redes periódicas unidimensionais e bidimensionais já vinham sendo estudadas desde o século XIX [2]. No entanto, o desenvolvimento de pesquisas sobre cristais fotônicos passou a receber maior atenção da comunidade científica somente com a publicação dos artigos de Yablonovitch [3] e John [4], em 1987. Estes trabalhos, de caráter teórico, procuravam demonstrar que a aplicação das equações de Maxwell a determinadas geometrias cristalinas tridimensionais possibilitava o controle da propagação eletromagnética por meio da existência de bandas fotônicas proibidas.

Dois anos após a publicação destes artigos, Yablonovitch e Gmitter [5] fabricaram um cristal de célula unitária FCC tendo em vista a verificação experimental do aparecimento de um PBG na região espectral de microondas. Entretanto, as medições dos espectros de reflexão contrariaram as previsões teóricas, mostrando que o band gap desaparecia nas bordas da primeira zona de Brillouin devido a uma superposição de bandas permitidas nestas localizações. Esta contradição entre os resultados teóricos e experimentais levou à revisão do formalismo matemático utilizado, o qual se baseava em uma aproximação escalar para a solução da equação de onda. Somente com a adoção rigorosa da natureza vetorial desta equação, notabilizada pelo método da expansão em ondas planas (plane wave expansion method - PWEM), passou a haver concordância entre os resultados teóricos e os experimentais [6]. 
Em 1990, Ho et al. [7] publicam o primeiro trabalho teórico que previu corretamente a existência de uma geometria cristalina com um completo PBG. Este trabalho consistiu essencialmente em abandonar a aproximação escalar utilizada em [5] e obedecer rigorosamente à natureza vetorial dos campos eletromagnéticos. A estrutura consistia em uma rede diamante de esferas dielétricas imersas em ar. A maior parte do cristal era composta por ar (cerca de 81\%), o que significa que as esferas eram interconectadas. $O$ PBG relativo encontrado era de aproximadamente $29 \%$ e tinha sua largura fortemente dependente do fator de empacotamento. Outro importante resultado é que o PBG encontrado continuava existindo mesmo quando se fabricava o material inverso, ou seja, esferas de ar imersas no material dielétrico.

Um ano após a publicação do artigo de Ho et al., Yablonovitch apresenta à comunidade científica um cristal fotônico com rede diamante que também possui um completo PBG, uma geometria que ficou conhecida como Yablonovite [8]-[9]. A fabricação deste cristal foi realizada por meio dos seguintes procedimentos: um corpo de material dielétrico foi coberto por uma matriz com um arranjo periódico triangular de lacunas. Posteriormente, cada lacuna foi perfurada três vezes, com as perfurações fazendo um ângulo de $35^{\circ}$ relativamente à reta normal e separadas entre si por $120^{\circ}$ no plano azimutal. O esquema de fabricação deste cristal é mostrado na Fig. 1.3.

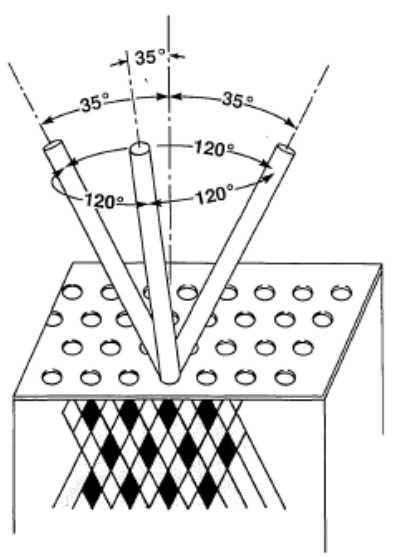

Fig. 1.3 - Esquema de fabricação do cristal Yablonovite [8]-[9]. 
Após os trabalhos iniciais de Ho e Yablonovitch, seguiram-se publicações de diversos artigos com distintas geometrias cristalinas, passando a investigar estruturas que pudessem apresentar bandas proibidas na região óptica do espectro eletromagnético. Neste contexto, destacam-se os cristais tipo woodpile, os quais são formados por múltiplas camadas de wafers dielétricos organizados por procedimento LBL (layer-by-layer), tal como mostra a Fig. 1.4 (a) [10]. Entretanto, a redução das dimensões desta estrutura para escalas nanométricas mostrou-se ser de elevada complexidade, o que acabou por limitar a faixa espectral de aplicação deste tipo de cristal. Tendo em vista superar esta limitação, a comunidade científica passou a dedicar especial interesse em cristais coloidais auto-organizados (Fig. 1.4 (b)) [11]. Sob este prisma, é importante ressaltar o trabalho de Tarhan et al. [12] publicado em 1996, que investigou as bandas fotônicas de cristais coloidais formados por opalas artificiais de poliestireno. Em 1998, Busch e John [13] publicam um importante artigo que mostra como o contraste de índice de refração pode ser utilizado para controlar a largura do PBG em cristais formados por opalas inversas, isto é, esferas de ar imersas em um material dielétrico com índice de refração maior que 1,0. No entanto, a grande desvantagem destes cristais é a dificuldade de introdução de defeitos controlados para aplicações de guiamento e chaveamento ópticos [13].

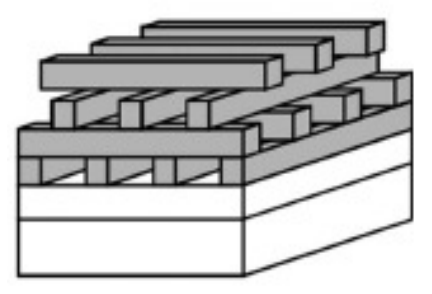

(a)

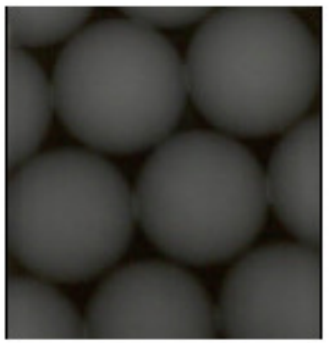

(b)

Fig 1.4 - Em (a) é mostrada uma visualização esquemática de um cristal tridimensional tipo woodpile [10], (b) corresponde à fotomicrografia de opalas monodispersas de látex em um cristal coloidal [11]. 
Diante da dificuldade de adição controlada de defeitos em redes cristalinas tridimensionais, a perspectiva de desenvolver guias ópticos a partir destas estruturas ainda encontrava grandes obstáculos para sua concretização. Somava-se a isto a necessidade de elevado suporte de processamento e armazenamento computacionais para a realização de modelagens realísticas de cristais tridimensionais, isto é, modelagens capazes de compreender defeitos da rede cristalina e a extensão finita do cristal.

Como proposta para superar estas limitações, Meade et al. [14] publicam o conceito de fitas de cristal fotônico (photonic crystal slabs). Estas estruturas consistem em redes periódicas bidimensionais de extensão finita nas quais são introduzidos estreitos canais por onde a luz pode ser guiada com mínimas perdas (Fig. 1.5).

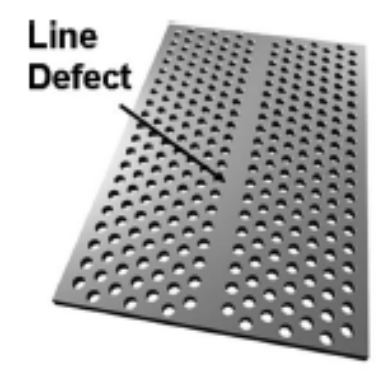

Fig. 1.5 - Guia de onda implementado em photonic crystal slab.

Acompanhando a publicação deste trabalho, diversas investigações foram realizadas com slabs de cristal fotônico, procurando mostrar o alto confinamento da luz mesmo em canais que sofriam grandes curvaturas, como pode ser verificado, por exemplo, em [15]-[16]. Empregando o conceito de slab de cristal fotônico, Villeneuve et al. [17] conseguem implementar uma microcavidade ressonante com alto fator de qualidade por meio da introdução de um defeito local (ou pontual). Este trabalho propiciou a implementação de lasers a partir de cristais fotônicos em microescala e abriu caminho para a obtenção de nanolasers. 
Seguindo estes trabalhos, Johnson et al. [18] estudaram o efeito da espessura finita de slabs de cristal fotônico na largura do band gap. Foi demonstrado que, passando de uma estrutura infinita para uma rede periódica bidimensional de espessura finita, a largura do band gap sofre uma redução superior a 40\% em relação ao caso ideal devido a perdas de radiação.

Diante do contexto acima, os slabs de cristal fotônico tornaram-se a base de implementação de diversos dispositivos ópticos. Do ponto de vista experimental, isto se deve à facilidade de fabricação de tais estruturas. Do ponto de vista teórico, apesar de o cristal possuir extensão finita, a periodicidade apenas bidimensional torna o esforço computacional para cálculos de diagrama de bandas e espectros de refletância/transmitância bem menor que no caso de redes periódicas tridimensionais.

A elevada capacidade de confinamento e guiamento óptico de slabs de cristal fotônico pode ser evidenciada no desenvolvimento de demultiplexadores para operação em sistemas WDM [19]-[20]. A eficiência de acoplamento com outros dispositivos fotônicos, como fibras ópticas, também é consideravelmente melhorada diante do emprego destes cristais como acopladores ou chaveadores ópticos [21]-[22].

Uma contribuição importante de slabs de cristal fotônico reside no desenvolvimento de fontes laser com eficiência superior às fontes convencionais [23]-[24]. Em 2007, o controle da resistência térmica de uma nanocavidade baseada em slab de cristal fotônico propiciou obter um nanolaser com operação em onda contínua à temperatura ambiente [25]. Outra importante área de aplicação corresponde à biofotônica, em que estes cristais têm sido empregados para operar como biosensores para medições de concentração de proteínas, possibilitando precisão na escala de $0,2 \mu \mathrm{g} / \mathrm{ml}[26]-[27]$.

A Fig. 1.6 ilustra alguns exemplos de dispositivos baseados em slabs de cristal fotônico. 


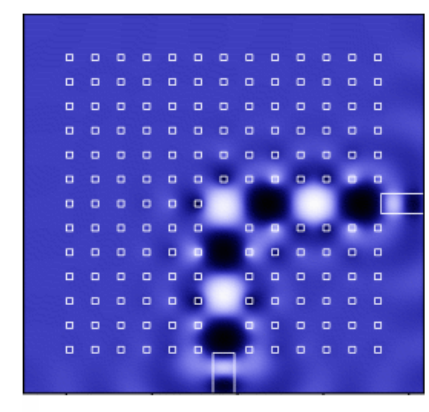

(a)

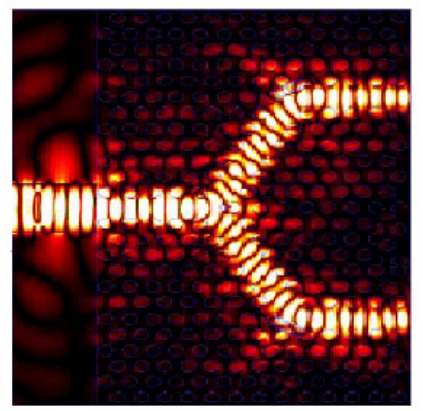

(b)

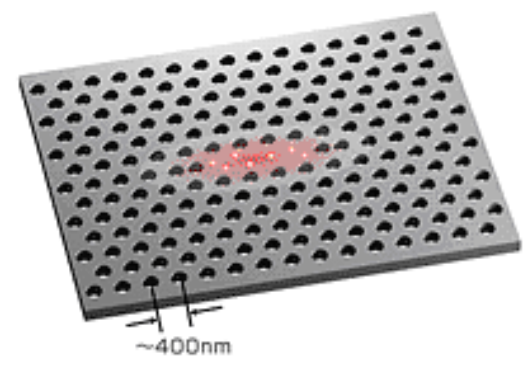

(c)

Fig. 1.6 - Exemplos de dispositivos ópticos baseados em slabs de cristal fotônico: (a) guia de onda com curvatura de $90^{\circ}$; (b) divisor de potência óptica; (c) microcavidade ressonante.

Apesar de atualmente os slabs de cristais 2D serem amplamente empregados em sistemas ópticos, a atual escala de evolução das técnicas de fabricação e do suporte para simulações computacionais propicia que esforços sejam direcionados para pesquisas com cristais fotônicos de periodicidade tridimensional, trazendo como principal impacto tecnológico o controle da propagação luminosa em todas as direções espaciais [28]-[29]. Este atual estágio de desenvolvimento de cristais fotônicos se configura como o contexto no qual está inserido o presente trabalho, o qual se dedica a desenvolver uma modelagem numérica de cristais fotônicos tridimensionais por meio do método FDTD.

No entanto, antes de abordar o objetivo deste trabalho, são mostradas a seguir as dificuldades envolvidas na análise numérica de cristais 3D, procurando evidenciar a importância central do desenvolvimento do suporte para simulações computacionais no estudo destas estruturas. 


\section{2 - Dificuldades envolvidas na simulação computacional da propagação eletromagnética por cristais fotônicos $3 \mathrm{D}$.}

O emprego de cristais fotônicos 1D e 2D em sistemas ópticos é uma realidade palpável. As vantagens de aplicação destes materiais são a facilidade de fabricação e existência de suporte computacional ao projeto de dispositivos.

Entretanto, as propriedades ópticas destes cristais são restritas apenas a uma única direção ou a um plano. Por outro lado, o completo controle da propagação de fótons ao longo de todo o espaço deve considerar, necessariamente, o emprego de cristais fotônicos com periodicidade tridimensional.

Ao lado das dificuldades de fabricação de redes cristalinas tridimensionais, o que requer métodos com alto grau de precisão, o desenvolvimento de algoritmos capazes de simular a propagação eletromagnética em cristais fotônicos 3D é outro desafio crucial para a comunidade científica. Para que seja considerado eficiente, o algoritmo implementado deve assegurar o cálculo de uma resposta eletromagnética precisa em uma larga faixa espectral. Este requisito requer elevado custo de processamento e memória computacionais para ser atendido. Como consequiência, isto limitou o cálculo da propagação eletromagnética a cristais 3D de rede cristalina perfeita e infinita.

Como mencionado na seção anterior, o estudo das propriedades ópticas de cristais fotônicos tridimensionais teve como ferramenta de cálculo inicial o método da expansão em ondas planas (PWEM), o qual permite calcular o diagrama de bandas do cristal adotando rigorosamente a natureza vetorial dos campos eletromagnéticos. No entanto, muito da eficiência deste método deve-se à consideração de que a rede periódica é ideal e, como conseqüência, pode ser modelada utilizando apenas uma célula unitária do cristal. Se por um lado isto possibilita 
computar as frequiências permitidas e proibidas da estrutura com o suporte computacional disponível, por outro, não há a possibilidade de computar espectros de transmissão/reflexão, pois os cálculos PWEM são restritos ao interior do cristal.

À época da publicação dos primeiros artigos teóricos sobre cristais fotônicos tridimensionais, já era notória a capacidade do método FDTD de superar as limitações inerentes ao PWEM. Essencialmente, o método FDTD é baseado na resolução direta das equações diferenciais de Maxwell para o cálculo de campos eletromagnéticos em um dado meio, seja ele contínuo ou estratificado [30]. Este método encontrou adesão massiva entre diversos grupos de pesquisa dedicados ao estudo de cristais fotônicos. Entretanto, a execução do algoritmo FDTD requer alta velocidade de processamento e grande capacidade de armazenamento de dados. As razões deste elevado esforço computacional serão discutidas detalhadamente no capítulo 2, mas se pode adiantar que elas são decorrentes das seguintes características do método: as células de discretização do domínio computacional devem ser de, no máximo, 1/40 de comprimento de onda para evitar dispersão numérica e, para que o algoritmo seja estável, o incremento temporal é limitado por um valor máximo relacionado aos incrementos espaciais [30]. Como conseqüência, sua aplicação esteve por muito tempo restrita a geometrias 1D e 2D.

Até recentemente, a grande maioria das pesquisas esteve focada na exploração das propriedades ópticas de slabs de cristal fotônico utilizando como ferramenta de cálculo o método FDTD, como é bem exemplificado em [20]-[22]. Nestes estudos, apesar de o método ser empregado em sua forma tridimensional, de tal maneira a levar em conta a espessura finita do cristal, a rede cristalina simulada apresenta uma periodicidade apenas bidimensional.

Somente com recentes avanços na arquitetura, processamento e memória computacionais, tornou-se viável investigar a modelagem por FDTD de cristais fotônicos com periodicidade tridimensional. 
O marco inicial da aplicação do método FDTD a uma rede cristalina tridimensional é o trabalho desenvolvido por Hermann e Hess [31]. Este trabalho utilizou o método FDTD na dedução do diagrama de bandas de um cristal fotônico formado por opalas inversas, procurando demonstrar que, para a realização de cálculos suficientemente precisos, era necessário obter a transformada de Fourier de uma dada componente de campo em diversos pontos da malha computacional. Conforme mencionado na publicação, mesmo com a utilização de um cluster de processadores para o cálculo do diagrama de bandas, o algoritmo consumiu tempo de processamento superior a um mês.

A dissertação vale-se da infraestrutura computacional disponível atualmente para revisitar o método FDTD e explorar sua robustez na modelagem de um cristal fotônico tridimensional, levando em consideração a espessura finita da rede cristalina.

\section{3 - Objetivo}

Este trabalho tem como objetivo a implementação de um algoritmo FDTD para o cálculo de parâmetros espectrais de cristais fotônicos com periodicidade tridimensional, a saber: diagrama de bandas e espectros de refletância.

Para o cálculo do diagrama de bandas, a modelagem desenvolvida neste trabalho segue o procedimento descrito em [31], com a diferença de que a rede cristalina passa a ser considerada finita ao longo de uma direção. O cálculo de espectros de refletância possibilita investigar padrões de difração de Bragg à medida que o ângulo de incidência em relação a um dado plano cristalino é variado. 
O algoritmo desenvolvido é aplicado ao estudo do cristal fotônico de célula unitária FCC fabricado pelo Instituto de Química de Araraquara, unidade subordinada à Universidade Estadual Paulista (UNESP) [32]. Este cristal é formado por opalas de látex e foi fabricado utilizando técnica de auto-organização. Os estudos teóricos realizados por FDTD visam investigar as propriedades da propagação luminosa neste cristal, as quais haviam sido já estudadas experimentalmente [32].

Como este trabalho realiza a aplicação do algoritmo desenvolvido a uma estrutura cristalina real, além da discussão acerca do método numérico empregado, também é realizada uma breve explanação sobre técnicas de fabricação, com ênfase no processo de preparação do cristal formado por opalas de látex. A inclusão deste tópico no trabalho é de grande importância para esclarecer diferenças entre os resultados obtidos teoricamente e aqueles determinados experimentalmente. 


\section{2 - MODELAGEM DE CRISTAIS FOTÔNICOS PELO MÉTODO DAS DIFERENÇAS FINITAS NO DOMÍNIO DO TEMPO (FDTD)}

A modelagem numérica de cristais fotônicos deve considerar rigorosamente a natureza vetorial das equações de Maxwell. Esta exigência é diretamente atendida pelo método das diferenças finitas no domínio do tempo (FDTD). A aplicação deste método ao estudo de cristais fotônicos é o objeto de discussão deste capítulo.

Primeiramente, são apresentados os fundamentos teóricos que norteiam os estudos de cristais fotônicos, com uma breve discussão das principais técnicas de modelagem numérica utilizadas. Tal discussão tem por finalidade justificar o emprego do método FDTD neste trabalho. Uma seção é especialmente dedicada ao método da expansão em ondas planas (PWEM), uma formulação cuja compreensão é imprescindível para a modelagem da excitação no cálculo do diagrama de bandas por FDTD. Além disto, a explanação acerca do PWEM possibilita uma revisão geral dos principais conceitos físico-matemáticos relativos a redes cristalinas.

Posteriormente, são abordadas as características gerais do método FDTD. Esta abordagem é acompanhada por uma discussão acerca da modelagem da excitação e das terminações do domínio computacional, isto é, a formulação adotada para o comportamento da onda eletromagnética nas fronteiras da região sob análise. Serão discutidas particularmente duas condições de fronteira: a condição de camada perfeitamente casada (perfectly matched layer PML) e a condição de fronteira periódica.

Também é dada atenção à aplicação da forma discreta da transformada de Fourier (discrete Fourier transform - DFT) ao algoritmo FDTD para a obtenção de informações espectrais, as quais compreendem o cálculo de diagrama de bandas e refletância especular. 


\section{1 - Eletromagnetismo de estruturas periódicas}

A propagação de ondas eletromagnéticas por estruturas dielétricas periódicas guarda uma estreita analogia com o movimento de elétrons em um semicondutor. Neste último caso, o potencial periódico introduzido pela rede cristalina é responsável por impedir a propagação eletrônica a energias arbitrárias. No caso da propagação de fótons, a variação periódica do índice de refração realiza o papel de "potencial periódico", produzindo bandas de freqüências proibidas à propagação luminosa [1]-[2]. Conseqüentemente, é de se esperar que muito da teoria eletrônica de semicondutores possua o seu análogo eletromagnético.

As propriedades eletromagnéticas de estruturas periódicas podem ser explicadas por meio da Eletrodinâmica Clássica, a qual é matematicamente sumarizada nas quatro equações de Maxwell. Neste trabalho, é assumido que os materiais que compõem a rede cristalina são dielétricos perfeitos não-magnéticos e é desconsiderada a variação da permissividade elétrica com a freqüência. Partindo destas suposições, manipulações algébricas das equações de Maxwell levam à equação que governa a propagação fotônica em estruturas periódicas, a qual é explicitada em (2.1), onde vetor campo magnético $\bar{H}$ é assumido ter variação temporal harmônica [2]:

$$
\nabla \times\left(\frac{1}{\varepsilon(\bar{r})} \nabla \times \bar{H}(\bar{r})\right)=\left(\frac{\omega}{c}\right)^{2} \bar{H}(\bar{r})
$$

Em (2.1), $\mathcal{E}(\bar{r})$ é a permissividade elétrica, a qual é assumida variar apenas com o vetor posição $\bar{r}, \omega$ é a freqüência angular e $c$ é a velocidade da luz no vácuo. 
Observa-se que (2.1) corresponde à realização de uma operação sobre a função $\bar{H}(\bar{r})$ que leva a esta mesma função multiplicada pelo escalar $(\omega / c)^{2}$. Isto é matematicamente identificado como um problema de autovalores. O operador que atua sobre $\bar{H}(\bar{r})$ realiza o rotacional deste campo, divide o resultado pela função permissividade elétrica e realiza um novo rotacional. Para tornar isto mais explícito, (2.1) é reescrita sob uma forma mais compacta:

$$
\begin{aligned}
& \Theta \bar{H}(\bar{r})=\left(\frac{\omega}{c}\right)^{2} \bar{H}(\bar{r}), \text { onde } \\
& \Theta \bar{H}(\bar{r})=\nabla \times\left(\frac{1}{\varepsilon(\bar{r})} \nabla \times \bar{H}(\bar{r})\right)
\end{aligned}
$$

Deve ser destacado que o operador $\Theta$ conserva a linearidade das equações de Maxwell. Em outras palavras, se $\bar{H}_{1}(\bar{r})$ e $\bar{H}_{2}(\bar{r})$ são soluções de (2.2) para uma mesma frequiência $\omega$, então a combinação linear $\alpha \bar{H}_{1}(\bar{r})+\beta \bar{H}_{2}(\bar{r})$, onde $\alpha$ e $\beta$ são constantes, é também uma solução de (2.2).

Uma importante conclusão obtida a partir do que foi mostrado acima é a similaridade entre (2.2) e a equação para a função de onda de elétrons em um semicondutor, na qual o respectivo problema de autovalores é alcançado pela aplicação do operador hamiltoniano à função de onda do elétron. Nos dois casos, os operadores possuem duas importantes propriedades: os autovalores, fisicamente denominados autoenergias, são reais e as respectivas autofunções são ortogonais entre si. 
Entretanto, existe uma grande diferença entre os modos de resolução do referido problema de autovalores no caso eletrônico e no caso fotônico. Neste último, uma adequada solução de (2.2) deve partir do formalismo vetorial inerente a esta equação.

Um grande desafio encontrado pela comunidade científica é o desenvolvimento de algoritmos capazes de modelar a propagação eletromagnética em cristais fotônicos, seja pela resolução de (2.2) ou por meio da aplicação direta das equações de Maxwell. Desde a década de 90, várias abordagens têm sido propostas, destacando-se o método da expansão em ondas planas (PWEM - plane wave expansion method), o método das diferenças finitas no domínio do tempo (FDTD - finite difference time domain), o método dos elementos finitos (FEM - finite element method) e o método da matriz de transferência. O FEM [33] necessita da solução de equações dos campos elétrico e magnético para cada elemento de discretização, o que tem como consequiência a necessidade de resolução de grandes sistemas de equações, especialmente no caso tridimensional. O método da matriz de transferência [34], assim como o método FDTD, é de diferenças finitas, mas possui a limitação de utilizar como excitação inicial uma onda plana monocromática. Além disso, é menos flexível que a abordagem FDTD por apresentar instabilidades durante o processo de integração, dependendo da geometria a ser analisada. Em virtude da facilidade de implementação, dois métodos comumente empregados são o PWEM e o FDTD. Como, especialmente no que se refere à modelagem da excitação, a aplicação do método FDTD ao estudo de cristais fotônicos requer conhecimentos sobre a expansão em ondas planas, a seção a seguir é dedicada a uma explanação acerca do PWEM. 


\subsection{1 - O método da expansão em ondas planas (PWEM - plane wave expansion method)}

Neste trabalho, a importância do método da expansão em ondas planas reside na modelagem da excitação para a obtenção do diagrama de bandas do cristal. Soma-se a isto a necessidade de explicitar conceitos físico-matemáticos relacionados a redes cristalinas, os quais estão embutidos na formulação do PWEM. Por conseguinte, esta seção objetiva discorrer brevemente sobre este método, de tal forma a esclarecer os aspectos desta técnica úteis para o cálculo de diagramas de bandas através do método FDTD. Uma análise aprofundada sobre expansão em ondas planas pode ser encontrada em [7].

O PWEM constitui-se em um método análogo ao utilizado para determinar as energias permitidas em um sólido semicondutor. Partindo desta analogia, considera-se que a propagação eletromagnética em um cristal fotônico está sujeita à variação periódica da permissividade elétrica tal qual a função de onda de um elétron é afetada pelo potencial periódico de um cristal. Como conseqüência, os modos eletromagnéticos em uma rede cristalina deverão obedecer ao Teorema de Bloch [2]. Por meio deste teorema, o autovetor $\bar{H}(\bar{r})$, solução de (2.2), corresponde a uma onda plana modulada por uma função cuja periodicidade é a mesma da permissividade elétrica $\varepsilon(\bar{r})$. Ou seja, matematicamente, $\bar{H}(\bar{r})$ toma a forma $(2.3)$ :

$$
\bar{H}(\bar{r}+\bar{R})=e^{\bar{k} \cdot \bar{R}} \bar{H}(\bar{r})
$$

$\bar{R}$ é o período da rede cristalina e

$\bar{k}$ é o vetor de onda que especifica a direção de propagação 
Deve ser observado que o Teorema de Bloch parte do princípio de que a rede cristalina seja infinita. Devido a esta característica, os cálculos podem ser reduzidos a uma célula unitária do cristal.

Estabelecida a forma da solução de (2.2), parte-se para a expressão da função permissividade elétrica. Como esta função é periódica, pode-se escrevê-la em termos da série de Fourier, conforme é expresso em (2.4):

$$
\varepsilon(\bar{r})=\sum_{\bar{G}} \varepsilon_{\bar{G}} e^{j \bar{G} \cdot \bar{r}}
$$

O vetor $\bar{G}$ utilizado em (2.4) descreve o espaço de Fourier ou rede recíproca da função $\varepsilon(\bar{r})$. A rede recíproca também é um espaço periódico, ao qual pertencem os vetores de onda que descrevem todas as direções de propagação na rede cristalina [2]. Devido a esta periodicidade, é possível encontrar uma unidade mínima que, analogamente à célula primitiva do cristal, constrói a rede recíproca por meio de operações translacionais. Tal unidade, sendo qualificada como uma célula primitiva de Wigner-Seitz [35], corresponde à primeira zona de Brillouin do cristal fotônico. Conseqüentemente, para determinar as frequiências permitidas à propagação no cristal fotônico, é suficiente utilizar o conjunto de vetores de onda pertencentes à primeira zona de Brillouin. Como a primeira zona de Brillouin é construída a partir de operações rotacionais e reflexivas de uma unidade de repetição ainda menor, o conjunto de vetores de onda pode ser restringido a esta região, a qual é denominada zona irredutível de Brillouin. 
Voltando a (2.3), o fato de $\bar{H}(\bar{r})$ ser periódico também permite que tal função seja decomposta em série de Fourier, o que explica o nome do método aqui descrito. A expressão para $\bar{H}(\bar{r})$ é então escrita de acordo com (2.5):

$$
\begin{aligned}
& \bar{H}(\bar{r})=\sum_{\bar{G}} h \bar{a} e^{j(\bar{k}+\bar{G}) \cdot \bar{r}} \\
& \bar{a} \text { é o vetor unitário que indica a direção de } \bar{H} \text { e } h \text { é a componente de } \bar{H} \text { na direção } \\
& \bar{a} .
\end{aligned}
$$

Em (2.5), o vetor $\bar{G}$ varre a zona irredutível de Brillouin da rede cristalina. Aplicando (2.4) e (2.5) em (2.2), obtém-se um conjunto infinito de equações lineares, o qual é truncado de acordo com o número de ondas planas utilizadas em (2.5). A resolução deste sistema de equações possibilita a determinação das autofreqüências e, por conseguinte, das bandas fotônicas do cristal.

Deve ser ressaltado que o PWEM se configura como um problema vetorial. Tal caráter exige elevado esforço computacional, especialmente no que se refere a cristais tridimensionais. Além desta característica, o método apresenta várias limitações: sua eficiência está intimamente relacionada à perfeição do cristal, o que torna complexa a aplicação do PWEM a estruturas com defeitos na rede cristalina, como, por exemplo, extensão finita. Outro importante ponto a ser observado é a não-universalidade do PWEM, isto é, o método está restrito ao cálculo de autofrequiências, não possibilitando a obtenção dos espectros de refletância/transmitância. Tal limitação é decorrente do fato de que os cálculos dos campos eletromagnéticos são realizados no interior da rede cristalina. 
Em vista das limitações acima citadas, a pesquisa com cristais fotônicos tem voltado cada vez mais sua atenção ao método FDTD, especialmente com o avanço da capacidade de armazenamento e processamento computacionais. A seguir, são apresentadas as características gerais do método FDTD e suas correspondentes especificidades para o estudo de cristais fotônicos.

\section{2 - O método FDTD - características gerais}

Desde sua formulação inicial, feita por Yee em 1966 [36], e posterior desenvolvimento realizado por Taflove [30], o método FDTD tem se tornado cada vez mais utilizado em problemas de propagação eletromagnética, abrangendo desde a faixa espectral de microondas até a região óptica. Constitui-se em um método bastante flexível, pois é baseado na solução direta das equações de Maxwell, sem que seja necessária a obtenção de uma equação de onda específica para o campo elétrico ou magnético. Além disto, o método FDTD torna possível a obtenção de diversos parâmetros eletromagnéticos, tais como espectros de reflexão e transmissão, por meio de uma única simulação.

Um importante aspecto do método FDTD é a sua natureza explícita, ou seja, a determinação do valor de uma dada componente de campo no instante $t_{l}$ depende somente de valores obtidos no instante anterior $t_{0}$. Esta característica traz importantes consequiências na utilização do método FDTD: por um lado, simplifica em alto grau a implementação do algoritmo computacional em vista de ser essencialmente um processo iterativo. No entanto, restringe o algoritmo a um caráter condicionalmente estável (o que ocorre com métodos explícitos em geral), ou seja, o incremento de tempo $\Delta t$ utilizado na iteração temporal deve obedecer a um limite 
superior a fim de que a amplitude da onda propagante não cresça indefinidamente. Outro aspecto importante a ser considerado é a escolha dos valores dos incrementos espaciais. Tais incrementos não podem exceder uma determinada fração do menor comprimento de onda contido no espectro da excitação. Com isto, busca-se evitar a dispersão numérica, ou seja, variação da velocidade de fase com o comprimento de onda, causada exclusivamente pela malha computacional.

No que se refere aos valores possíveis do incremento de tempo $\Delta t$, foi utilizado neste trabalho o critério de Courant-Friedrich-Levy (CFL) [30], o qual é matematicamente expresso em (2.6). Nesta expressão, $\Delta x, \Delta y$ e $\Delta z$ são os incrementos espaciais nas direções $x, y$ e $z$, respectivamente, e $c$ é a velocidade da luz no espaço livre.

$$
\Delta t \leq \frac{1}{c\left(\sqrt{\frac{1}{\Delta x^{2}}+\frac{1}{\Delta y^{2}}+\frac{1}{\Delta z^{2}}}\right)}
$$

Relativamente à dispersão numérica, o procedimento adotado para contornar este efeito é baseado na análise espectral da fonte utilizada na simulação. A partir de tal análise, define-se o menor comprimento de onda $\lambda$ contido no espectro da excitação para então escolher os valores para os incrementos espaciais. Uma escolha recomendada [30] é expressa em (2.7):

$$
\Delta x, \Delta y, \Delta z \leq \frac{\lambda}{40}
$$

Um estudo mais aprofundado acerca de estabilidade e dispersão numéricas relativas ao método FDTD pode ser encontrado em [30]. 


\subsection{1 - As expressões para as componentes de campo elétrico e magnético em FDTD}

Obedecidos os critérios anteriores para a obtenção de um algoritmo numericamente estável e não-dispersivo, o próximo passo consiste em implementar em diferenças finitas as equações para o rotacional dos campos elétrico $\bar{E}$ e magnético $\bar{H}$, as quais são mostradas, respectivamente, em (2.8) e (2.9), onde $\bar{B}$ é o vetor indução magnética e $\bar{D}$ é o vetor deslocamento elétrico. Nota-se que a simetria entre as duas equações é convenientemente assegurada pelas densidades superficiais de corrente magnética $\bar{J}_{m}$ e elétrica $\bar{J}_{e}$.

$$
\begin{aligned}
& \frac{\partial \bar{B}}{\partial t}=-\nabla \times \bar{E}-\bar{J}_{m} \\
& \frac{\partial \bar{D}}{\partial t}=\nabla \times \bar{H}-\bar{J}_{e}
\end{aligned}
$$

Considerando o espaço tridimensional, (2.8) e (2.9) são decompostas no conjunto de equações diferenciais acopladas (2.10)-(2.15).

$$
\begin{gathered}
\frac{\partial H_{x}}{\partial t}=\frac{1}{\mu}\left(\frac{\partial E_{y}}{\partial z}-\frac{\partial E_{z}}{\partial y}-\rho^{\prime} H_{x}\right) \\
\frac{\partial H_{y}}{\partial t}=\frac{1}{\mu}\left(\frac{\partial E_{z}}{\partial x}-\frac{\partial E_{x}}{\partial z}-\rho^{\prime} H_{y}\right) \\
\frac{\partial H_{z}}{\partial t}=\frac{1}{\mu}\left(\frac{\partial E_{x}}{\partial y}-\frac{\partial E_{y}}{\partial x}-\rho^{\prime} H_{z}\right)
\end{gathered}
$$




$$
\begin{gathered}
\frac{\partial E_{x}}{\partial t}=\frac{1}{\mathcal{E}}\left(\frac{\partial H_{z}}{\partial y}-\frac{\partial H_{y}}{\partial z}-\sigma E_{x}\right) \\
\frac{\partial E_{y}}{\partial t}=\frac{1}{\varepsilon}\left(\frac{\partial H_{x}}{\partial z}-\frac{\partial H_{z}}{\partial x}-\sigma E_{y}\right) \\
\frac{\partial E_{z}}{\partial t}=\frac{1}{\varepsilon}\left(\frac{\partial H_{y}}{\partial x}-\frac{\partial H_{x}}{\partial y}-\sigma E_{z}\right)
\end{gathered}
$$

Em (2.10)-(2.15), $\mu$ é a permeabilidade magnética, $\varepsilon$ é a permissividade elétrica, $\rho$ ’é a resistividade magnética e $\sigma$ é a condutividade elétrica. Estas duas últimas quantidades são explicitadas nas equações de Maxwell através da Lei de Ohm: $\bar{J}_{m}=\rho^{\prime} \bar{H}$ e $\bar{J}_{e}=\sigma \bar{E}$.

Deve-se, agora, escolher qual a técnica de diferenças finitas a ser utilizada em (2.10)(2.15). Tal escolha não é realizada arbitrariamente. No caso do método FDTD, as derivadas espaciais são aproximadas por diferenças centradas, as quais são de precisão de segunda ordem. Uma forma conveniente de compreender como ocorre tal aproximação é através da célula de Yee, uma ilustração que mostra como as componentes de campo elétrico e magnético estão dispostas em uma unidade de discretização da malha computacional. Tal disposição é, essencialmente, uma representação intuitiva de (2.8) e (2.9) em uma região livre de fonte magnética ou elétrica. Por esta configuração pode-se também observar que, apesar do método FDTD partir das equações do rotacional dos campos elétrico e mangnético (Lei da Indução de Faraday e Lei Circuital de Àmpere, respectivamente), engloba também as equações de divergência (Lei de Gauss). A célula de Yee é explicitada na Fig. 2.1, na qual as linhas pontilhadas indicam que as componentes de campo magnético estão deslocadas das componentes de campo elétrico por meio incremento espacial. 


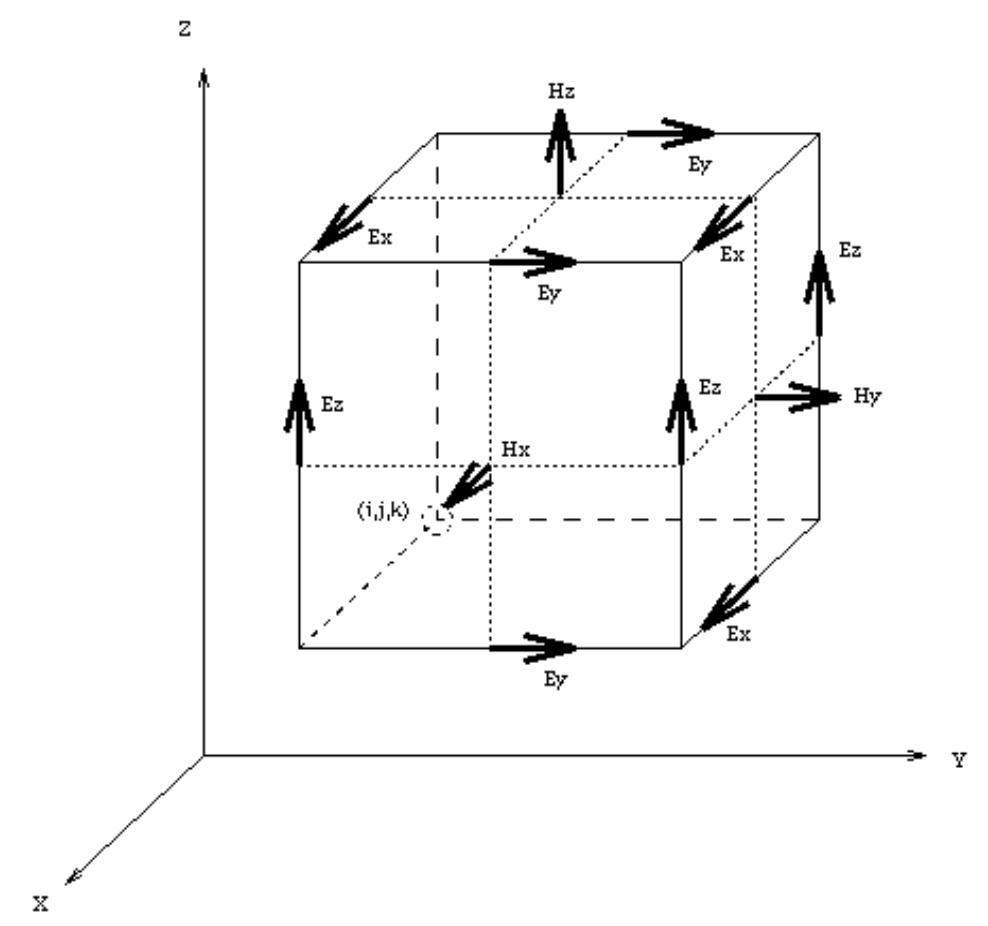

Fig. 2.1 - Célula de Yee tridimensional. As componentes de campo magnético estão deslocadas das componentes de campo elétrico por meio incremento espacial. Os índices $i, j$ e $k$ referem-se aos passos espaciais nas direções $x, y$ e $z$, respectivamente.

Relativamente à diferenciação temporal, a disposição das componentes de campo elétrico e magnético obedece ao arranjo denominado leapfrog, através do qual, em um determinado instante, as componentes de campo elétrico são calculadas a partir dos valores anteriores das componentes de campo magnético, armazenados previamente na memória computacional. Por conseguinte, as atualizações das componentes de campo magnético são calculadas a partir dos valores das componentes de campo elétrico computadas no passo temporal anterior. Este ciclo se repete até que a condição de parada do loop no tempo seja alcançada. Uma forma didática de visualizar o arranjo leapfrog é através da molécula computacional esquematizada na Fig. 2.2, na qual é mostrada a dependência de uma função $u$ no instante $n+l$ dos seus respectivos valores nos instantes $n$ e $n$ - 1 (o índice $i$ refere-se à localização espacial). 


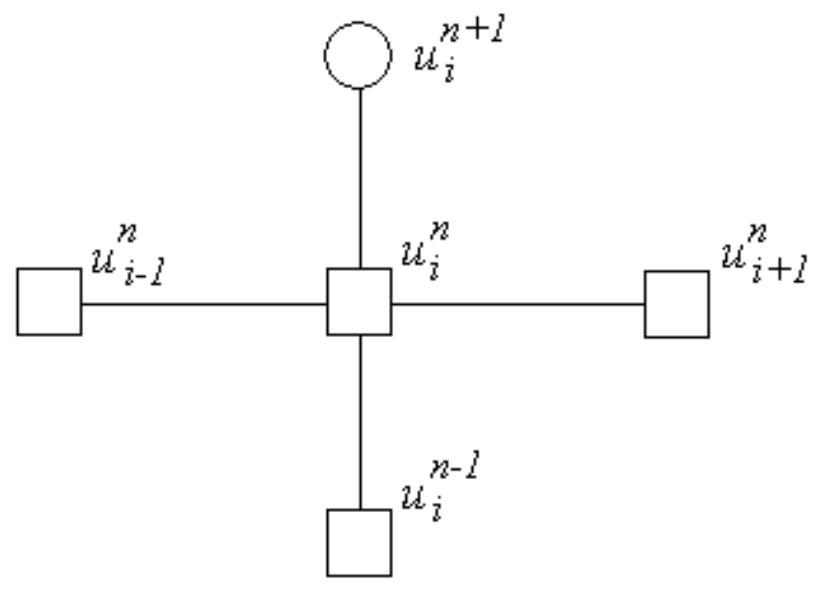

Fig. 2.2 - Molécula computacional para o arranjo leapfrog. A circunferência indica o valor desconhecido da função $u$ e os quadrados referem-se aos valores armazenados na memória computacional.

Para a descrição matemática dos esquemas de diferenças finitas no espaço e no tempo, utiliza-se o terno ordenado $(i, j, k)$ para denotar os pontos da malha computacional e $n$ para denotar os pontos no tempo. A partir desta indexação, as componentes de campo recebem a seguinte notação: $u_{a(i, j, k)}^{n}=u_{a}(i \Delta x, j \Delta y, k \Delta z, n \Delta t)$, em que $u$ corresponde a uma dada componente em uma direção cartesiana $a$. De acordo com o que foi mostrado anteriormente, $\Delta x$, $\Delta y$ e $\Delta z$ são os incrementos espaciais relativos às direções $x, y$ e $z$ do sistema de coordenadas cartesianas e $\Delta t$ é o incremento temporal.

Portanto, obedecendo ao esquema de diferença centrada, a primeira derivada espacial de uma componente de campo é aproximada por (2.16):

$\frac{\partial}{\partial x} u(i \Delta x, j \Delta y, k \Delta z, n \Delta t) \cong \frac{u_{i+1 / 2, j, k}^{n}-u_{i-1 / 2, j, k}^{n}}{\Delta x}$ 
No tempo, em uma considerada localização $(i, j, k)$, a primeira derivada temporal de $u$ é aproximada por (2.17):

$\frac{\partial}{\partial t} u(i \Delta x, j \Delta y, k \Delta z, n \Delta t) \cong \frac{u_{i, j, k}^{n+1 / 2}-u_{i, j, k}^{n-1 / 2}}{\Delta t}$

Com base em (2.16) e (2.17) e utilizando, quando necessário, a aproximação semiimplícita $u_{i, j, k}^{n} \cong \frac{u_{i, j, k}^{n+1 / 2}+u_{i, j, k}^{n-1 / 2}}{2}$, são obtidas as expressões para as componentes de campo elétrico e magnético em FDTD, as quais são mostradas em (2.18)-(2.23):

$$
\begin{aligned}
& H_{x(i, j, k)}^{n+1 / 2}=\left(\frac{1-\frac{\rho_{(i, j, k)}^{\prime} \Delta t}{2 \mu_{(i, j, k)}}}{1+\frac{\rho_{(i, j, k)}^{\prime} \Delta t}{2 \mu_{(i, j, k)}}}\right) H_{x(i, j, k)}^{n-1 / 2}+ \\
& \frac{\frac{\Delta t}{\mu_{(i, j, k)}}}{1+\frac{\rho_{(i, j, k)}^{\prime} \Delta t}{2 \mu_{(i, j, k)}}}\left(\frac{E_{y(i, j, k+1 / 2)}^{n}-E_{y(i, j, k-1 / 2)}^{n}}{\Delta z}-\frac{E_{z(i, j+1 / 2, k)}^{n}-E_{z(i, j-1 / 2, k)}^{n}}{\Delta y}\right)
\end{aligned}
$$




$$
\begin{aligned}
& H_{y(i, j, k)}^{n+1 / 2}=\left(\frac{1-\frac{\rho_{(i, j, k)}^{\prime} \Delta t}{2 \mu_{(i, j, k)}}}{1+\frac{\rho_{(i, j, k)}^{\prime} \Delta t}{2 \mu_{(i, j, k)}}}\right) H_{y(i, j, k)}^{n-1 / 2}+ \\
& \frac{\frac{\Delta t}{\mu_{(i, j, k)}}}{1+\frac{\rho_{(i, j, k)}^{\prime} \Delta t}{2 \mu_{(i, j, k)}}}\left(\frac{E_{z(i+1 / 2, j, k)}^{n}-E_{z(i-1 / 2, j, k)}^{n}}{\Delta x}-\frac{E_{x(i, j, k+1 / 2)}^{n}-E_{x(i, j, k-1 / 2)}^{n}}{\Delta z}\right) \\
& H_{z(i, j, k)}^{n+1 / 2}=\left(\frac{1-\frac{\rho_{(i, j, k)}^{\prime} \Delta t}{2 \mu_{(i, j, k)}}}{1+\frac{\rho_{(i, j, k)}^{\prime} \Delta t}{2 \mu_{(i, j, k)}}}\right) H_{z(i, j, k)}^{n-1 / 2}+ \\
& \frac{\frac{\Delta t}{\mu_{(i, j, k)}}}{1+\frac{\rho_{(i, j, k)}^{\prime} \Delta t}{2 \mu_{(i, j, k)}}}\left(\frac{E_{x(i, j+1 / 2, k)}^{n}-E_{x(i, j-1 / 2, k)}^{n}}{\Delta y}-\frac{E_{y(i+1 / 2, j, k)}^{n}-E_{y(i-1 / 2, j, k)}^{n}}{\Delta x}\right) \\
& E_{x(i, j, k)}^{n+1}=\left(\frac{1-\frac{\sigma_{(i, j, k)} \Delta t}{2 \varepsilon_{(i, j, k)}}}{1+\frac{\sigma_{(i, j, k)} \Delta t}{2 \varepsilon_{(i, j, k)}}}\right) E_{x(i, j, k)}^{n}+ \\
& \frac{\frac{\Delta t}{\varepsilon_{(i, j, k)}}}{1+\frac{\sigma_{(i, j, k)} \Delta t}{2 \varepsilon_{(i, j, k)}}}\left(\frac{H_{z(i, j+1 / 2, k)}^{n+1 / 2}-H_{z(i, j-1 / 2, k)}^{n+1 / 2}}{\Delta y}-\frac{H_{y(i, j, k+1 / 2)}^{n+1 / 2}-H_{y(i, j, k-1 / 2)}^{n+1 / 2}}{\Delta z}\right)
\end{aligned}
$$


$E_{y(i, j, k)}^{n+1}=\left(\frac{1-\frac{\sigma_{(i, j, k)} \Delta t}{2 \varepsilon_{(i, j, k)}}}{1+\frac{\sigma_{(i, j, k)} \Delta t}{2 \varepsilon_{(i, j, k)}}}\right) E_{y(i, j, k)}^{n}+$
$\frac{\frac{\Delta t}{\varepsilon_{(i, j, k)}}}{1+\frac{\sigma_{(i, j, k)} \Delta t}{2 \varepsilon_{(i, j, k)}}}\left(\frac{H_{x(i, j, k+1 / 2)}^{n+1 / 2}-H_{x(i, j, k-1 / 2)}^{n+1 / 2}}{\Delta z}-\frac{H_{z(i+1 / 2, j, k)}^{n+1 / 2}-H_{z(i-1 / 2, j, k)}^{n+1 / 2}}{\Delta x}\right)$

$E_{z(i, j, k)}^{n+1}=\left(\frac{1-\frac{\sigma_{(i, j, k)} \Delta t}{2 \varepsilon_{(i, j, k)}}}{1+\frac{\sigma_{(i, j, k)} \Delta t}{2 \varepsilon_{(i, j, k)}}}\right) E_{z(i, j, k)}^{n}+$

$\frac{\frac{\Delta t}{\varepsilon_{(i, j, k)}}}{1+\frac{\sigma_{(i, j, k)} \Delta t}{2 \varepsilon_{(i, j, k)}}}\left(\frac{H_{y(i+1 / 2, j, k)}^{n+1 / 2}-H_{y(i-1 / 2, j, k)}^{n+1 / 2}}{\Delta x}-\frac{H_{x(i, j+1 / 2, k)}^{n+1 / 2}-H_{x(i, j-1 / 2, k)}^{n+1 / 2}}{\Delta y}\right)$

Algumas observações importantes devem ser feitas com relação ao conjunto de equações (2.18)-(2.23):

- As distribuições de campo elétrico e magnético são obtidas realizando apenas uma simulação, uma vez que o método FDTD corresponde à resolução numérica das equações de Maxwell na forma diferencial em um único algoritmo computacional;

- As características eletromagnéticas dos materiais $(\mu, \varepsilon$ e $\sigma)$ no domínio computacional estão concentradas nos coeficientes das componentes de campo. Isto significa que, em meios estratificados, como é o caso de cristais fotônicos, tais coeficientes podem ser declarados como vetores, facilitando a implementação das equações em FDTD nas distintas regiões do domínio computacional; 
- $\quad$ Especificamente no que se refere à condutividade elétrica $\sigma$, o item precedente é de fundamental importância, pois possibilita a implementação da condição de contorno PML de forma direta, sem grandes modificações nas formas finais das equações em FDTD, como será mostrado posteriormente;

- $\quad$ Se, em uma determinada direção, a propagação eletromagnética for de uma onda plana (caso da propagação em meios que em uma dada direção são lineares e homogêneos), a configuração tridimensional de (2.18)-(2.23) pode ser reduzida a um plano e o problema sob análise pode ser tratado como um caso bidimensional. Esta abordagem é conhecida como método FDTD-compacto e é bastante útil, por exemplo, no estudo de propagação eletromagnética out of plane em cristais fotônicos de periodicidade bidimensional [37].

\section{3 - A modelagem da excitação eletromagnética pelo método FDTD}

A resposta óptica de um cristal fotônico depende da excitação eletromagnética utilizada pelo algoritmo FDTD. Tal escolha não segue qualquer procedimento pré-definido, mas sim depende fortemente do conhecimento sobre o comportamento físico esperado do cristal diante da fonte de excitação. Muitas vezes, fatores como a simetria do cristal ou o intervalo espectral sob análise propiciam importantes indícios de como deve ser implementada a fonte. A seguir, é realizada uma análise da modelagem das fontes utilizadas neste trabalho. 


\subsection{1 - Superposição de ondas planas}

Conforme discutido na seção 2.1, o diagrama de bandas de um cristal fotônico pode ser obtido a partir de uma superposição de ondas planas (PWEM) com vetores de onda pertencentes à primeira zona de Brillouin. No método FDTD, a expansão em ondas planas é também usada na modelagem da excitação para a obtenção do diagrama de bandas de um cristal fotônico. Neste trabalho, o PWEM foi aplicado ao vetor campo elétrico incidente no cristal, cuja forma fasorial é mostrada em (2.24), onde é suposta variação temporal harmônica:

$$
\bar{E}(\bar{r})=\sum_{\bar{G}} \bar{E}_{0} e^{j(\bar{k}+\bar{G}) \cdot \bar{r}}
$$

A questão prioritária na utilização de (2.24) é: qual o comprimento adequado deste somatório? Para exemplificar o problema, reporta-se ao exemplo de propagação de uma onda TEM na direção de periodicidade de um cristal unidimensional, conforme é mostrado na Fig. 2.3, na qual $a$ corresponde à constante de rede do cristal, $\varepsilon_{1}=12$ (silício) e $\varepsilon_{2}=1$ (ar).

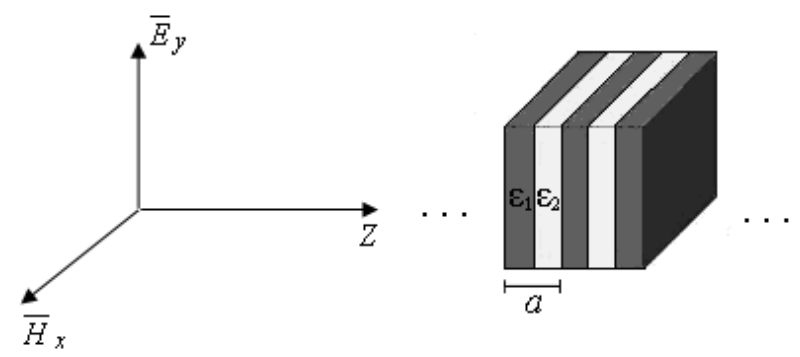

Fig. 2.3 - Propagação de uma onda TEM em um cristal fotônico unidimensional perfeito de período $a$ na direção $z$. 
Para fazer com que o cálculo da autofrequiência relacionada ao vetor de onda $\pi / a$ na vigésima banda convirja, são necessárias mais de trinta ondas planas em (2.24). Este resultado é apresentado em [1] e foi reproduzido neste trabalho por meio do método FDTD (Fig. 2.4). Desta forma, deve-se ter e mente que, quanto maior é o intervalo espectral sob análise, maior é o número de ondas planas a ser utilizado.

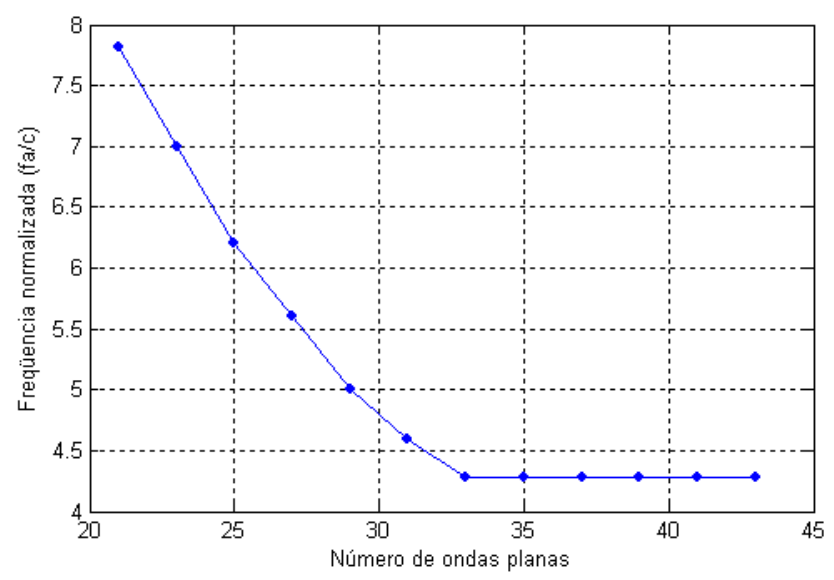

Fig. 2.4 - Convergência da autofreqüência como uma função do número de ondas planas usadas em (2.24). Este gráfico refere-se à vigésima banda na borda da zona de Brillouin do cristal mostrado na Fig. 2.3 .

\subsection{2 - O pulso senoidal de envoltória gaussiana}

Outro tipo de excitação bastante utilizada é a modulação de uma onda senoidal por uma envoltória gaussiana. Sua importância para análises espectrais reside no fato de que sua largura de faixa é finita, o que é bastante útil para o estudo de refletância realizado neste trabalho. A expressão desta fonte é dada em (2.25), na qual $\omega_{0}$ é a freqüência da portadora 
senoidal e $T_{0}$ é a constante de tempo relacionada à largura do pulso medida entre os pontos onde a amplitude da fonte é $e^{-1}$ do valor de pico:

$$
E(t)=E_{0} e^{-\left(t / T_{0}\right)^{2}} e^{j \omega_{0} t}
$$

De acordo com o que foi discutido anteriormente, deve ser obedecido um limite para a largura do pulso a fim de não levar à dispersão numérica, isto é, (2.25) deve satisfazer a seguinte relação de compromisso: a largura temporal do pulso deve ser tal que seu respectivo espectro contenha o intervalo de freqüências desejado sem tornar os incrementos espaciais demasiadamente pequenos. Uma forma útil de correlacionar a largura temporal com a largura espectral do pulso dado em (2.25) é por meio de sua respectiva Transformada de Fourier, a qual é mostrada em (2.26):

$$
E(\omega)=\sqrt{\pi} E_{0} T_{0} e^{-(1 / 4)\left(\omega-\omega_{0}\right)^{2} T_{0}^{2}}
$$

Um procedimento típico [38] é considerar $2 T_{0}$ a largura temporal do pulso dado em (2.25). Então, levando este procedimento para o domínio da frequiência, a largura de (2.26) é $\left(4 / T_{0}\right)$. Portanto, para definir os máximos valores dos incrementos espaciais em função da fonte, define-se $\omega_{0}+2 / T_{0}$ como a máxima freqüência no domínio computacional.

Uma representação comparativa entre (2.25) e (2.26) é realizada na Fig. 2.5. 


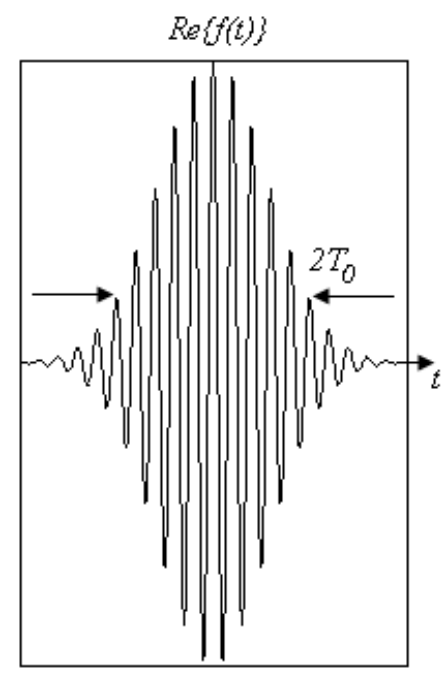

(a)

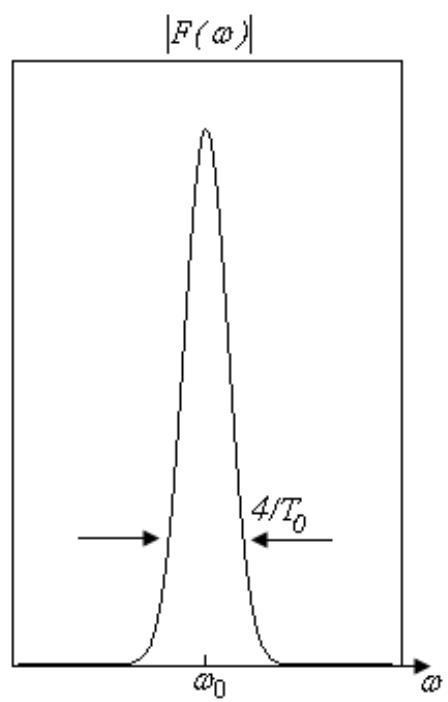

(b)

Fig. 2.5 - (a) Sinal senoidal $f(t)$ modulado por uma envoltória gaussiana. (b) Módulo da transformada de Fourier do sinal $f(t)$.

\section{4 - Condições de contorno - modelagem das terminações do domínio computacional}

A implementação do algoritmo baseado em FDTD requer um número limitado de pontos de discretização, ou seja, o domínio computacional onde os cálculos são realizados é finito. Conseqüentemente, as equações discretas (2.18)-(2.23) não podem ser aplicadas incondicionalmente nas paredes do domínio computacional, haja vista que as componentes de campo necessitarão de valores localizados em pontos externos à malha e, portanto, desconhecidos. Assim, superar este problema significa agregar ao algoritmo FDTD uma condição de contorno que simule o comportamento ondulatório fora do domínio computacional. Conforme é discutido em [30], são vários os tipos de condição de contorno que modelam as terminações da região sob análise. Entretanto, estas condições não são de uso arbitrário, isto é, as características do problema sob questão devem ser cuidadosamente analisadas para avaliar qual condição é a mais adequada. 
A seguir, são discutidas as duas condições de contorno empregadas neste trabalho: a condição de contorno periódica e a PML. A primeira é utilizada nas direções em que o cristal é infinito e a segunda, nas direções em que o cristal é considerado finito.

\subsection{1 - Condição de contorno periódica.}

A condição de contorno periódica se constitui em uma modelagem naturalmente utilizada em cristais fotônicos infinitos, pois é conseqüência direta do Teorema de Bloch. A partir da aplicação deste teorema, os valores das componentes de campo nas extremidades do domínio computacional têm suas respectivas fases e amplitudes relacionadas entre si por meio de funções harmônicas, conforme é descrito para a componente de campo genérica $\psi$ em (2.27)-(2.32) nas direções $x, y$ e $z$, respectivamente:

$$
\begin{aligned}
& \psi\left(x_{0}\right)=\psi\left(x_{\text {max }}\right) e^{j k_{x} L_{x}} \\
& \psi\left(y_{0}\right)=\psi\left(y_{\text {max }}\right) e^{j k_{y} L_{y}} \\
& \psi\left(z_{0}\right)=\psi\left(z_{\text {max }}\right) e^{j k_{z} L_{z}} \\
& \psi\left(x_{\text {max }}\right)=\psi\left(x_{0}\right) e^{-j k_{x} L_{x}} \\
& \psi\left(y_{\text {max }}\right)=\psi\left(y_{0}\right) e^{-j k_{y} L_{y}} \\
& \psi\left(z_{\text {max }}\right)=\psi\left(z_{0}\right) e^{-j k_{z} L_{z}}
\end{aligned}
$$


- $\mathrm{L}_{\mathrm{x}}, \mathrm{L}_{\mathrm{y}}$ e $\mathrm{L}_{\mathrm{z}}$ são os comprimentos do domínio computacional tridimensional e $\mathrm{x}_{0}, \mathrm{y}_{0}, \mathrm{z}_{0}$, $\mathrm{x}_{\max }, \mathrm{y}_{\max } \mathrm{e} \mathrm{z}_{\max }$ são as correspondentes extremidades iniciais e finais nas direções $x, y$ e $z$, respectivamente;

- $\mathrm{k}_{\mathrm{x}}, \mathrm{k}_{\mathrm{y}}$ e $\mathrm{k}_{\mathrm{z}}$ são as respectivas componentes do vetor de onda em $x, y$ e $z$.

Fisicamente, a condição de contorno periódica simula a continuidade da periodicidade do cristal externamente às fronteiras do domínio computacional. Isto significa que, nas direções em que o cristal é considerado infinito, é suficiente a discretização apenas da célula unitária do cristal.

Entretanto, não se deve inferir que esta condição de contorno é válida somente para cristais fotônicos perfeitos. Domínios que englobam estruturas cuja periodicidade é quebrada por algum tipo de defeito também podem se valer da condição de contorno periódica. Isto é realizado por meio da implementação de uma supercélula em lugar da célula unitária do cristal. Por supercélula entende-se uma estrutura detentora do defeito cristalino e de tamanho muito maior que a célula unitária original, ou seja, por um argumento comparativo, a supercélula é uma "célula unitária" que contém o defeito. Assim, com a utilização da condição de contorno periódica, são criadas imagens virtuais do defeito cristalino nas regiões exteriores ao domínio computacional de interesse. Uma conseqüência importante é que tais imagens podem ter um efeito significativo nos cálculos FDTD. Como forma de tornar tal influência desprezível, é necessário que o defeito cristalino esteja afastado das extremidades do domínio computacional que representa o cristal físico. Portanto, a grande desvantagem da utilização de supercélulas é a necessidade de aumentar o tamanho do domínio computacional. 
A Fig. 2.6 mostra um exemplo de supercélula para uma rede cristalina bidimensional contendo como defeito a falta de um disco dielétrico.

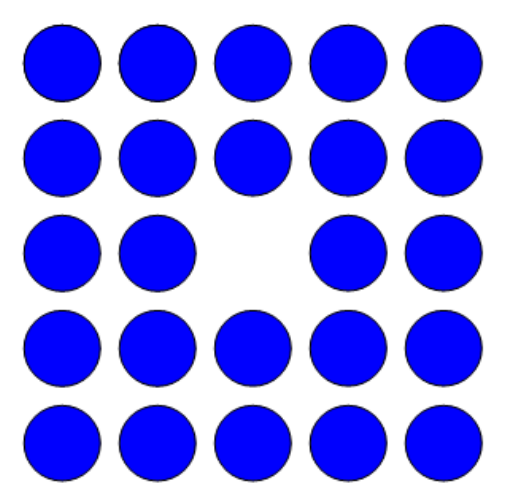

Fig. 2.6 - Supercélula de um cristal bidimensional com célula unitária quadrada. Observa-se que a supercélula contém o defeito do cristal.

\subsection{2 - Condição de camada perfeitamente casada - PML (perfectly matched layer)}

Quando se pretende simular propagação eletromagnética através de materiais de dimensões finitas, as paredes do domínio computacional devem emular a propagação da onda no espaço livre. Condições de contorno destinadas a este fim são denominadas genericamente de condições de fronteiras absorventes (ABC - absorbing boundary conditions). A qualificação absorvente provém da interpretação de que as extremidades do domínio computacional devem se comportar como absorvedores perfeitos da onda incidente, impedindo, conseqüentemente, reflexões puramente numéricas.

Atualmente, a modelagem $\mathrm{ABC}$ que reduz reflexões espúrias mais eficientemente é a PML, esta formulação foi desenvolvida por Berenger em [39]-[40] e se fundamenta na 
inserção de camadas cuja impedância transversal é perfeitamente casada com a impedância do espaço livre. Uma detalhada dedução de como implementar as equações FDTD para PML é dada em [41]. Serão abordados aqui somente os tópicos essenciais para a implementação do algoritmo com esta condição de contorno.

A PML, apesar de ser apenas um material virtual no algoritmo FDTD, possui a propriedade física de ser unixialmente anisotrópica. Devido a esta propriedade, o resultado matemático final é que cada equação acoplada dos rotacionais dos campos elétricos e magnéticos é dividida em duas subcomponentes.

Em aplicações FDTD, também é extremamente importante que a PML tenha um perfil de condutividade crescente em direção às fronteiras do domínio computacional. Isto torna possível que a onda, à medida que penetra no meio PML, seja atenuada, minimizando reflexões. Como consequiência, ao chegar à parede do domínio, obtém-se uma onda fortemente atenuada sofrendo reflexões extremamente pequenas. Estas características são sumarizadas matematicamente em (2.33)-(2.44), nas quais, para manter a notação usada em [39]-[40], a condutividade elétrica e a resistividade magnética são representadas por $\sigma$ e $\sigma^{*}$, respectivamente:

$$
\begin{gathered}
\varepsilon \frac{\partial E_{x y}}{\partial t}=\frac{\partial}{\partial y}\left(H_{z x}+H_{z y}\right)-\sigma_{y} E_{x y} \\
\varepsilon \frac{\partial E_{x z}}{\partial t}=-\frac{\partial}{\partial z}\left(H_{y z}+H_{y x}\right)-\sigma_{z} E_{x z} \\
\varepsilon \frac{\partial E_{y z}}{\partial t}=\frac{\partial}{\partial z}\left(H_{x y}+H_{x z}\right)-\sigma_{z} E_{y z}
\end{gathered}
$$




$$
\begin{aligned}
& \varepsilon \frac{\partial E_{y x}}{\partial t}=-\frac{\partial}{\partial x}\left(H_{z x}+H_{z y}\right)-\sigma_{x} E_{y x} \\
& \varepsilon \frac{\partial E_{z x}}{\partial t}=\frac{\partial}{\partial x}\left(H_{y z}+H_{y x}\right)-\sigma_{x} E_{z x} \\
& \varepsilon \frac{\partial E_{z y}}{\partial t}=-\frac{\partial}{\partial y}\left(H_{x y}+H_{x z}\right)-\sigma_{y} E_{z y} \\
& \mu \frac{\partial H_{x z}}{\partial t}=\frac{\partial}{\partial z}\left(E_{y z}+E_{y x}\right)-\sigma_{z}^{*} H_{x z} \\
& \mu \frac{\partial H_{x y}}{\partial t}=-\frac{\partial}{\partial y}\left(E_{z x}+E_{z y}\right)-\sigma_{y}^{*} H_{x y} \\
& \mu \frac{\partial H_{y z}}{\partial t}=-\frac{\partial}{\partial z}\left(E_{x y}+E_{x z}\right)-\sigma_{z}^{*} H_{y z} \\
& \mu \frac{\partial H_{y x}}{\partial t}=\frac{\partial}{\partial x}\left(E_{z x}+E_{z y}\right)-\sigma_{x}^{*} H_{y x} \\
& \mu \frac{\partial H_{z x}}{\partial t}=-\frac{\partial}{\partial x}\left(E_{y z}+E_{y x}\right)-\sigma_{x}^{*} H_{z x} \\
& \mu \frac{\partial H_{z y}}{\partial t}=\frac{\partial}{\partial y}\left(E_{x y}+E_{x z}\right)-\sigma_{y}^{*} H_{z y}
\end{aligned}
$$

A notação $\sigma_{s}$ indica a condutividade pertencente à camada perpendicular à direção $s$ $(s=x, y, z)$.

A determinação de $\sigma^{*}$ é efetuada pela condição (2.45), a qual representa o casamento de impedância entre o espaço livre e a PML para incidência normal. Esta relação, em conjunto com a anisotropia contida em (2.33)-(2.44), possibilita que o casamento de impedância seja realizado para qualquer ângulo de incidência [39]-[40]: 


$$
\frac{\sigma}{\varepsilon_{0}}=\frac{\sigma^{*}}{\mu_{0}}
$$

Em (2.45), $\varepsilon_{0}$ e $\mu_{0}$ são, respectivamente, a permissividade elétrica e permeabilidade magnética do espaço livre.

A questão que imediatamente surge é a seguinte: qual deve ser o perfil de condutividade na região PML? As aplicações FDTD definem a variação de $\sigma$ e $\sigma^{*}$ tipicamente por meio de funções polinomiais da forma (2.46), em que $s_{0}$ corresponde à localização da interface PML/espaço livre, $\sigma_{s_{\max }}$ corresponde à condutividade máxima e $m$ é o grau do polinômio (geralmente quadrático):

$$
\sigma(s)=\frac{\sigma_{s_{\text {max }}}\left|s-s_{0}\right|^{m}}{d^{m}}, s=x, y, z
$$

Uma eficiente escolha para $\sigma_{s_{\max }}$ é dada em (2.47) [42]:

$$
\sigma_{s_{\max }}=\frac{(m+1)}{150 \pi \Delta s}
$$

Portanto, utilizando (2.46)-(2.47), é implementada a PML no espaço tridimensional. Uma visualização geométrica desta condição de contorno é mostrada na Fig. 2.7. 


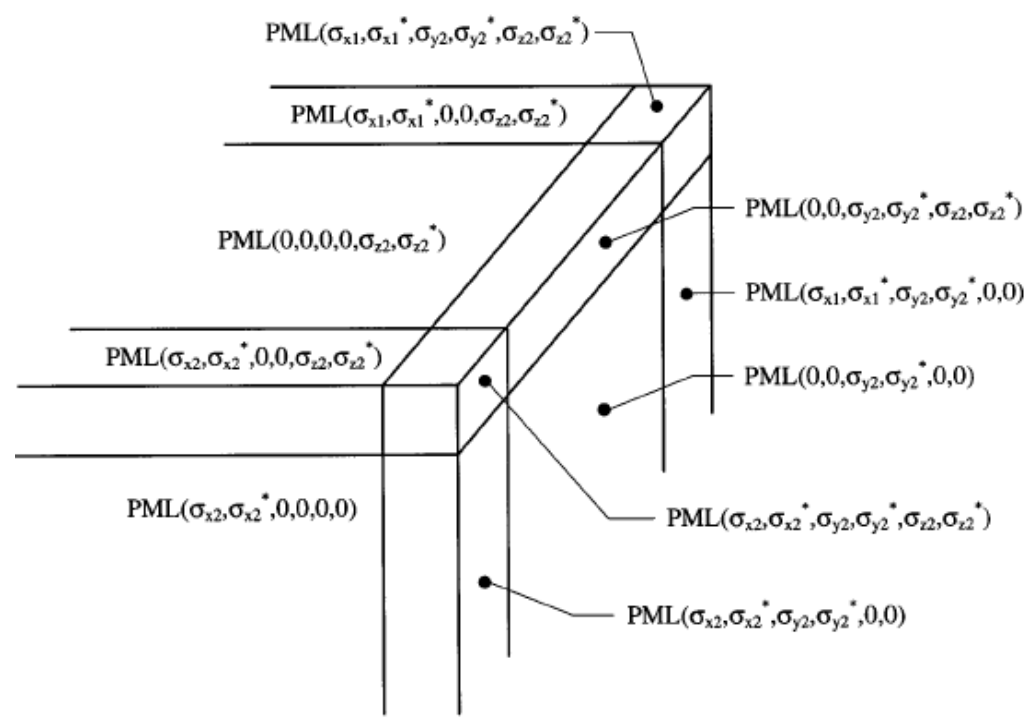

Fig. 2.7 - Parte superior direita da camada PML. As demais regiões são similares às correspondentes nesta figura.

\section{5 - Análise no domínio espectral}

Conforme discutido nas seções anteriores, o método FDTD implementa o cálculo dos campos no domínio do tempo. Entretanto, as aplicações do método para dispositivos baseados em cristais fotônicos geralmente requerem resultados no domínio da freqüência. Conseqüentemente, a extração de informação espectral a partir de resultados FDTD requer a implementação de um algoritmo auxiliar para o cálculo da transformada de Fourier dos campos em um ou mais pontos da malha computacional. A expressão analítica para a transformada de Fourier é dada em (2.48): 


$$
f(\bar{r}, \omega)=\int_{-\infty}^{+\infty} f(\bar{r}, t) e^{-j \omega t} d t
$$

A realização numérica de (2.48) ocorre mediante a aplicação da DFT (discrete Fourier transform) dada em (2.49), em que $\Omega$ é a freqüência discreta e $n$ é a amostra temporal [43]:

$$
f(\bar{r}, \Omega)=\Delta t \sum_{n=1}^{N} f(\bar{r}, n) e^{-j \Omega n \Delta t}
$$

Para o cálculo do diagrama de bandas de um cristal fotônico, deve-se obter a transformada de Fourier das sequiências temporais de componentes de campo em diversos pontos da malha de discretização. Por conseguinte, considerando $N$ passos temporais em uma malha com $S$ pontos, a transformada de Fourier necessitará de $S x 2 N$ unidades de memória computacional. Para reduzir o alto custo de memória para a DFT duas soluções são possíveis: a utilização de rotinas FFT (fast Fourier transform), ou ainda utilizar a DFT on-the-fly [44]. Esta última técnica significa que, após cada iteração temporal é calculada o somatório (2.49), ou seja, o cálculo da DFT é realizado dentro do loop de tempo do algoritmo FDTD, o que acelera a computação da DFT e reduz o custo de memória para $S x N$ unidades. O cálculo da DFT pela técnica on-the-fly é especialmente eficiente quando a máxima freqüência determinada por $\Delta t$ devido à condição de estabilidade é muito maior que a faixa espectral considerada para os resultados físicos.

No presente trabalho, o cálculo da DFT por meio da técnica on-the-fly foi utilizado para a determinação do diagrama de bandas dos cristais fotônicos aqui estudados. Nestes 
casos, após o cálculo da transformadas de Fourier de uma dada componente de campo em diversos pontos do domínio FDTD (os quais são escolhidos aleatoriamente), é realizado um somatório destas transformadas. Assim, para uma dada direção $\bar{k}$ da zona irredutível de Brillouin, as frequiências permitidas são aquelas correspondentes aos picos do espectro de amplitude obtido.

O algoritmo correspondente à DFT convencional foi utilizado para o cálculo da refletância em uma dada direção. O espectro de refletância é determinado por meio da razão entre as transformadas de Fourier dos campos refletido e incidente.

\section{6 - Fluxograma do algoritmo baseado em FDTD}

Finalmente, é apresentado na Fig. 2.8 um fluxograma geral da aplicação do método FDTD para obtenção de informações espectrais de cristais fotônicos. Deve ser observado que o cálculo da DFT mostrado neste fluxograma corresponde ao caso convencional, utilizado para a determinação de espectros de refletância. Para o cálculo de diagrama de bandas, o algoritmo correspondente à DFT on-the-fly encontra-se no loop FDTD. 


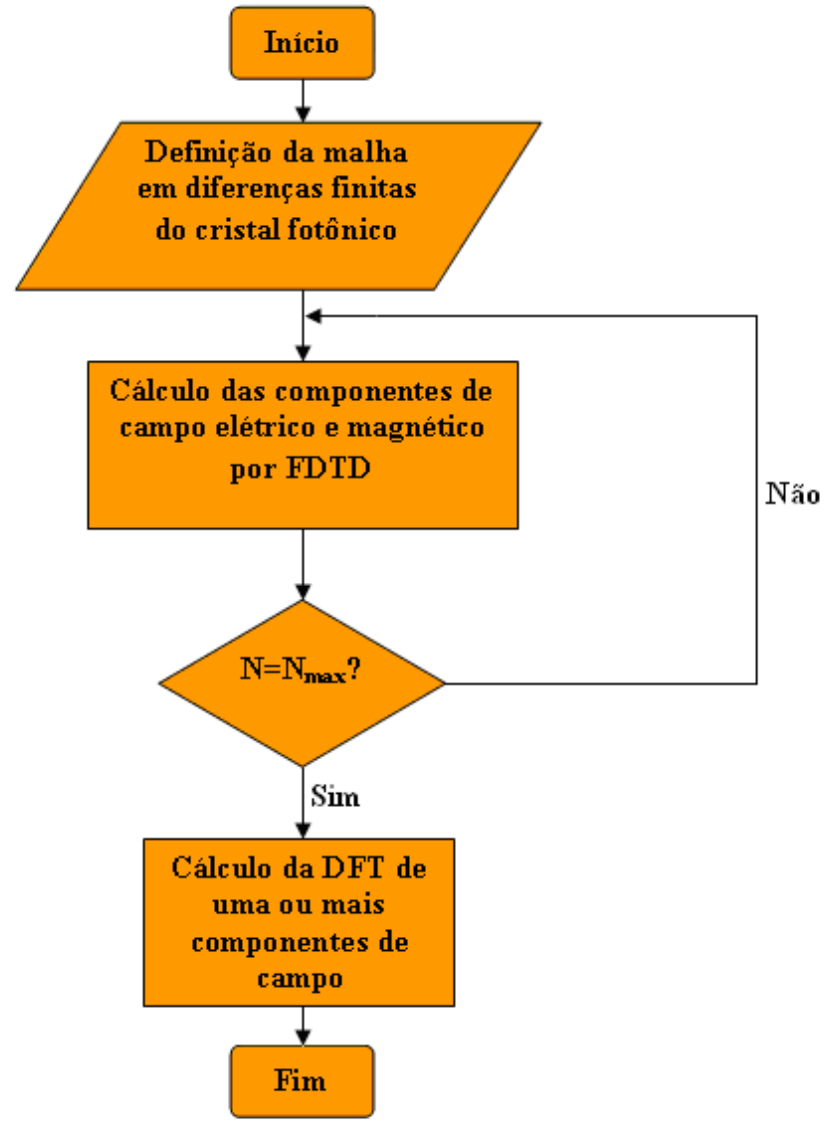

Fig. 2.8 - Fluxograma do algoritmo baseado em FDTD aplicado a cristais fotônicos. O critério de parada $\mathrm{N}_{\max }$ corresponde ao maior passo de tempo definido no algoritmo. 


\section{3 - DIAGRAMA DE BANDAS DO CRISTAL FOTÔNICO TRIDIMENSIONAL COMPOSTO POR OPALAS DE LÁTEX}

No capítulo precedente, foram discutidas as estratégias de implementação do algoritmo FDTD para cálculo de diagrama de bandas e espectros de refletância de cristais fotônicos tridimensionais. Esta ferramenta numérica foi aplicada ao estudo do cristal auto-organizado constituído por opalas de látex e produzido pelo Instituto de Química de Araraquara [32]. O presente capítulo trata da apresentação e discussão dos resultados computados por FDTD relativos a este cristal. Mais especificamente, são abordados resultados para o diagrama de bandas do cristal fotônico tridimensional de rede FCC. Os resultados relativos aos espectros de refletância são discutidos no capítulo 4.

A seção inicial versa sobre as principais técnicas de fabricação de cristais fotônicos tridimensionais, com maior atenção à técnica utilizada na preparação de cristais coloidais autoorganizados. Objetiva-se, assim, mostrar as particularidades inerentes ao processo de fabricação do cristal de látex, o que é de grande importância no auxílio à discussão dos resultados numericamente obtidos.

As demais seções dedicam-se a apresentar e discutir os resultados para diagrama de bandas obtidos a partir do método FDTD, levando em conta o caráter tridimensional da periodicidade e a espessura finita do cristal. A apresentação destes resultados se inicia com a aferição do algoritmo FDTD. Tal aferição foi realizada por meio do cálculo do diagrama de bandas do cristal formado por opalas inversas descrito em [13] e [31]. Em seguida, é apresentado o diagrama de bandas do cristal de látex. A análise deste resultado segue uma linha comparativa com o cristal formado por opalas inversas, tendo por fim demonstrar a influência do contraste de índice de refração na obtenção de um completo PBG. Ainda como forma de avaliar tal influência, 
é analisada a variação da largura do band gap com o índice de refração para uma dada direção de propagação. Para elucidar o comportamento eletromagnético em diferentes direções de propagação, também são apresentadas distribuições de densidade de fluxo elétrico ao longo de uma seção transversal da rede cristalina.

O capítulo é encerrado com uma discussão sobre a alteração do diagrama de bandas do cristal de látex quando o fator de empacotamento é reduzido de seu valor original (74\%) para 54\%. Esta discussão tem por finalidade demonstrar que alterações na configuração inicial da rede cristalina têm a propriedade de alterar o diagrama de bandas do cristal de forma significativa.

\section{1 - Técnicas de preparação de cristais fotônicos tridimensionais}

Tradicionalmente, a preparação de cristais fotônicos em muito é auxiliada pela infraestrutura existente para a fabricação de dispositivos microeletrônicos. Nesta abordagem está inserido o método de litografia planar [45], através do qual a periodicidade desejada é "escrita" em sucessivas camadas de material dielétrico por um procedimento seqüencial conhecido como LBL (layer-by-layer), uma técnica compatível com a tecnologia de fabricação de dispositivos CMOS. Entretanto, o processo de litografia é demorado, especialmente pela alta precisão exigida na repetição da periodicidade do cristal em cada camada. Além disto, enquanto modernos dispositivos microeletrônicos envolvem muitas camadas de material semicondutor, cristais fotônicos podem requerer um número ainda maior. Este é o caso, por exemplo, de estruturas woodpile, em que quatro camadas dielétricas são necessárias para a preparação de uma célula unitária do cristal [46]. 
Outra abordagem LBL consiste na utilização de materiais fotosensíveis (resists) para a implementação da estrutura molde (template) de uma camada de cristal fotônico, uma técnica proposta inicialmente por Sun et al. em 1999 [47]. Segundo esta abordagem, um laser pulsado de largura temporal bastante pequena (geralmente na escala de femtossegundo), ao ser difratado por uma máscara que contém o desenho da periodicidade projetada, realiza a fotopolimerização do material resist. Este processo é repetido diversas vezes até que seja obtido o número de camadas desejado. Com a síntese template realizada, o material resultante é submetido à corrosão seletiva para que então se obtenha o cristal fotônico com a rede cristalina esperada. Uma variante desta técnica foi proposta por Campbell et al. em 2000 [48] e recebeu a denominação holografia paralela. Este método consiste na utilização de um padrão de interferência de lasers coerentes que carrega a periodicidade projetada. $\mathrm{O}$ feixe de lasers incide no material resist levando à obtenção do cristal.

De menor custo que as técnicas descritas anteriormente, a fabricação de cristais fotônicos tridimensionais partindo da auto-organização de esferas monodispersas [49] se constitui em um método bastante empregado, apesar de ser limitado às redes cristalinas do tipo FCC (facecentered-cubic), BCC (body-centered-cubic) e HCP (hexagonal-closed-packed). Por meio desta técnica, é formado um molde coloidal de partículas que é utilizado posteriormente para a obtenção do cristal com um determinado contraste de índice de refração. As estruturas resultantes são denominadas opalas artificiais, em analogia às opalas encontradas na natureza. Além do baixo custo, uma grande vantagem é que este não é um processo seqüencial, mas sim paralelo, levando à obtenção de muitas camadas em um intervalo de tempo menor quando comparado aos métodos citados anteriormente. Como desvantagem, menciona-se a dificuldade no controle da distribuição das partículas, o que pode levar ao aparecimento de defeitos aleatórios ao longo da rede cristalina, tais como variação do diâmetro das opalas e camadas de área efetiva menor que 
outras. A seguir, é discutida a técnica de auto-organização utilizada pelo Instituto de Química de Araraquara na produção do cristal fotônico aqui estudado.

\subsection{1 - Preparação do cristal FCC constituído por opalas de látex}

O texto a seguir corresponde a uma breve descrição da técnica de auto-organização utilizada na preparação do cristal fotônico formado por opalas de látex. Tal descrição contempla apenas os pontos principais do processo de fabricação implementado pelo Instituto de Química de Araraquara. Informações detalhadas acerca deste processo podem ser encontradas em [32].

As opalas de látex foram sintetizadas de acordo com um processo de polimerização baseado na formação e crescimento de núcleos esféricos dispersos em uma emulsão composta por água, estireno e persulfato de potássio.

Primeiramente, o estireno é submetido a sucessivos processos de lavagem para que sejam retirados agentes inibidores de sua polimerização. Após isto, o estireno é imerso em água em um procedimento que ocorre sob agitação a uma temperatura de aproximadamente $70{ }^{\circ} \mathrm{C}$. Ao longo do processo, ocorre a adição lenta do iniciador, o qual é constituído por $100 \mathrm{ml}$ de 2,45 x $10^{-2} \mathrm{~mol} / \mathrm{l}$ de solução aquosa de persulfato de potássio. A adição do iniciador é realizada por um bombeamento de $0,07 \mathrm{ml} / \mathrm{min}$ durante $24 \mathrm{~h}$. A emulsão é mantida sob agitação após a adição completa do iniciador por um período de $4 \mathrm{~h}$.

Após 28 h de reação, verifica-se a existência de um denso colóide de opalas de látex. Esta suspensão passa por um processo de filtragem para que sejam retirados núcleos não totalmente formados. 
O processo de separação das opalas foi realizado através de centrifugação, sendo que esta etapa a formação de uma estrutura compacta e com um arranjo cristalino definido.

As quatro amostras sintetizadas foram identificadas segundo suas respectivas velocidades nominais de agitação, a saber: $250 \mathrm{rpm}, 300 \mathrm{rpm}, 350 \mathrm{rpm}$ e $400 \mathrm{rpm}$. Por conseguinte, as amostras passaram a ser denominadas por: látex-250, látex-300, látex-350 e látex-400. As fotomicrografias das quatro amostras obtidas são apresentadas na Fig. 3.1. Estas imagens evidenciam a existência de defeitos ao longo do cristal causados por empilhamento inadequado das opalas em algumas localizações.
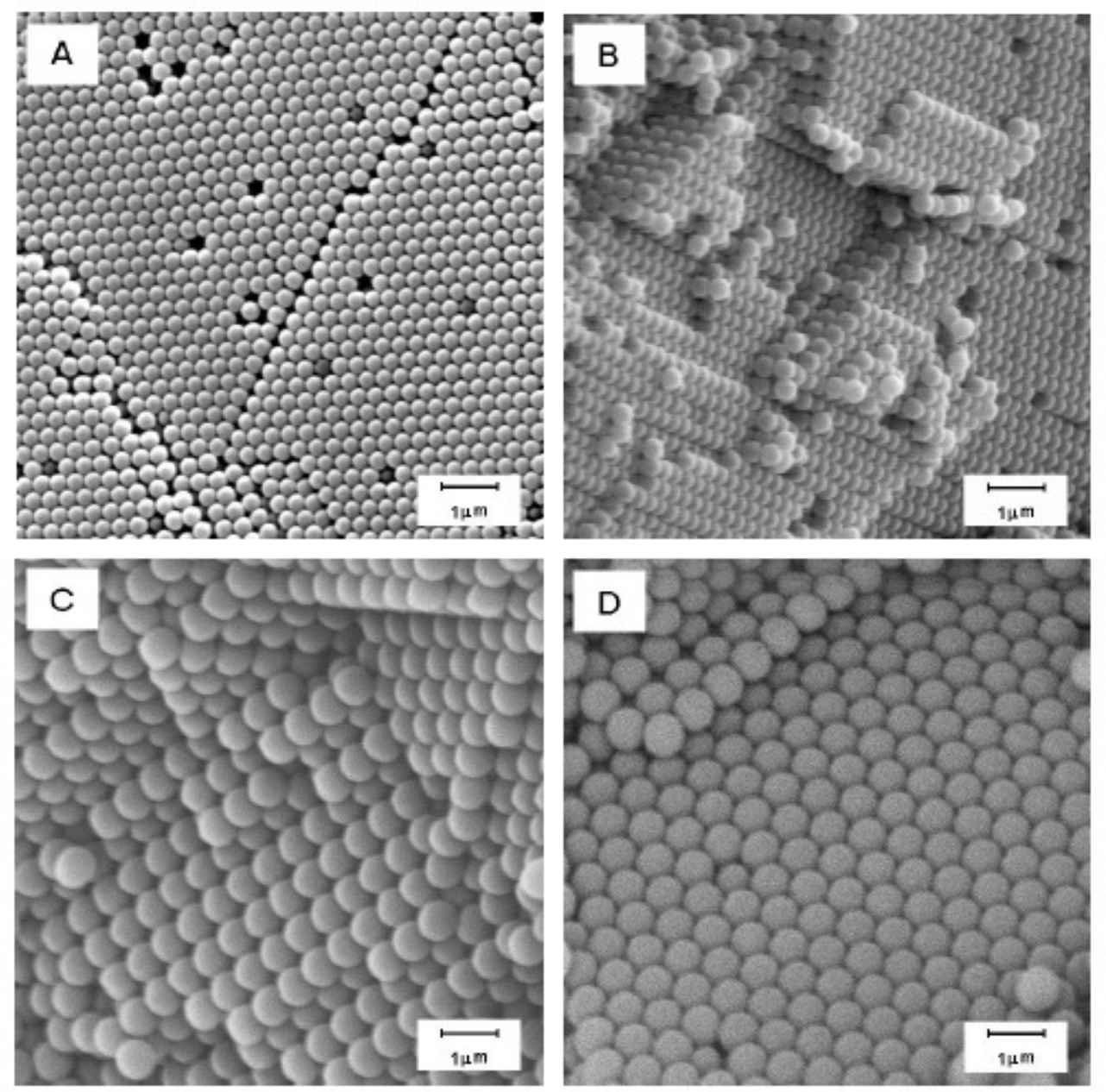

Fig. 3.1 - Fotomicrografias das amostras cristalinas formadas por opalas de látex em uma rede FCC: (A) látex-250, (B) látex-300, (C) látex-350 e (D) látex-400 [32]. 
As seções seguintes apresentam e discutem os diagramas de bandas obtidos a partir do método FDTD para o cristal constituído por opalas de látex. Como preâmbulo de tal discussão, são descritos a seguir os procedimentos de definição da malha discretizada e o suporte computacional empregado na execução do algoritmo FDTD.

\section{2 - Definição da malha computacional}

Antes de apresentar os resultados obtidos numericamente, é importante destacar algumas características de construção da malha computacional, as quais têm por finalidade melhorar a performance de processamento do algoritmo FDTD. A seguir, é descrita a abordagem empregada neste trabalho para a descrição da estrutura FCC do cristal.

Considera-se a célula unitária FCC mostrada na Fig. 3.2. Os eixos cartesianos indicam os passos espaciais nas direções $x, y$ e $z$. Um cálculo realista da resposta eletromagnética do cristal deve considerar a extensão finita da estrutura, o que pode ser diretamente implementado no algoritmo FDTD. 


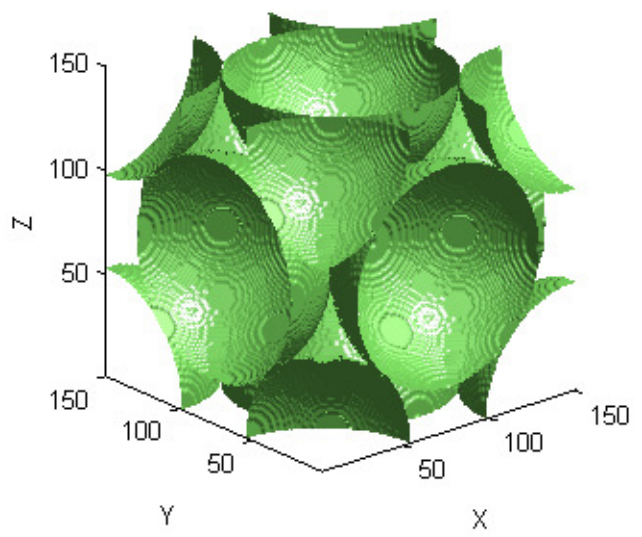

Fig. 3.2 - Célula unitária de um cristal FCC implementado em uma malha de diferenças finitas. As coordenadas espaciais são especificadas em termos dos passos de discretização espacial da malha computacional.

No entanto, a consideração de que o cristal seja finito em todas as direções requer elevada capacidade de processamento e memória computacionais, o que torna a iteração FDTD demasiadamente demorada, especialmente no caso da obtenção do diagrama de bandas. Neste trabalho, a solução empregada para superar esta dificuldade foi considerar o cristal finito na direção $z$, porém, infinito no plano $x y$. Esta modelagem requer duas condições de contorno distintas: nas extremidades do domínio computacional em que o cristal é considerado infinito (direções $x$ e $y$ ), utilizam-se condições de contorno periódicas e, na direção em que o cristal é finito (direção z), é aplicada PML.

A rede cristalina modelada é um cubo de aresta $3 a$ ( $a$ é a constante de rede). O domínio computacional onde o cristal está inserido possui tamanho de $3 a$ nas direções $x$ e $y$ e $5 a$ na direção $z$. Esta geometria é mostrada na Fig. 3.3. 


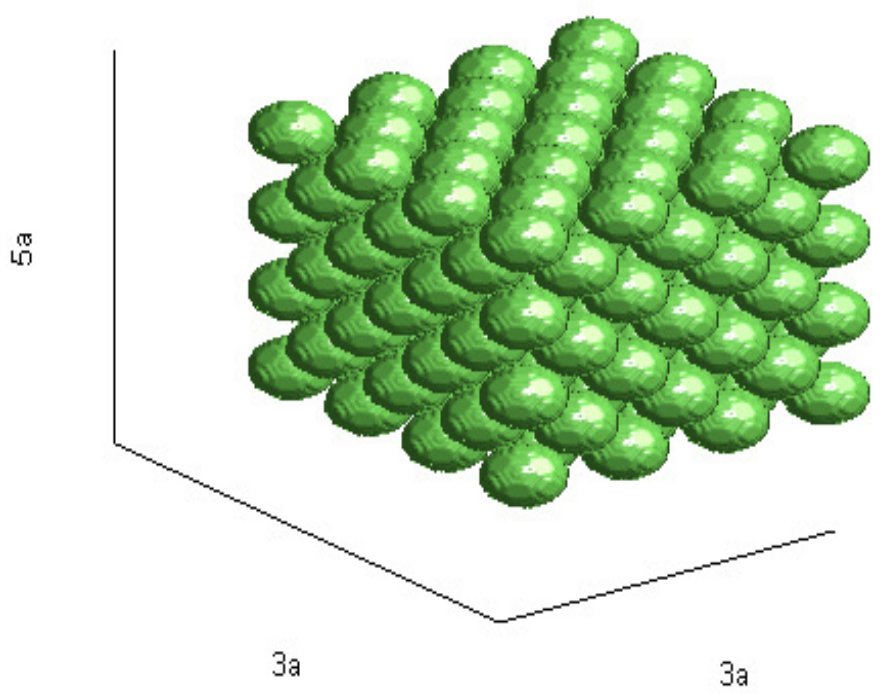

Fig. 3.3 - Visualização do cristal fotônico FCC considerado infinito apenas nas direções $x$ e $y$. O comprimento de 5a corresponde ao tamanho completo da malha computacional na direção $z$, englobando a altura de 3a do cristal e 2a relativamente ao espaço livre.

\subsection{1 - Suporte computacional utilizado}

Um importante ponto a ser destacado é a infraestrutura computacional utilizada para a execução do algoritmo FDTD, a qual requer grande robustez, especialmente por se tratar de simulações no espaço tridimensional.

Neste trabalho, os cálculos FDTD foram executados em um cluster composto por 24 processadores Xeon Intel, de 2,8 GHz cada, os quais estão distribuídos igualmente entre 12 nós, cada nó possuindo 2 GB de memória RAM. A fotografia deste cluster é apresentada na Fig. 3.4. 


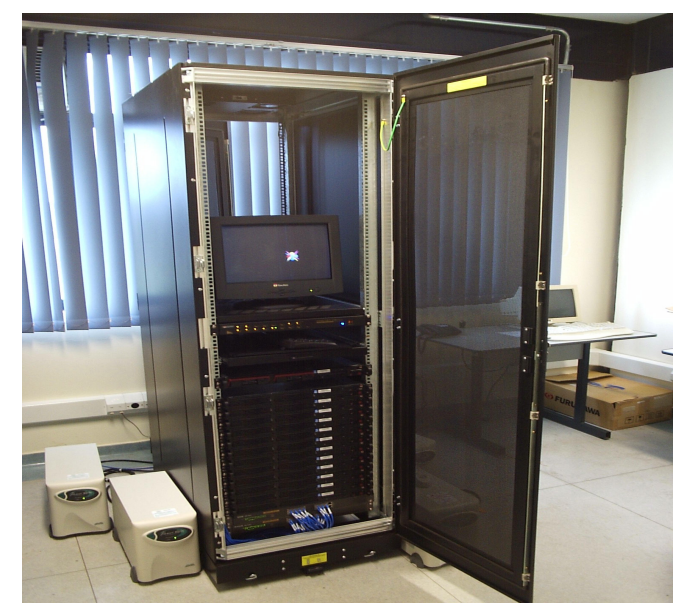

Fig. 3.4 - Cluster do grupo de telecomunicações da Escola de Engenharia de São Carlos/USP.

Relativamente à obtenção de diagrama de bandas, a execução dos cálculos FDTD utilizou 60 pontos da zona irredutível de Brillouin, cada qual correspondendo a um vetor de onda. Comumente, um grupo de 10 pontos era inserido simultaneamente no cluster. Cada ponto do grupo era enviado a um processador, o qual ficava, desta forma, responsável pela determinação das autofreqüências de um específico vetor de onda. Como os cálculos das autofreqüências para cada grupo de 10 pontos durava mais que 3 dias, o tempo médio do cálculo do diagrama de bandas era superior a 18 dias. Mesmo com este suporte computacional, os cálculos realizados neste trabalho limitaram-se a cristais FCC perfeitos e redes que possuem uma variação uniforme do fator de empacotamento (fração do volume da célula unitária preenchido por opalas). O motivo desta limitação é a necessidade de estruturas bem maiores que a mostrada na Fig. 3.3 para modelar defeitos relativos a variações aleatórias da posição das opalas, o que, por seu turno, exige excessivo esforço de processamento e armazenamento de dados. 


\subsection{2 - Nomenclatura empregada nesta dissertação}

De forma a impedir interpretações equivocadas das designações utilizadas nesta dissertação, é definida, a seguir, a nomenclatura empregada na discussão dos resultados. As denominações utilizadas obedecem ao que é usado nas publicações científicas concernentes a cristais fotônicos, conforme é exemplificado em [1], [18] e [44].

Em cristais fotônicos finitos imersos em ar, alguns modos do diagrama de bandas do cristal possuem um índice de refração efetivo (constante de propagação normalizada pelo vetor de onda do espaço livre) $n_{e f}<1,0$. Esta dissertação designa tais modos como radiados, isto é, correspondem a oscilações que se estendem do cristal para o ar. Em caso contrário, ou seja, quando $n_{e f}>1,0$, os modos são denominados confinados, oscilando no cristal e possuindo um decaimento exponencial nas proximidades da interface cristal-ar. Tais designações serão usadas na comparação entre o diagrama de bandas do cristal e a curva de dispersão do ar, não mudando de significado ao longo do texto, a menos que seja expresso o contrário.

A seguir, é discutida a aferição do algoritmo FDTD para o cálculo de diagrama de bandas desenvolvido neste trabalho. 


\section{3 - Cristal formado por opalas inversas - Aferição do algoritmo FDTD para o cálculo de diagrama de bandas}

O cristal FCC formado por opalas inversas descrito em [13] e [31] é composto por opalas de ar imersas em um material hipotético com índice de refração igual a 3,6. Esta estrutura é um conhecido exemplo de cristal fotônico tridimensional com PBG ao longo de toda a zona irredutível de Brillouin.

Tendo por finalidade validar a modelagem aqui desenvolvida, o algoritmo implementado foi aplicado ao cálculo do diagrama de bandas do cristal formado por opalas inversas. O resultado obtido foi aferido com aqueles expressos em [13] e [31]. Para realizar a simulação computacional, o diâmetro das opalas foi fixado em 303,5 nm. Este diâmetro corresponde ao valor encontrado experimentalmente para a amostra látex-300, cristal que possui um ordenamento de opalas mais próximo da rede FCC perfeita entre aqueles mostrados na Fig. 3.1.

O diagrama de bandas calculado pelo algoritmo FDTD é mostrado na Fig. 3.5. Os valores de vetor de onda destacados na abscissa do diagrama correspondem aos pontos de simetria da zona irredutível de Brillouin. É evidenciado que, embora haja segmentos da zona de Brillouin que apresentem bandas proibidas, somente a região delimitada pela faixa em preto corresponde a um PBG completo no intervalo espectral normalizado. 


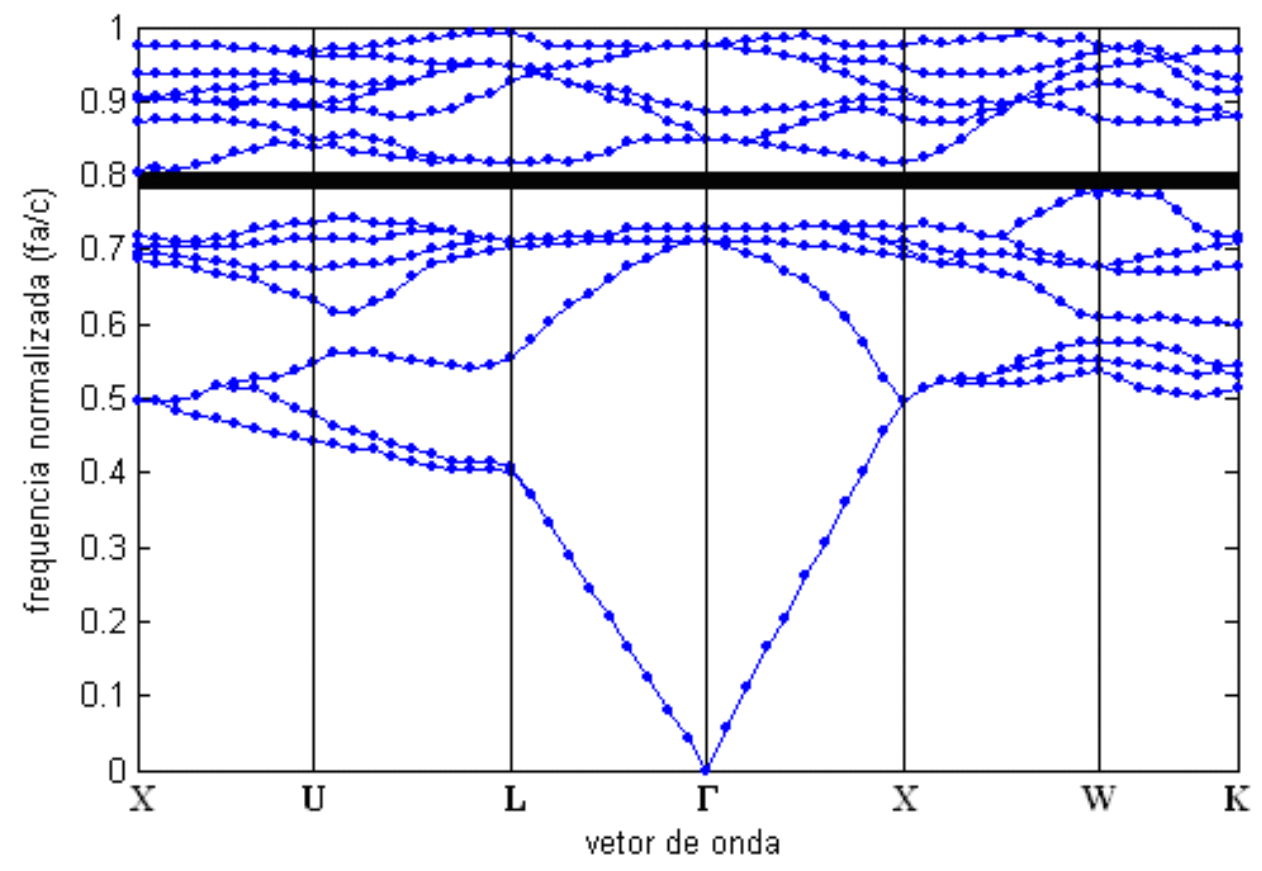

Fig. 3.5 - Diagrama de bandas do cristal formado por opalas inversas. A faixa em preto corresponde ao PBG completo.

As tabelas I e II trazem uma comparação entre as autofreqüências normalizadas que delimitam o PBG na Fig. 3.5 e as correspondentes encontradas em [13] e [31]. Os valores tomados estão relacionados aos pontos de simetria da zona irredutível de Brillouin. Os erros percentuais presentes nas tabelas I e II são relativos aos valores expressos em [13] e [31], respectivamente. 
Tabela I. Valores das autofreqüências normalizadas que delimitam o PBG no cristal formado por opalas inversas.

Comparação entre os resultados deste trabalho e aqueles expressos em [13].

\begin{tabular}{c||c|c|c||c|c|c||c|c|c}
\hline \hline $\begin{array}{c}\text { Pontos da } \\
\text { zona } \\
\begin{array}{c}\text { irredutível } \\
\text { de } \\
\text { Brillouin }\end{array}\end{array}$ & $\begin{array}{c}\text { Úlima banda permitida } \\
\text { inferior ao PBG }\end{array}$ & \multicolumn{2}{c|}{$\begin{array}{c}\text { Primeira banda permitida } \\
\text { superior ao PBG }\end{array}$} & \multicolumn{2}{|c|}{$\begin{array}{c}\text { Largura da banda } \\
\text { proibida }\end{array}$} \\
\hline $\mathbf{X}$ & $\begin{array}{c}\text { Este } \\
\text { trabalho }\end{array}$ & {$[13]$} & $\begin{array}{c}\text { Módulo } \\
\text { do erro } \\
\text { relativo } \\
(\%)\end{array}$ & $\begin{array}{c}\text { Este } \\
\text { trabalho }\end{array}$ & {$[13]$} & $\begin{array}{c}\text { Módulo } \\
\text { do erro } \\
\text { relativo } \\
(\%)\end{array}$ & $\begin{array}{c}\text { Este } \\
\text { trabalho }\end{array}$ & $\begin{array}{c}\text { Módulo } \\
\text { do erro } \\
\text { relativo } \\
(\%)\end{array}$ \\
\hline $\mathbf{U}$ & 0,721 & 0,721 & 0 & 0,812 & 0,812 & 0 & 0,091 & 0,091 & 0 \\
\hline $\mathbf{L}$ & 0,740 & 0,742 & 0,270 & 0,870 & 0,871 & 0,114 & 0,130 & 0,129 & 0,77 \\
\hline $\boldsymbol{\Gamma}$ & 0,728 & 0,730 & 0,273 & 0,839 & 0,840 & 0,119 & 0,111 & 0,110 & 0,909 \\
\hline $\mathbf{W}$ & 0,748 & 0,750 & 0,267 & 0,834 & 0,836 & 0,239 & 0,086 & 0,086 & 0 \\
\hline $\mathbf{K}$ & 0,790 & 0,788 & 0,253 & 0,880 & 0,877 & 0,342 & 0,09 & 0,089 & 1,120 \\
\hline
\end{tabular}

Tabela II. Valores das autofreqüências normalizadas que delimitam o PBG no cristal formado por opalas inversas.

Comparação entre os resultados deste trabalho e aqueles expressos em [31].

\begin{tabular}{|c|c|c|c|c|c|c|c|c|c|}
\hline \multirow{2}{*}{$\begin{array}{l}\text { Pontos da } \\
\text { zona } \\
\text { irredutível } \\
\text { de } \\
\text { Brillouin }\end{array}$} & \multicolumn{3}{|c|}{$\begin{array}{l}\text { Última banda permitida } \\
\text { inferior ao PBG }\end{array}$} & \multicolumn{3}{|c|}{$\begin{array}{c}\text { Primeira banda permitida } \\
\text { superior ao PBG }\end{array}$} & \multicolumn{3}{|c|}{$\begin{array}{c}\text { Largura da banda } \\
\text { proibida }\end{array}$} \\
\hline & $\begin{array}{l}\text { Este } \\
\text { trabalho }\end{array}$ & [31] & $\begin{array}{c}\text { Módulo } \\
\text { do erro } \\
\text { relativo } \\
(\%)\end{array}$ & $\begin{array}{l}\text { Este } \\
\text { trabalho }\end{array}$ & [31] & $\begin{array}{c}\text { Módulo } \\
\text { do erro } \\
\text { relativo } \\
(\%)\end{array}$ & $\begin{array}{l}\text { Este } \\
\text { trabalho }\end{array}$ & [31] & $\begin{array}{c}\text { Módulo } \\
\text { do erro } \\
\text { relativo } \\
(\%)\end{array}$ \\
\hline $\mathbf{X}$ & 0,721 & 0,730 & 1,232 & 0,812 & 0,850 & 4,470 & 0,091 & 0,120 & 24,160 \\
\hline $\mathbf{U}$ & 0,740 & 0,760 & 2,631 & 0,870 & 0,900 & 3,333 & 0,130 & 0,140 & 7,142 \\
\hline $\mathbf{L}$ & 0,728 & 0,749 & 2,803 & 0,839 & 0,907 & 7,497 & 0,111 & 0,158 & 29,74 \\
\hline$\Gamma$ & 0,748 & 0,750 & 0,267 & 0,834 & 0,876 & 4,794 & 0,086 & 0,126 & 31,746 \\
\hline $\mathbf{W}$ & 0,790 & 0,795 & 0,628 & 0,880 & 0,926 & 4,967 & 0,09 & 0,139 & 35,251 \\
\hline $\mathbf{K}$ & 0,720 & 0,738 & 2,439 & 0,901 & 0,921 & 2,171 & 0,181 & 0,183 & 1,092 \\
\hline
\end{tabular}

Na tabela I, a análise comparativa mostra uma grande concordância entre os resultados FDTD e os correspondentes mostrados em [13]. Demonstrando a existência de um PBG pouco acima da freqüência normalizada 7,0. Tal concordância ocorre não só na comparação da largura 
da banda proibida, a qual foi obtida com um erro relativo máximo de $1,120 \%$, mas também nos valores das freqüências que delimitam o PBG. Neste caso, o máximo erro relativo é de $0,342 \%$.

No entanto, a aferição correspondente à tabela II evidencia que, em [31], em cada ponto de simetria da zona de Brillouin, o PBG possui uma largura maior que a calculada pelo algoritmo FDTD aqui implementado, com um erro relativo máximo superior a 35\%. As bandas permitidas imediatamente acima e abaixo do PBG em [31] também compreendem freqüências maiores que as calculadas pelo algoritmo FDTD, alcançando um erro relativo superior a 7\%. Uma explicação possível para esta divergência é que este trabalho utilizou um número maior de pontos espaciais e de iterações temporais que o empregado em [31], o que melhora a precisão da DFT (discrete Fourier transform).

De modo a ilustrar a distribuição de campo proveniente da excitação empregada para o cálculo do diagrama de bandas (vide capítulo 2 - seção 2.3), são apresentadas na Fig. 3.6 distribuições de densidade de fluxo elétrico para o cristal formado por opalas inversas. Os cálculos foram realizados para os pontos $\mathbf{X}$ e $\mathbf{K}$ da zona de Brillouin e as distribuições de campo foram tomadas em uma seção da célula unitária normal à direção $z$.

É mostrado na Fig. 3.6 que a concentração de campo na região de alto índice de refração é bem maior que a encontrada no ar. 


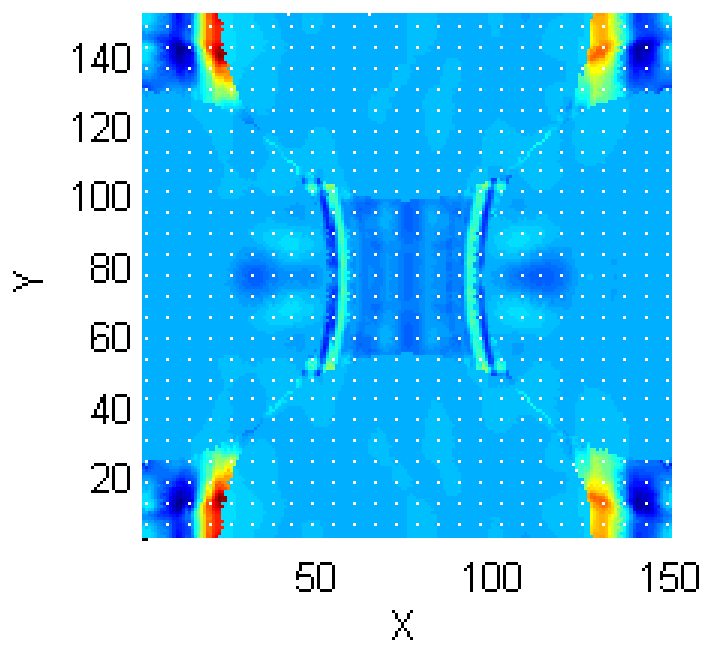

(a)

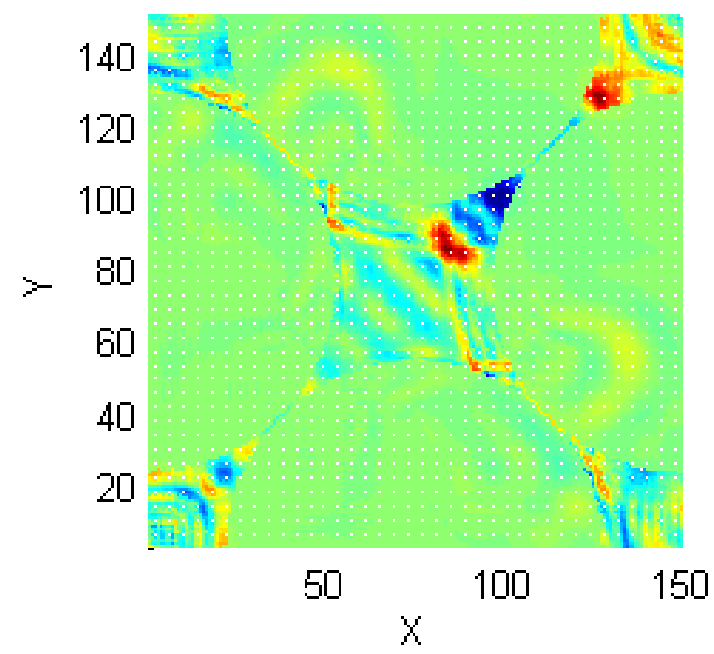

(b)

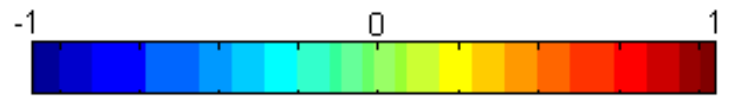

Fig. 3.6 - Distribuição de densidade de fluxo elétrico para os pontos (a) $\mathbf{X}$ e (b) K, pertencentes à zona irredutível de Brillouin do cristal formado por opalas inversas. As coordenadas $x$ e $y$ indicam os passos de discretização espacial. 


\subsection{1 - Comparação entre o diagrama de bandas e a curva de dispersão do ar - modos radiados e modos confinados no cristal fotônico tridimensional}

Conforme mencionado na seção 3.2, em um cristal fotônico finito em pelo menos uma direção, alguns modos do diagrama de bandas do cristal são modos confinados, isto é, possuem índice de refração efetivo maior que o meio externo à rede periódica, enquanto que os demais são modos radiados. Estes modos podem ser determinados a partir da comparação entre o diagrama de bandas do cristal e a curva de dispersão do meio que o cerca.

Na Fig. 3.7, esta comparação é realizada para o cristal FCC formado por opalas inversas cujo meio externo é o ar. A curva de dispersão do ar está destacada pela linha em vermelho. Todo modo do diagrama de bandas acima da curva de dispersão do ar está relacionado a um vetor de

onda $\bar{k}$ tal que o índice de refração efetivo $n_{e f}=k / k_{o}<1,0$, onde $k$ é o módulo do vetor $\bar{k}$ relativo a uma dada freqüência normalizada $\mathrm{F}$ e $k_{o}$ é o módulo do vetor de onda no espaço livre para esta mesma freqüência. Estes modos oscilam do cristal para o ar, sendo denominados, portanto, modos radiados. O contrário ocorre na região abaixo da curva de dispersão do ar. Nesta região, os modos são tais que $n_{e f}=k / k_{o}>1,0$, o que os identifica como modos confinados, oscilando no interior da rede cristalina e decaindo exponencialmente nas proximidades da interface cristal-ar. 


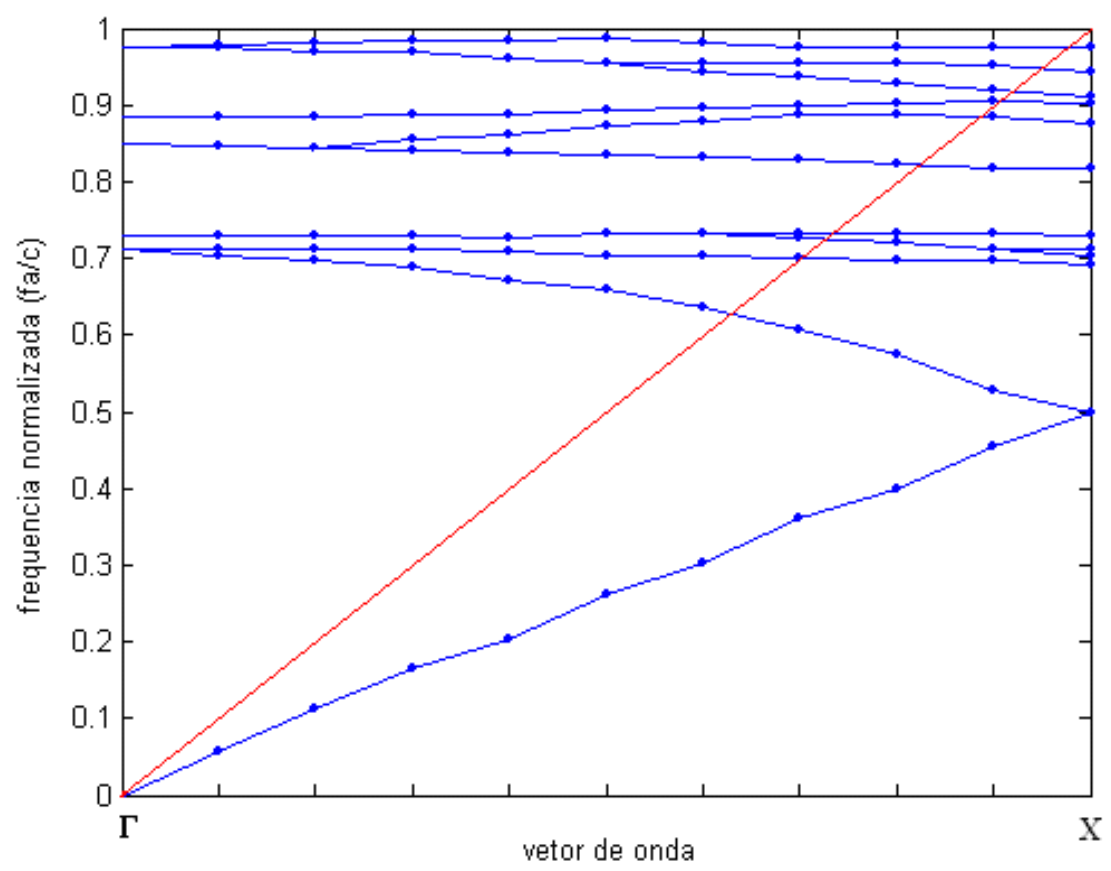

Fig. 3.7 - Modos radiados e modos confinados do cristal fotônico formado por opalas inversas. Os modos acima da curva de dispersão do ar (linha em vermelho) correspondem aos modos radiados. Os modos abaixo da curva de dispersão do ar são os modos confinados do cristal.

\section{4 - Cristal auto-organizado formado por opalas de látex}

Na Fig. 3.8, é mostrado o diagrama de bandas calculado pelo algoritmo FDTD para o cristal formado por opalas de látex imersas em ar. O diâmetro das opalas empregado na simulação computacional foi de $303,5 \mathrm{~nm}$. Este valor corresponde ao diâmetro encontrado experimentalmente para o cristal látex-300, o qual, como já mencionado na seção anterior, apresentou um ordenamento de opalas mais próximo da rede FCC perfeita.

Diferentemente do cristal formado por opalas inversas, observa-se na Fig. 3.8 a inexistência de um PBG que se mantenha ao longo de todas as direções de propagação, característica determinada pelo baixo contraste entre os índices de refração do látex e do ar [13]. 
No cristal formado por opalas de látex, o contraste é de apenas 0,59 , enquanto que, no cristal formado por opalas inversas, o contraste é de 2,6.

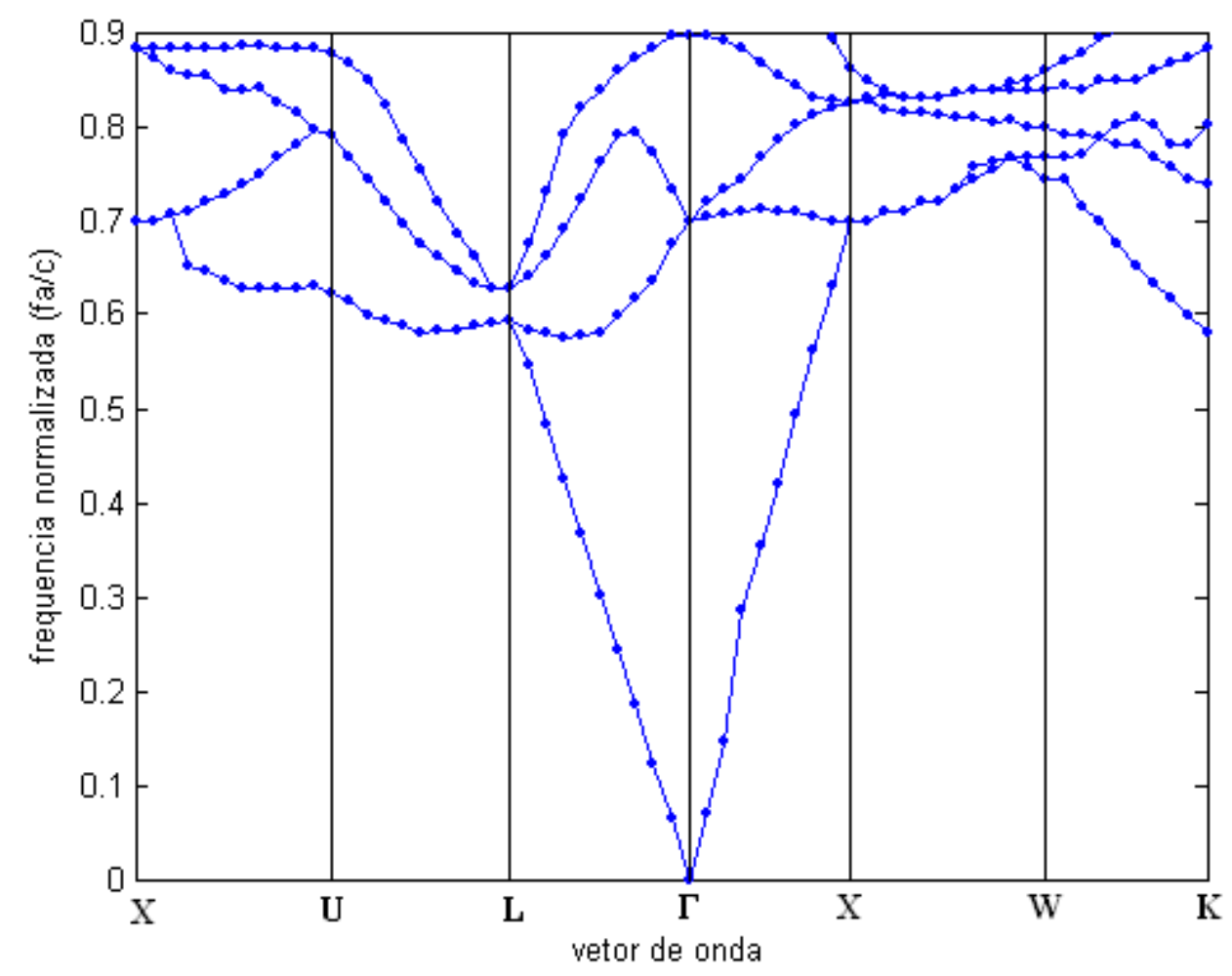

Fig. 3.8 - Diagrama de bandas obtido por FDTD para o cristal FCC formado por opalas de látex.

Para entender a influência do índice de refração $n$ na formação de bandas proibidas em cristais fotônicos FCC, o algoritmo FDTD calculou a variação da largura do band gap relativo à medida que $n$ é aumentado. Este valor foi calculado entre a primeira e segunda banda permitidas na direção X. Esta direção foi escolhida por permitir observar significativas variações do band gap diante do incremento de $n$ [13]. As opalas são supostas imersas em ar e o diâmetro destas é o valor utilizado para obter o diagrama de bandas da Fig. 3.8. A variação da largura do band gap relativo com o índice de refração é apresentado na Fig. 3.9. Observa-se que o surgimento de um band gap somente é possível para índices de refração maiores que 3,0. 


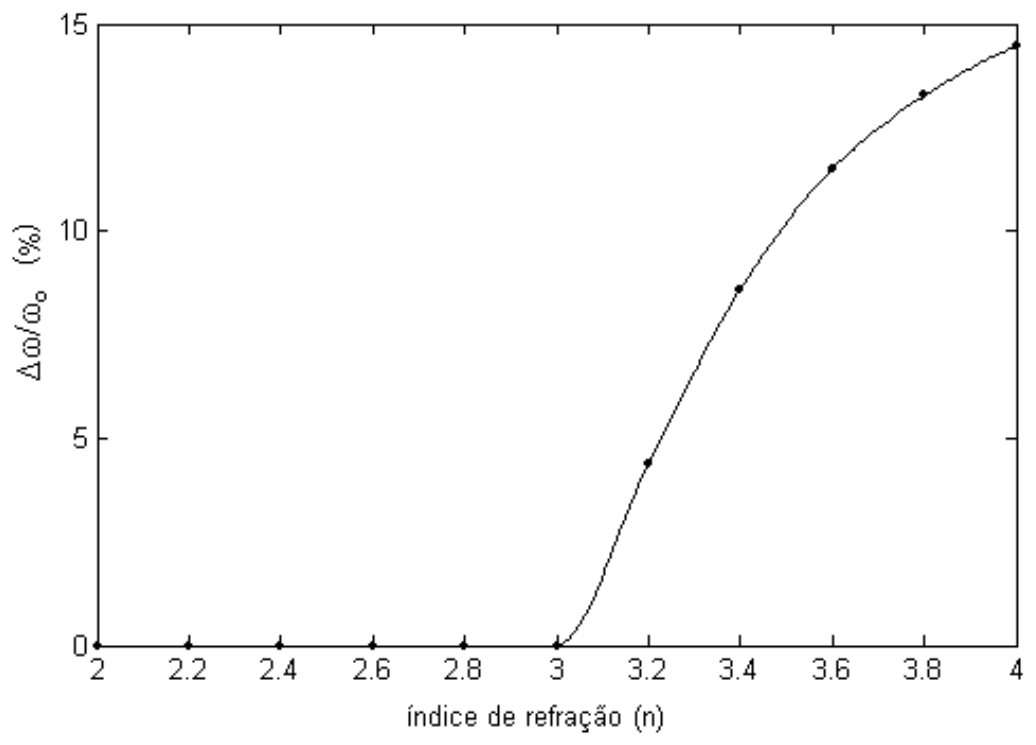

Fig. 3.9 - Variação do PBG relativo em função do índice de refração para a direção $\mathbf{X}$ da zona irredutível de Brillouin; $\omega_{\mathrm{o}}$ corresponde à frequiência central do band gap.

Assim como foi feito para o cristal formado por opalas inversas, foram obtidas distribuições de densidade de fluxo elétrico ao longo de uma seção da célula unitária do cristal de látex. Esta seção é normal à direção $z$ e os pontos da zona de Brillouin escolhidos para a realização dos cálculos são $\mathbf{X}$ e $\mathbf{K}$. A excitação empregada corresponde àquela utilizada para o cálculo do diagrama de bandas. As distribuições de campo calculadas são mostradas na Fig. 3.10. Observa-se que estas distribuições dificilmente permitem identificar a seção reta da rede cristalina, o que é um indício da dificuldade em se alcançar uma banda proibida completa [1]. 


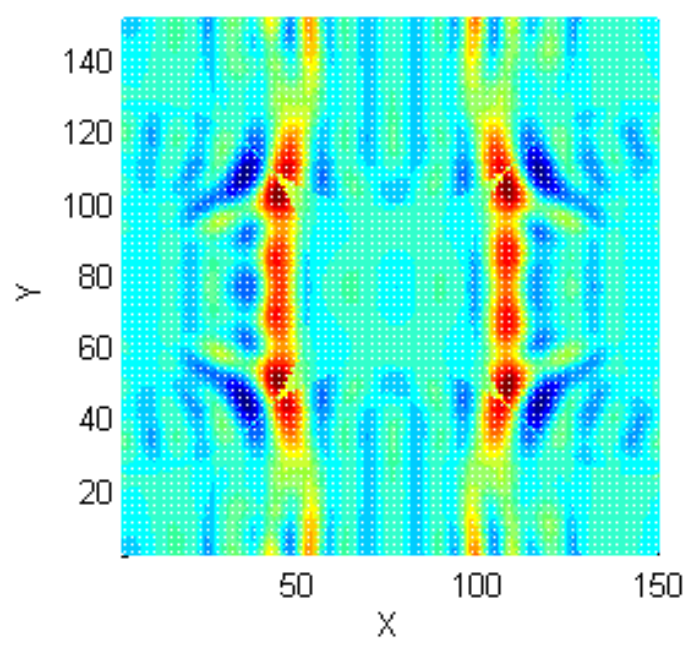

(a)

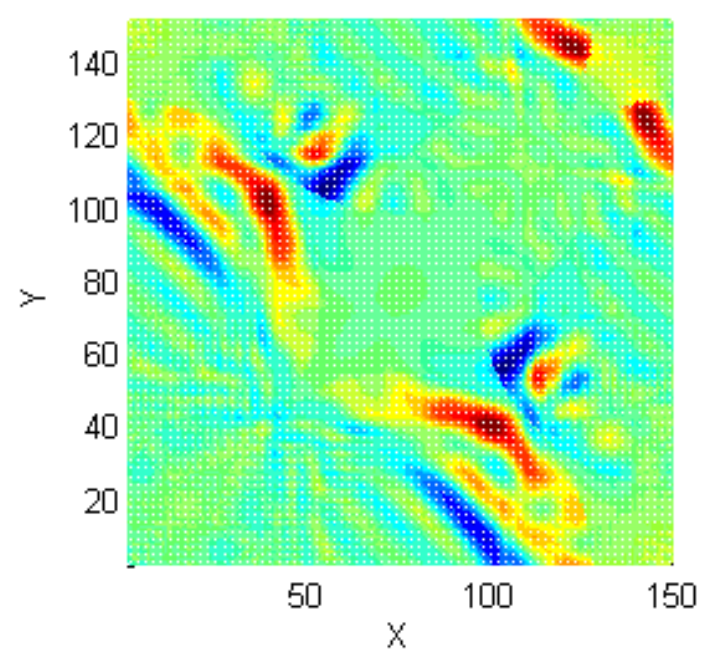

(b)

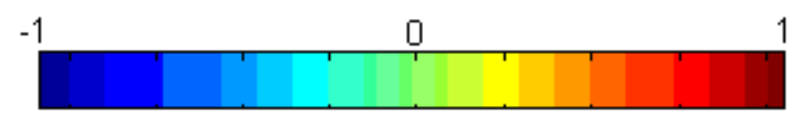

Fig. 3.10 - Distribuição de densidade de fluxo elétrico para os pontos (a) $\mathbf{X}$ e (b) $\mathbf{K}$, pertencentes à zona irredutível de Brillouin do cristal formado por opalas de látex. As coordenadas $x$ e $y$ indicam os passos de discretização espacial. 


\subsection{1 - Modos radiados e modos confinados do cristal formado por opalas de látex}

Utilizando a mesma análise comparativa empregada na Fig. 3.7, pode-se identificar quais são os modos radiados e os modos confinados no diagrama de bandas do cristal de látex.

Na Fig. 3.11, os modos radiados são aqueles localizados acima da curva de dispersão do ar (linha em vermelho). Os modos confinados localizam-se abaixo desta curva.

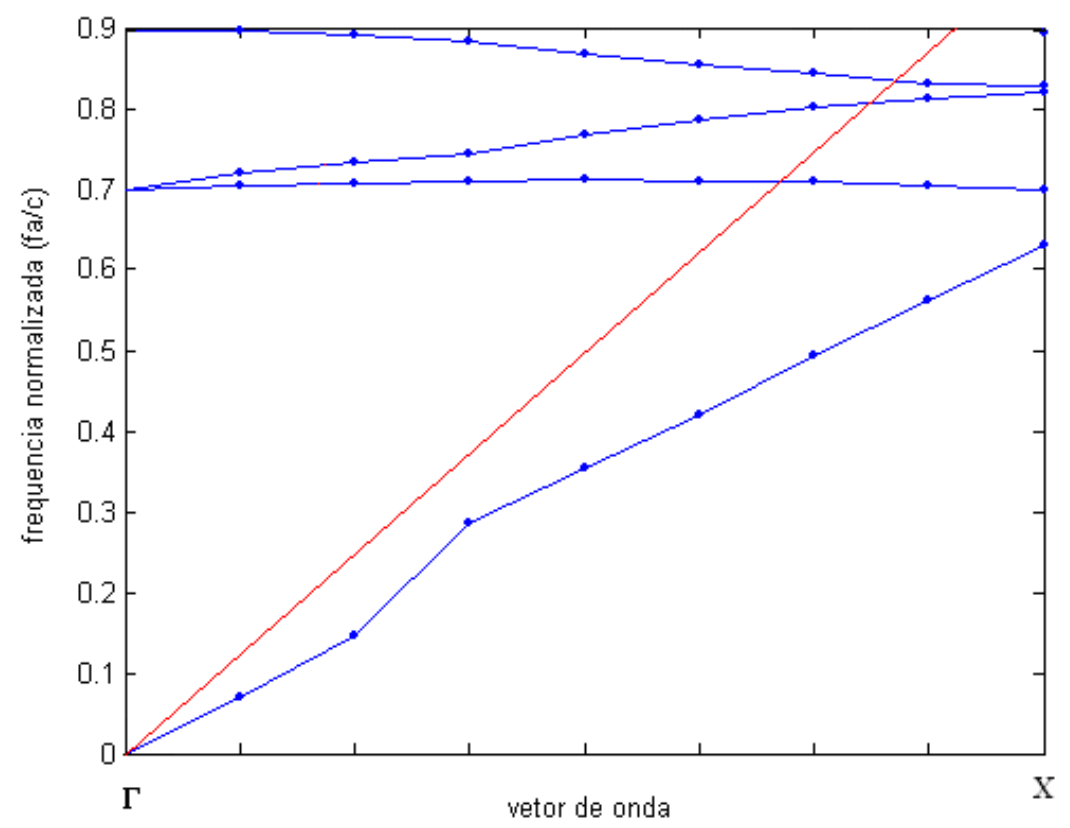

Fig. 3.11 - Modos radiados e modos confinados do cristal fotônico formado por opalas de látex. Os modos acima da curva de dispersão do ar (linha em vermelho) correspondem aos modos radiados. Os modos abaixo da curva de dispersão do ar são os modos confinados do cristal. 
O cálculo do diagrama de bandas do cristal de látex pelo método FDTD evidenciou que o baixo contraste de índice de refração impossibilita o aparecimento de um completo PBG. No entanto, bandas proibidas existem em alguns segmentos da zona irredutível de Brillouin deste cristal. Por exemplo, existe um band gap compreendendo o intervalo espectral normalizado ]0,7;0,9[ ao longo da direção $\Gamma$. Isto demonstra que, para algumas direções de propagação e determinadas faixas espectrais, pode-se ter disponível um band gap para o controle da propagação de fótons.

O diagrama de bandas da Fig. 3.8 corresponde à rede FCC perfeita, a qual possui fator de empacotamento $f p$ igual a $74 \%$. Com a finalidade de avaliar o diagrama de bandas de uma rede cristalina imperfeita, o algoritmo FDTD foi empregado na modelagem de um cristal fotônico também formado por opalas de látex, porém, com fator de empacotamento de 54\%. Conforme será apresentado no capítulo 4, este valor corresponde à amostra látex-400. O diagrama de bandas obtido para esta nova estrutura é o assunto da seção a seguir.

\section{5 - Diagrama de bandas do cristal formado por opalas de látex para $f p=54 \%$}

Conforme descrito em [1], o escalonamento das dimensões do cristal, isto é, modificações na constante de rede $a$ e no raio $r$ das opalas dielétricas, não acarreta modificações no diagrama de bandas quando este é expresso em termos de um espectro normalizado, desde que a razão $r / a$, seja mantida constante. Por conseguinte, uma maneira de alterar o digrama de bandas do cristal fotônico é modificar esta razão.

Como forma de avaliar a variação do diagrama de bandas com a modificação de um parâmetro cristalino estrutural, o método FDTD foi empregado no cálculo do diagrama de bandas 
do cristal de látex com $f p=54 \%$. A implementação deste valor na distribuição das opalas admite que o raio das mesmas permaneça fixo em $303,5 \mathrm{~nm}$. Assim, para alcançar 54\%, basta modificar a constante de rede $a$ de acordo com (3.1) [35]:

$$
\frac{r}{a}=\sqrt[3]{\frac{3 f p}{16 \pi}}
$$

Com a nova constante de rede obtida a partir de (3.1), o correspondente diagrama de bandas foi calculado pelo método FDTD aplicando os mesmos procedimentos empregados no cristal FCC de látex. O diagrama de bandas do cristal com $f p=54 \%$ é apresentado na Fig. 3. 12.

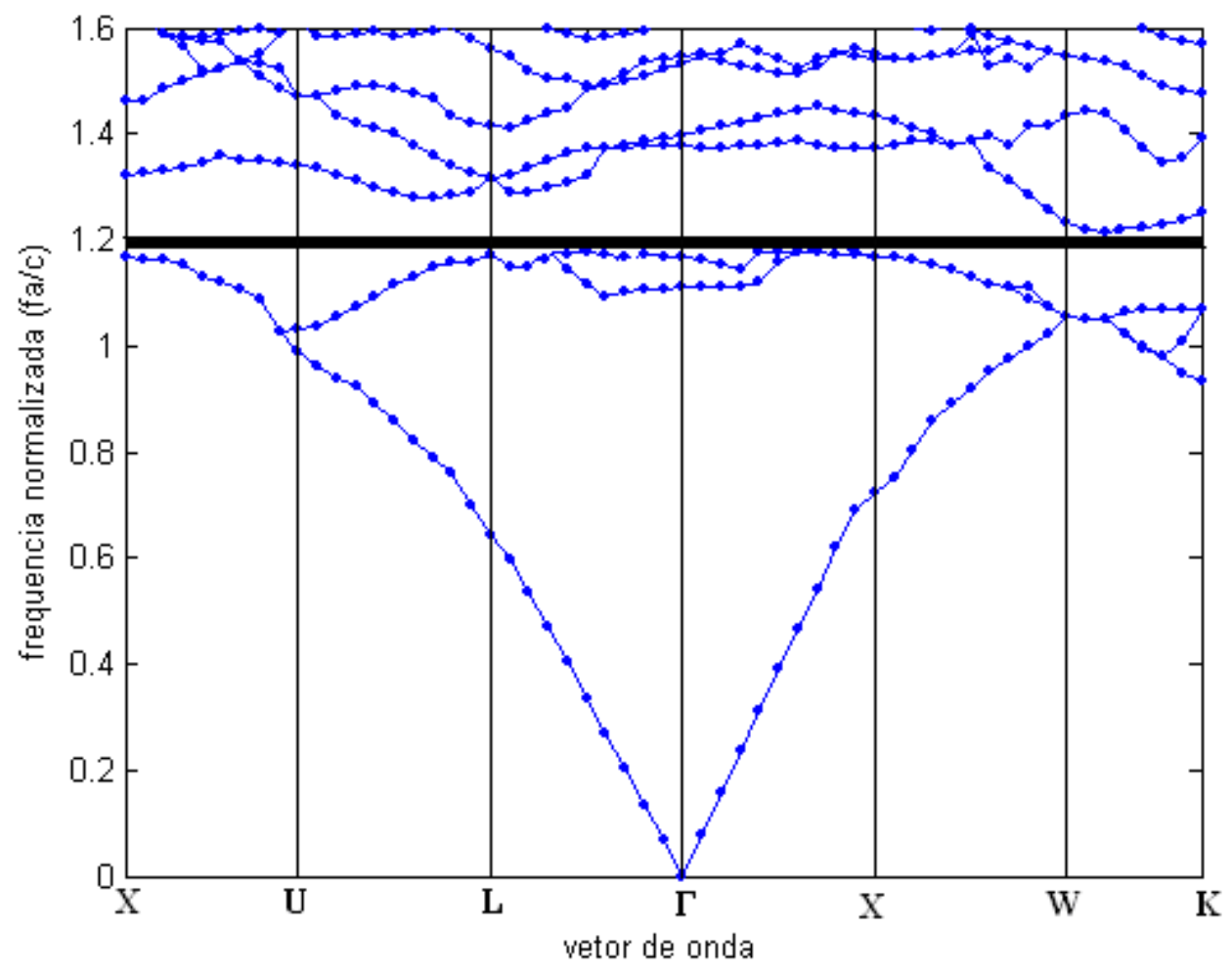

Fig. 3.12 - Diagrama de bandas do cristal de látex $\operatorname{com} f p=54 \%$. A faixa em preto corresponde ao PBG completo. 
O diagrama de bandas da Fig. 3.12 difere significativamente do que foi apresentado na Fig. 3.8, mostrando a existência de um PBG completo (faixa em preto) pouco acima da freqüência normalizada 1,0. Na região de 0 a 1,0, ocorre a presença de um pseudogap, o qual evanesce devido à superposição de bandas fotônicas permitidas nos pontos $\mathbf{U}$ e W. Este diagrama de bandas deve-se à nova configuração de rede obtida com a variação do fator de empacotamento, a qual não é mais um arranjo FCC, apesar de as distâncias interplanares permanecerem inalteradas.

Na Fig. 3.12, a existência de uma banda proibida ao longo de toda a zona irredutível de Brillouin demonstra que o fator de empacotamento é um parâmetro significativo a ser considerado no projeto de um cristal fotônico tridimensional, haja vista que variações no seu respectivo valor podem significar a obtenção de um completo PBG.

De todo modo, seja no cristal com $f p=54 \%$, seja no cristal FCC perfeito, podem ser observados gaps fotônicos ao longo de certas direções de propagação. A existência destas bandas proibidas está associada ao fenômeno da difração de Bragg e, por seu turno, possibilita investigar o quão bem ordenadas as opalas estão na rede cristalina.

A investigação de padrões de difração de Bragg relacionados às amostras de cristal fotônico fabricadas é o objeto de discussão do próximo capítulo. 


\section{4 - ESPECTROS DE REFLETÂNCIA ASSOCIADOS AO CRISTAL COMPOSTO POR OPALAS DE LÁTEX}

Este capítulo dá prosseguimento à apresentação e discussão dos resultados obtidos por FDTD relativos ao cristal formado por opalas de látex. A abordagem aqui desenvolvida é direcionada à investigação de padrões de difração de Bragg associados aos planos da rede cristalina. Esta investigação é conduzida pelo cálculo de espectros de refletância através do método FDTD, seguindo uma linha comparativa com a caracterização experimental do cristal realizada pelo Instituto de Química de Araraquara [32].

A discussão realizada neste capítulo toma como base o conceito da difração de Bragg para analisar a variação do comprimento de onda de pico e largura de faixa do espectro de refletância diante do aumento do ângulo de incidência. Isto possibilita não somente averigüar o arranjo das opalas de látex na rede cristalina, como também evidenciar que o cristal apresenta bandas fotônicas proibidas em certas direções de propagação.

A seção inicial dedica-se a apresentar os resultados experimentais de refletância especular para cada uma das amostras fabricadas. São discutidos também os valores obtidos para diâmetro das opalas, fator de empacotamento e índice de refração efetivo, estimados a partir de um ajuste entre os valores experimentais e o que é predito pelo princípio da difração de Bragg.

As seções seguintes tratam dos resultados de refletância obtidos numericamente a partir do método FDTD, empregando os valores de diâmetro e fator de empacotamento apresentados na seção anterior. Primeiramente, é discutido o procedimento que possibilita o cálculo do comprimento de onda de Bragg à medida que o ângulo de incidência é aumentado. Posteriormente, os resultados numéricos são apresentados em conjunto com os valores experimentais, de tal forma que seja possível estabelecer comparações entre as curvas obtidas. 
Encerrando o capítulo, o conceito de FWHM (full width at half maximum) é utilizado para investigar a variação da largura do espectro de refletância à medida que o ângulo de incidência é aumentado. Este resultado foi obtido numericamente a partir do método FDTD e refere-se à rede cristalina perfeita.

\section{1 - Espectros de refletância associados à família de planos (111) do cristal de látex}

Estudar as propriedades ópticas de um cristal fotônico por meio de espectros de refletância possibilita avaliar a qualidade da rede cristalina obtida, isto é, verificar se o cristal de fato apresenta o arranjo esperado. Mediante a incidência de um feixe óptico normal à superfície do cristal, a obtenção de um comprimento de onda de reflexão pode indicar a existência de um plano cristalino. No entanto, isto não permite afirmar que a periodicidade obtida seja a mesma também para outras direções da rede. Por outro lado, se o ângulo de incidência do feixe óptico for variado, pode-se obter uma variação do comprimento de onda de reflexão condizente com que é previsto pelo princípio da difração de Bragg e assegurar que a separação interplanar leva, em boa medida, à periodicidade desejada.

A expressão que permite o cálculo do comprimento de onda de Bragg $\lambda_{M}$, o qual corresponde ao comprimento de onda de reflexão, como função do ângulo de incidência $\theta$ (medido a partir da normal ao plano no qual a onda incide) é dada em (4.1) [50]-[51]:

$$
\lambda_{M}=\frac{2 d_{h k l}}{m} \sqrt{n_{e f}^{2}-\operatorname{sen}^{2} \theta}
$$


onde $d_{h k l}$ corresponde à distância interplanar e $m$ é a ordem de difração, a qual é assumida neste trabalho ser igual a 1 . Os subscritos $h, k$ e $l$ referem-se aos índices de Miller que definem o plano cristalino [35].

Em uma primeira aproximação [32], o índice de refração efetivo $n_{e f}$ do cristal pode ser determinado a partir da expressão dada em (4.2), em que $f p$ é o fator de empacotamento, $n_{\text {mat }}$ é o índice de refração das opalas (1,59 para o látex) e $n_{a r}$ corresponde ao índice de refração do espaço livre:

$n_{e f}=f p n_{m a t}+(1-f p) n_{a r}$

De acordo com o que é descrito em [32], a caracterização do cristal composto por opalas de látex foi realizada mediante a obtenção dos espectros de refletância sob diferentes ângulos de incidência, tomando como referência a família de planos (111). Esta caracterização foi realizada para as quatro amostras fabricadas (vide capítulo 3 - seção 3.1).

Os espectros de refletância obtidos experimentalmente são mostrados na Fig. 4.1. É observado um progressivo deslocamento do pico de refletância para menores comprimentos de onda à medida que o ângulo de incidência é aumentado, como é esperado a partir de (4.1).

Para estimar o fator de empacotamento, o diâmetro das opalas e o índice de refração efetivo de cada amostra, foi realizado em [32] um ajuste (fitting) entre os valores de $\lambda_{M}$ experimentais e os calculados a partir de (4.1). Os resultados estão listados na tabela III. 

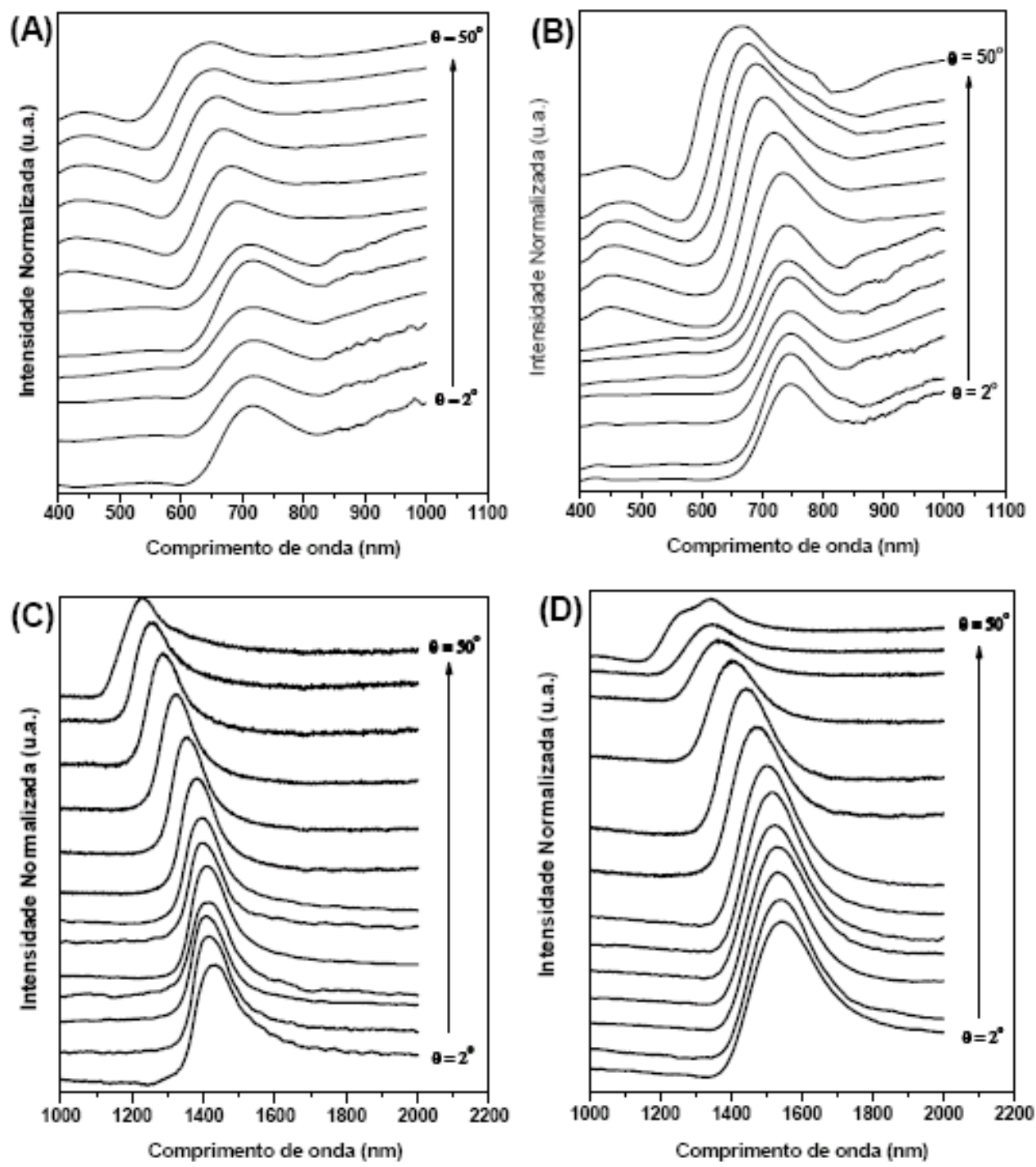

Fig. 4.1 - Espectros de refletância obtidos experimentalmente sob diferentes ângulos de incidência: (A) látex-250, (B) látex-300, (C) látex-350, (D) látex-400 [32]. 
Tabela III. Valores de fator de empacotamento, diâmetro das opalas e índice de refração efetivo das amostras de cristal fotônico fabricadas [32].

\begin{tabular}{c|c||c|c}
\hline \hline $\begin{array}{c}\text { Amostra de cristal } \\
\text { fotônico }\end{array}$ & $\begin{array}{c}\text { Fator de } \\
\text { empacotamento (\%) }\end{array}$ & $\begin{array}{c}\text { Diâmetro das opalas } \\
(\mathrm{nm})\end{array}$ & $\begin{array}{c}\text { Índice de refração } \\
\text { efetivo }\end{array}$ \\
\hline \hline látex-250 & 73 & 290 & 1,43 \\
\hline látex-300 & 73 & 303,5 & 1,43 \\
\hline látex-350 & 59 & 610 & 1,35 \\
\hline látex-400 & 54 & 685 & 1,32 \\
\hline
\end{tabular}

Este trabalho realizou a determinação teórica dos espectros de refletância por meio do método FDTD. As simulações computacionais foram realizadas para cada amostra de tal modo a obter o comprimento de onda de Bragg para diferentes ângulos de incidência no plano (111). Os valores de fator de empacotamento, diâmetro das opalas e índice efetivo utilizados nas simulações são aqueles listados na tabela III.

Antes de realizar a discussão dos resultados obtidos numericamente, faz-se oportuna uma breve explanação sobre como obter os valores de comprimento de onda de Bragg a partir do método FDTD. A seguir, é explicado o procedimento empregado neste trabalho para o cálculo de $\lambda_{M}$ à medida que o ângulo de incidência $\theta$ é variado.

\subsection{1 - Procedimento de cálculo do comprimento de onda de Bragg $\left(\lambda_{M}\right)$ pelo método FDTD}

Para o cálculo dos espectros de refletância, a fonte de excitação eletromagnética empregada nas simulações consistiu de um dipolo elétrico que produz um sinal senoidal de 
envoltória gaussiana. O ângulo que a reta proveniente do dipolo faz com a normal ao plano (111) corresponde ao ângulo de incidência [52].

A refletância corresponde ao quadrado da razão entre os módulos dos espectros do campo refletido e do campo incidente. Para a obtenção destes espectros, aplica-se DFT (discrete Fourier transform) à seqüência temporal de uma dada componente de campo (elétrico ou magnético) em pontos distintos da malha computacional. Estes pontos são localizados observando que o ângulo de incidência é igual ao ângulo de reflexão. A Fig. 4.2 esquematiza as localizações dos pontos de reflexão e incidência para uma onda que atinge a fronteira da estrutura modelada. O plano correspondente a esta fronteira é transversal à página. Os símbolos $\mathbf{x}$ e $\bullet$ representam, respectivamente, os pontos onde são tomados os campos refletido e incidente.

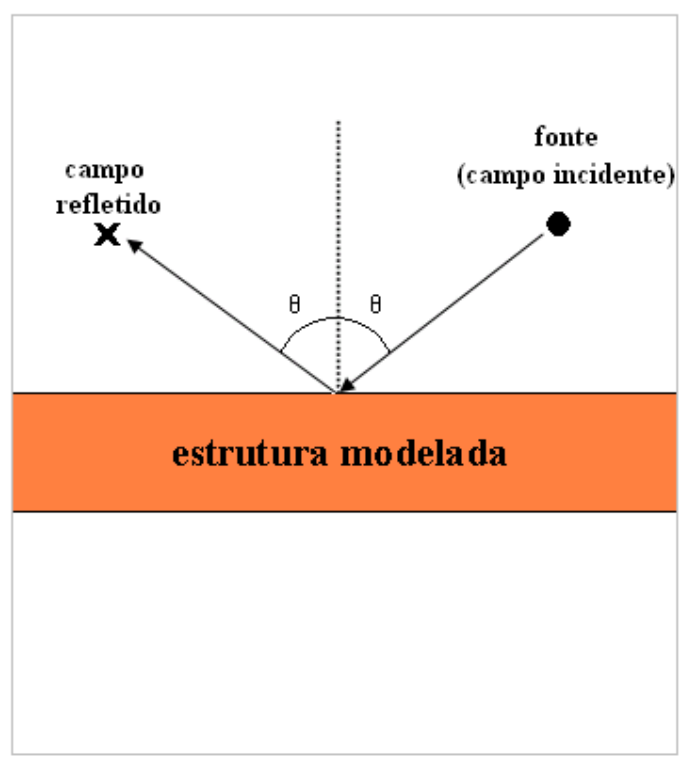

Fig. 4.2 - Visualização esquemática dos pontos onde é tomada a seqüência temporal dos campos incidente e refletido. A linha tracejada é normal à fronteira da estrutura modelada. A linha em cinza delimita o domínio computacional.

Como mencionado anteriormente, em princípio, obtém-se o espectro de refletância a partir do quadrado da razão entre os módulos das DFTs dos campos refletido e incidente. 
Entretanto, é preciso ter em mente que as frentes de onda que se propagam a partir da fonte e incidem na estrutura também passam pelo ponto de reflexão. Em outras palavras, também existe energia eletromagnética incidente no ponto onde é tomado o campo refletido. Por conseguinte, o ponto de reflexão compreende, na verdade, ondas incidentes e refletidas.

Para obter a seqüência temporal do campo efetivamente refletido é necessário subtrair o campo incidente do campo calculado no ponto de reflexão. Com isto, o espectro de refletância, expresso em termos da DFT do campo elétrico, é dado por (4.3) [52]:

$$
R(\lambda)=\left|\frac{E_{\text {total }}(\lambda)-E_{\text {inc }}(\lambda)}{E_{\text {inc }}(\lambda)}\right|^{2}
$$

Em (4.3), $E_{\text {total }}(\lambda)$ é a DFT do campo tomado no ponto de reflexão, o qual corresponde à superposição entre o campo refletido e o incidente, e $E_{\text {inc }}(\lambda)$ é a DFT do campo tomado no ponto de incidência. A partir do procedimento de cálculo acima, $\lambda_{M}$ é determinado obtendo-se o comprimento de onda correspondente ao pico de $R(\lambda)$. Os valores de $\lambda_{M}$ obtidos a partir do método FDTD são mostrados a seguir.

\subsection{2 - Variação do comprimento de onda de Bragg à medida que o ângulo de incidência é aumentado}

Na Fig. 4.3, são apresentados os comprimentos de onda de Bragg dos espectros de refletância relativos às quatro amostras fabricadas. Em cada gráfico, os resultados FDTD são apresentados conjuntamente com os resultados experimentais. 


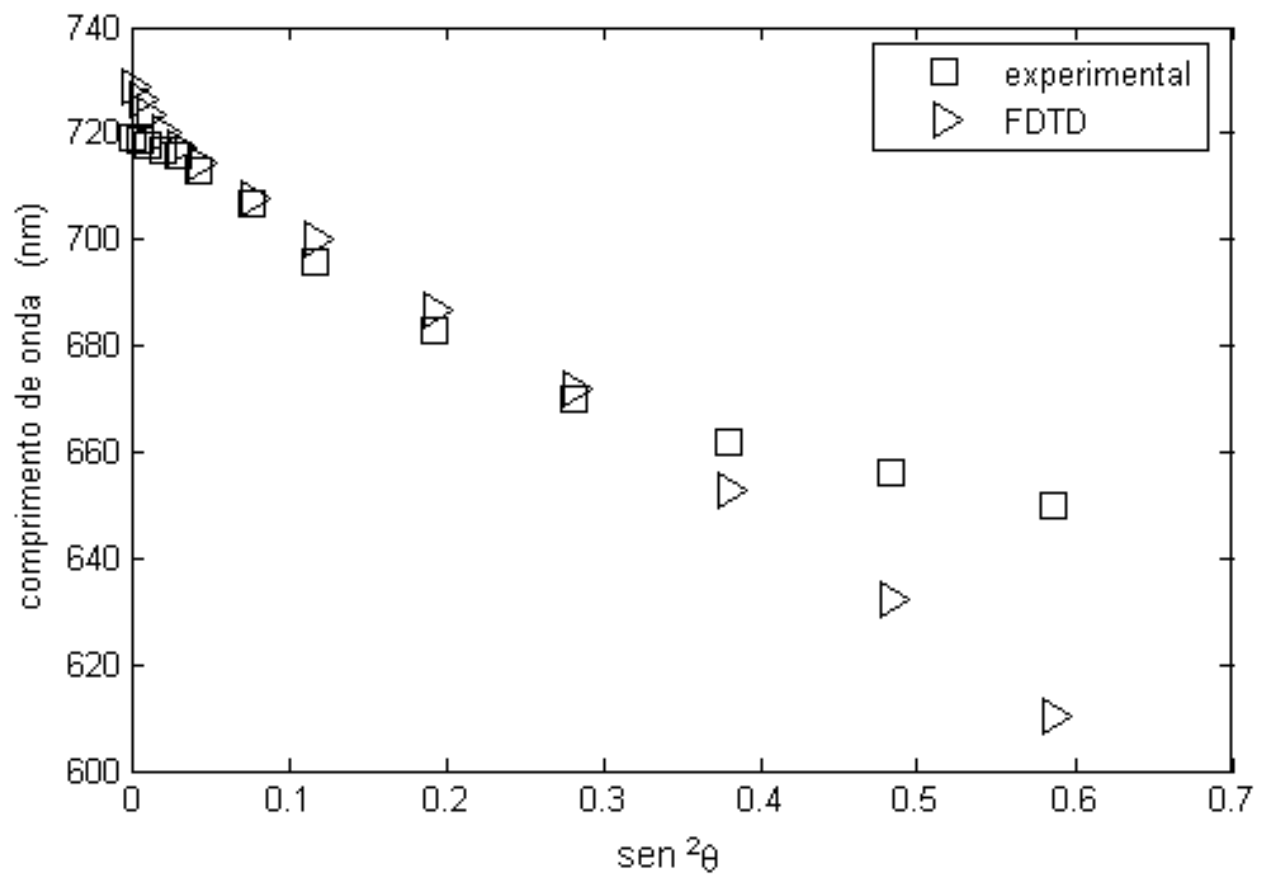

(a)

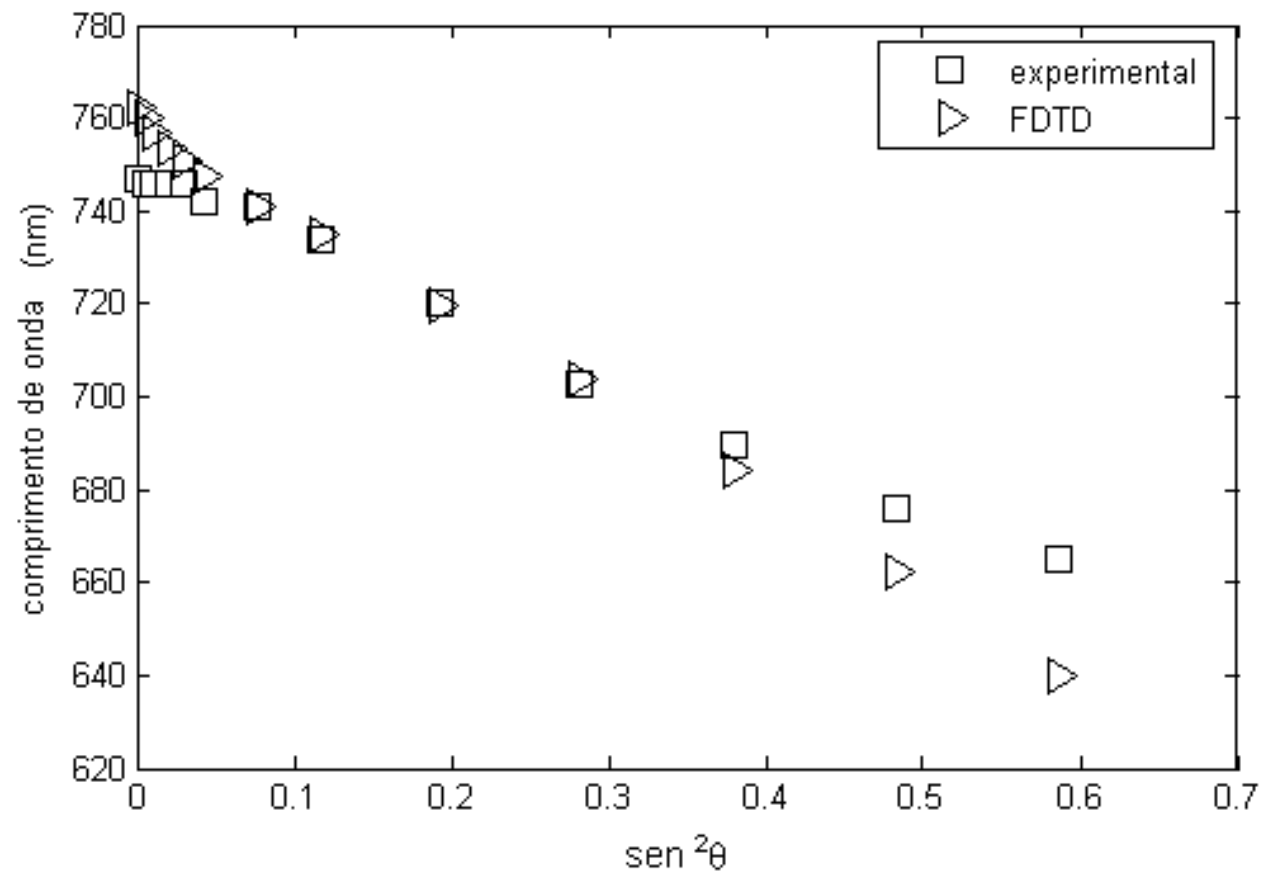

(b) 


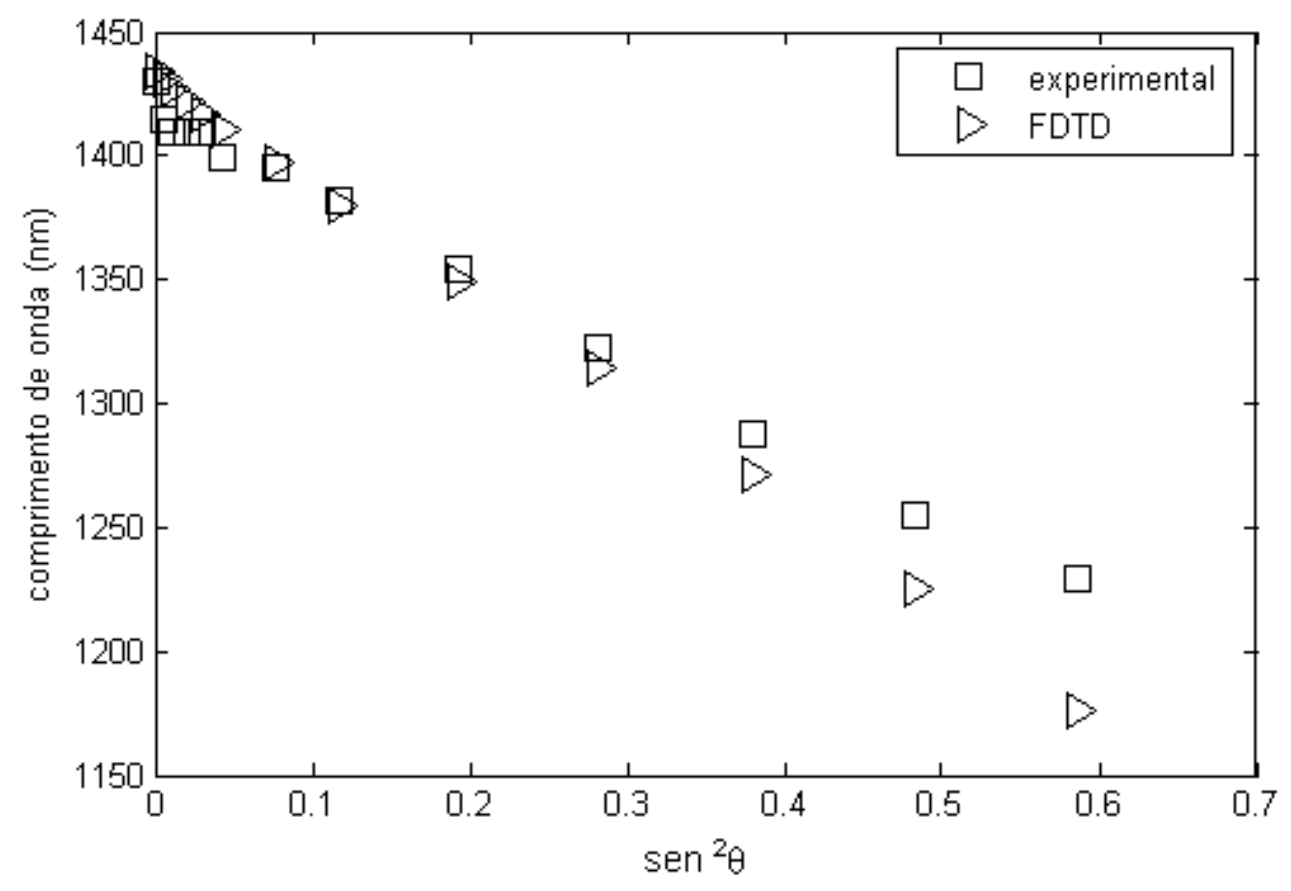

(c)

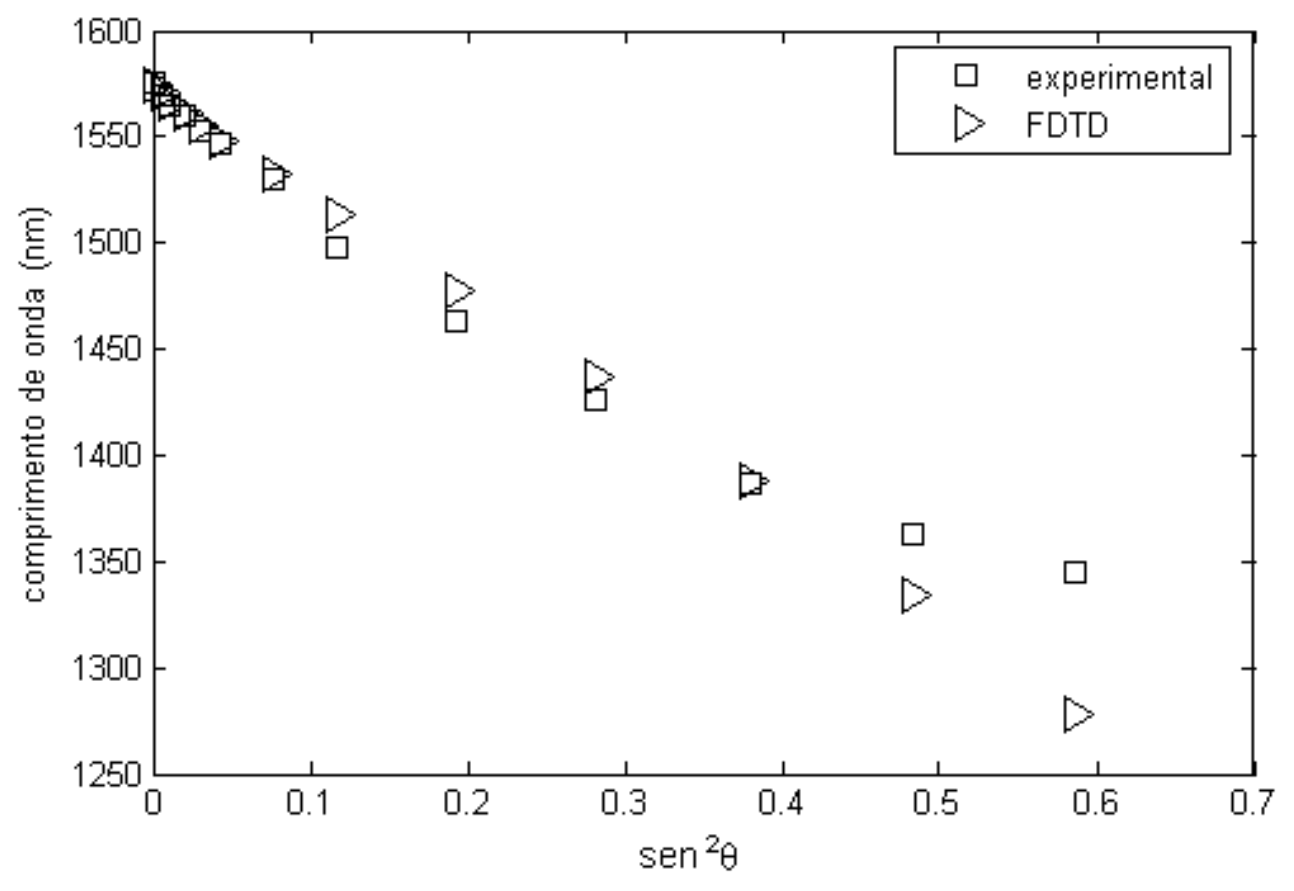

(d)

Fig. 4.3 - Variação do comprimento de onda de Bragg $\operatorname{com}^{2} \operatorname{sen}^{2} \theta$. Os diagramas correspondem às quatro amostras fabricadas: (a) látex-250, (b) látex-300, (c) látex-350 e (d) látex-400. 
O algoritmo FDTD foi empregado no cálculo de alguns espectros de refletância para a amostra látex-400. Estes espectros foram obtidos para quatro valores de $\theta$ e são mostrados na Fig. 4.4.

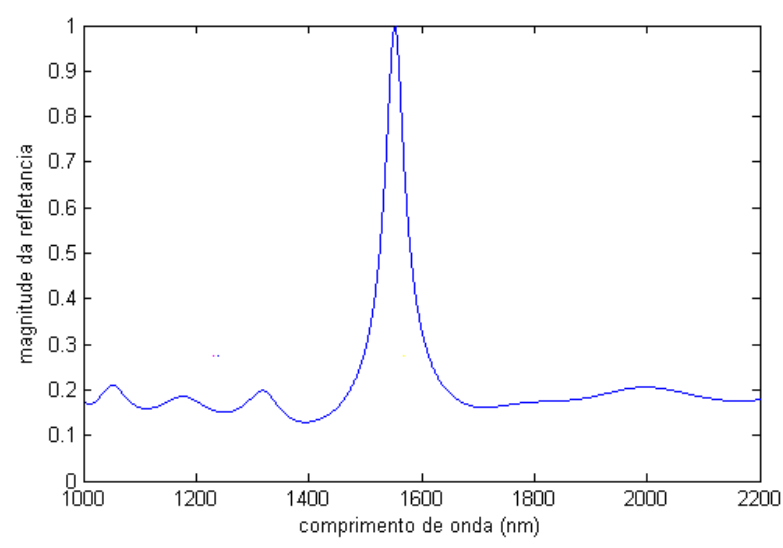

(a) $\theta=2^{\circ}, \lambda_{\max }=1555 \mathrm{~nm}$.

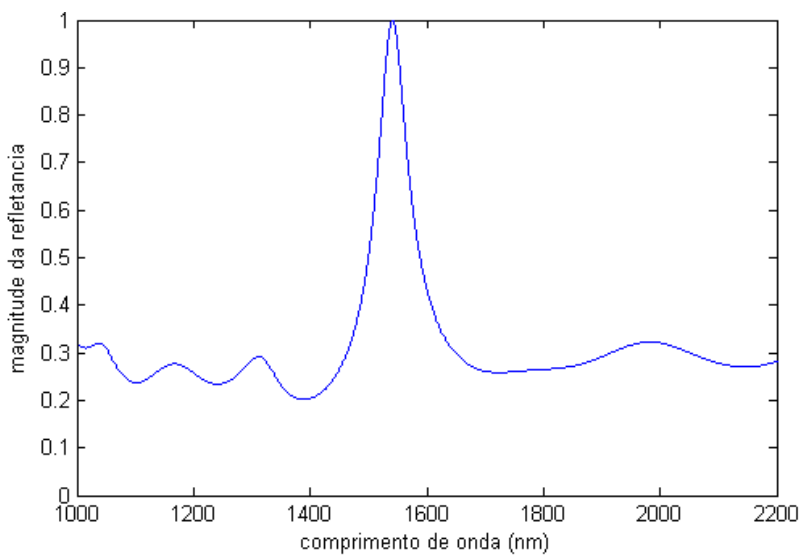

(b) $\theta=10^{\circ}, \lambda_{\max }=1542 \mathrm{~nm}$.

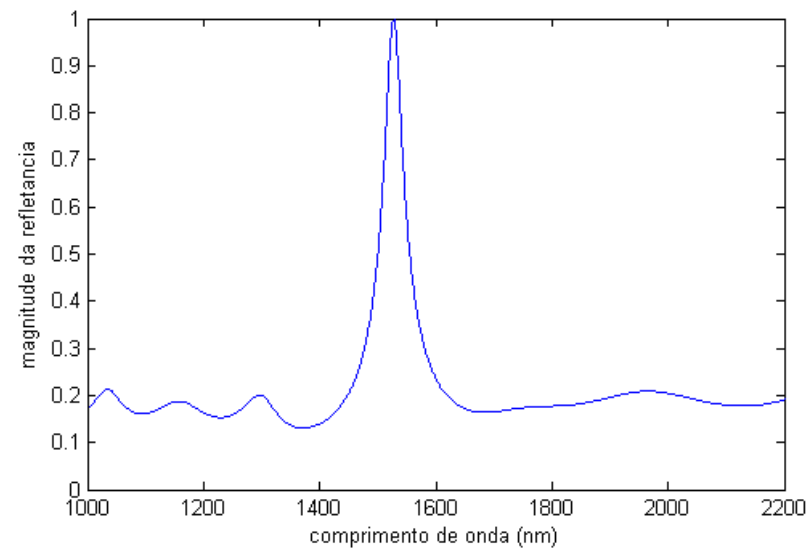

(c) $\theta=15^{\circ}, \lambda_{\max }=1528 \mathrm{~nm}$.

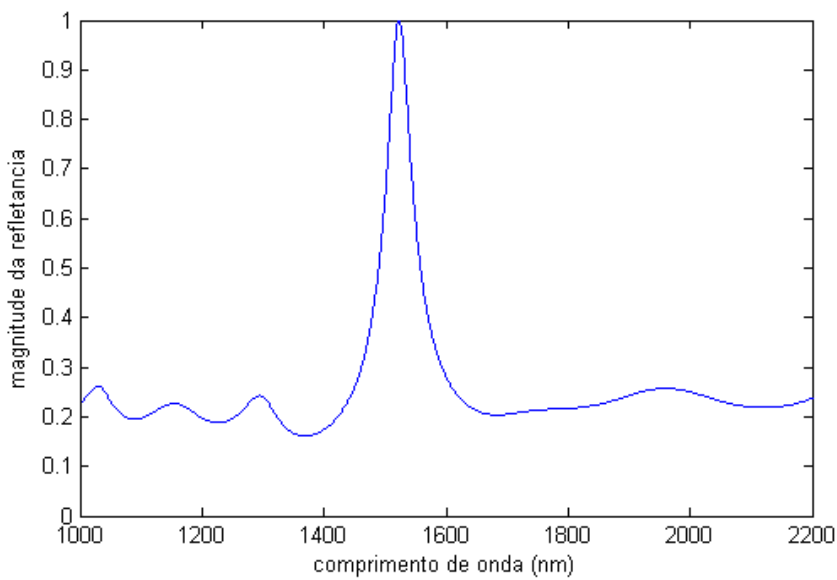

(d) $\theta=20^{\circ}, \lambda_{\max }=1515 \mathrm{~nm}$.

Fig. 4.4 - Espectros de refletância para ângulos de incidência (a) $\theta=2^{\circ}$, (b) $\theta=10^{\circ}$, (c) $\theta=15^{\circ}$ e (d) $\theta=20^{\circ}$ no plano (111) obtidos por FDTD. 
Os comprimentos de onda calculados a partir do método FDTD concordam com o que é predito por (4.1). Por outro lado, desviam-se dos resultados experimentais à medida que é aumentado o ângulo de incidência. As razões possíveis desta divergência compreendem dois fatores:

I. Imperfeições das redes cristalinas fabricadas;

II. Alargamento da faixa espectral de refletância ocasionado por reflexões de planos adjacentes;

No que se refere ao item I, as imperfeições dos cristais fabricados estão distribuídas randomicamente pela rede, levando a modificações também randômicas das distâncias interplanares [53]-[54]. Esta variação nas separações entre os planos cristalinos tem como efeito desviar o comprimento de onda de Bragg $\lambda_{M}$ do valor associado à rede perfeita, levando a diferenças entre os valores numéricos e experimentais de $\lambda_{M}$ à medida que é aumentado o ângulo de incidência.

Modelar a aleatoriedade da variação da distância interplanar exige modelar a distribuição randômica de um grande número de opalas. Isto implica supor um cristal de dimensões bem maiores que a estrutura aqui modelada, o que, por sua vez, exige excessiva capacidade de processamento e armazenamento de dados. Apesar de o suporte computacional aqui utilizado limitar a modelagem a cristais sem desordenamento na distribuição das opalas, foi possível obter um indicativo do impacto da variação de $d_{111}$ no valor do comprimento de onda de Bragg por meio do método FDTD. Para realizar esta simulação, o aumento da distância interplanar foi considerado uniforme, isto é, o incremento da separação foi sempre o mesmo entre qualquer par de planos consecutivos (111). Os cálculos partiram da rede FCC perfeita e consideraram o ângulo 
de incidência constante. Como, para a amostra látex-300 (estrutura mais próxima da rede FCC perfeita entre os cristais fabricados), a diferença entre os valores numéricos e experimentais é significativa para $38^{\circ}$, o ângulo de incidência foi fixado neste valor à medida que a distância interplanar $d_{111}$ era aumentada.

O diagrama resultante desta simulação é mostrado na Fig. 4.5. Observa-se que um aumento percentual pouco maior que $7,5 \%$ no valor de $d_{111}$ desloca $\lambda_{M}$ de $681 \mathrm{~nm}$ (valor relacionado à rede perfeita) para, aproximadamente, $730 \mathrm{~nm}$, ou seja, um desvio percentual de $7,20 \%$.

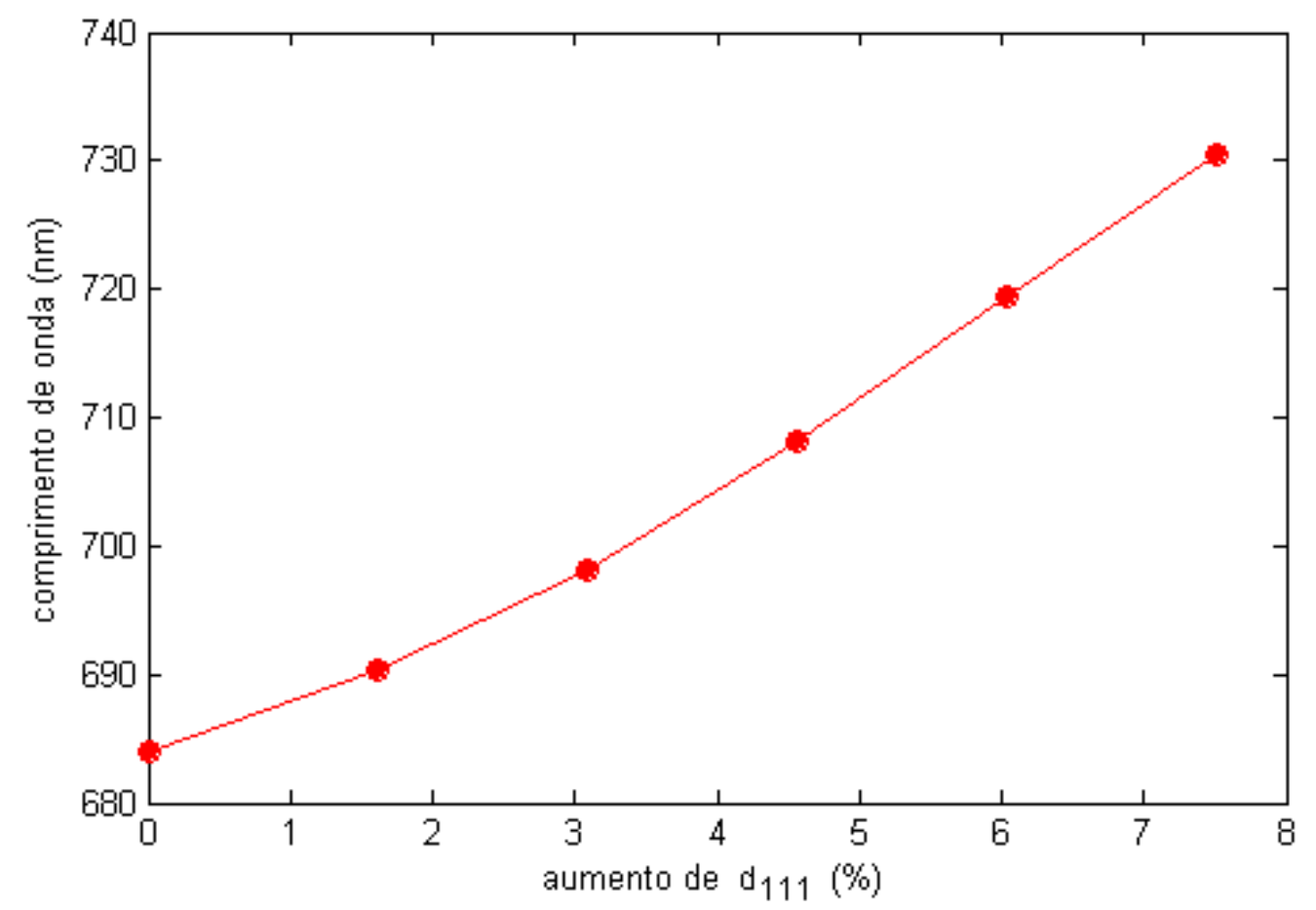

Fig. 4.5 - Variação do comprimento de onda de Bragg à medida que a distância interplanar $d_{111}$ é aumentada. O valor do ângulo de incidência está fixado em $\theta=38^{\circ}$. 
Os resultados mostrados na Fig. 4.3, em conjunto com o que é indicado na Fig. 4.5, permitem inferir que, apesar de o cálculo FDTD sugerir teoricamente que um arranjo FCC foi obtido, a existência de defeitos cristalinos distribuídos randomicamente ao longo das amostras fabricadas desvia o comprimento de onda de Bragg do valor associado à rede perfeita.

Reflexões devido a planos adjacentes (item II) apresentam ainda maior influência na variação da largura do espectro de refletância [54], como será mostrado posteriormente.

Deve ser observado ainda que, para um cristal infinito e sem defeitos, o espectro de refletância corresponde exatamente ao comprimento de onda de Bragg $\lambda_{M}$. Como a estrutura aqui modelada é de espessura finita, os espectros obtidos pelo método FDTD também incluem comprimentos de onda próximos a $\lambda_{M}$. Tendo isto em vista, um importante parâmetro a ser discutido é a largura dos espectros de refletância. A investigação deste parâmetro permite avaliar a influência de reflexões simultâneas de planos adjacentes e também da espessura finita do cristal nos padrões de difração de Bragg.

A variação da largura dos espectros de refletância é objeto de discussão da seção a seguir.

\section{2 - Variação da largura do espectro de refletância com o ângulo de incidência}

Para definir a largura dos espectros de refletância, foi empregado o conceito de FWHM (full width at half maximun). Isto significa que a largura espectral é obtida através da diferença entre os comprimentos de onda nos quais a intensidade cai à metade do valor de pico. Uma visualização esquemática da definição do FWHM é mostrada na Fig. 4.6. 


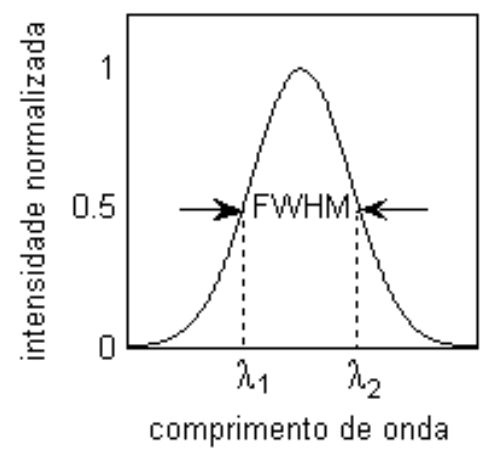

Fig.4.6 - A definição de FWHM compreende o intervalo espectral no qual a intensidade cai à metade do valor de pico.

A variação da largura espectral com o aumento do ângulo de incidência foi obtida através do método FDTD para o cristal formado por opalas de látex com diâmetro de 303,5 nm, valor relativo à amostra látex-300, cuja estrutura cristalina foi a que apresentou um ordenamento de opalas mais próximo da rede FCC perfeita.

Os resultados obtidos numericamente são mostrados na Fig. 4.7. O diagrama apresentado evidencia que, para valores de $\theta$ inferiores a $20^{\circ}$, a largura espectral permanece estabilizada em torno de $3,7 \%$. No entanto, à medida que o ângulo de incidência é aumentado, este parâmetro experimenta um crescimento em direção a $10 \%$. 


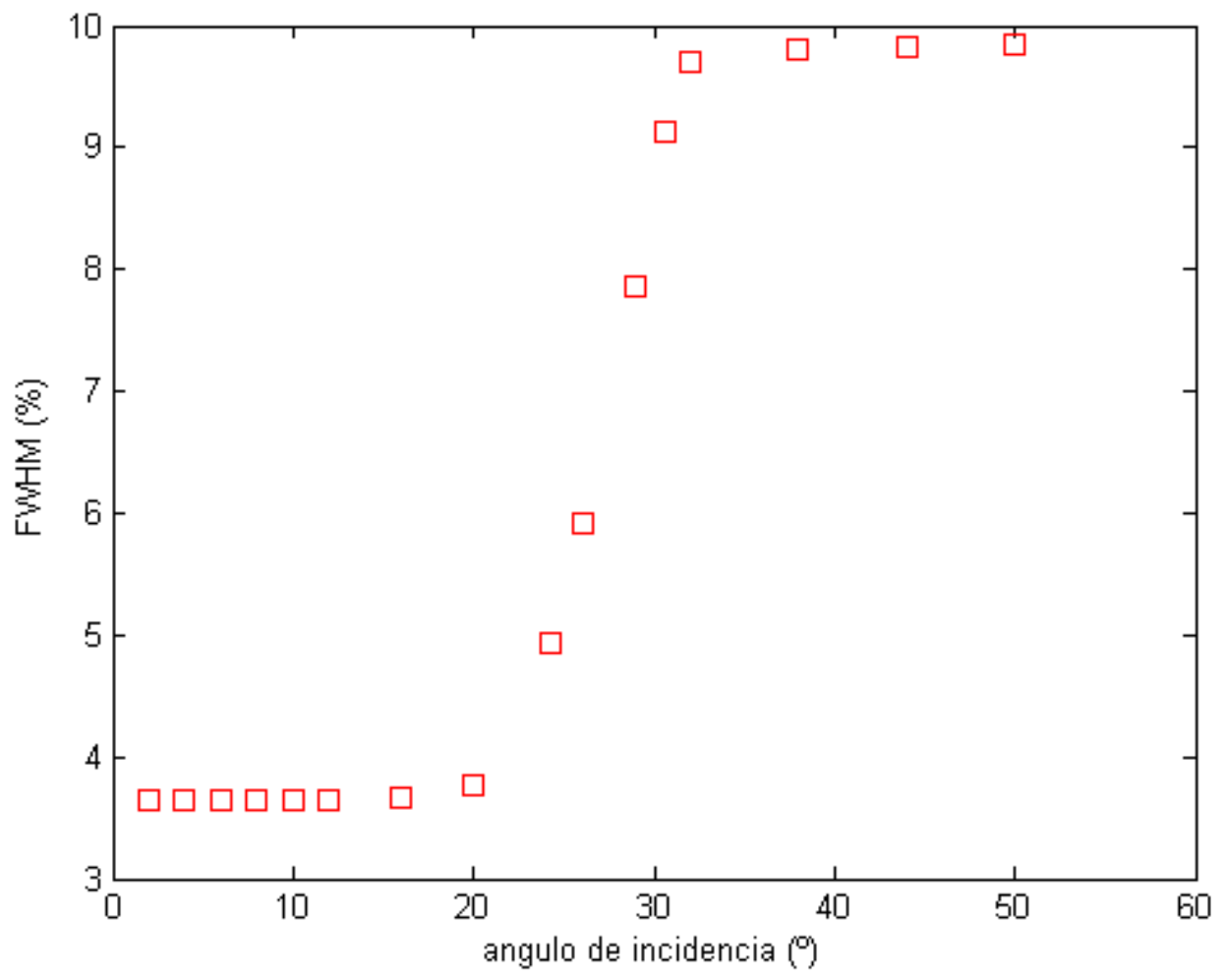

Fig. 4.7 - Variação do FWHM calculada por FDTD à medida que o ângulo de incidência é aumentado. O valor percentual é tomado em relação ao comprimento de onda do pico de refletância.

O gráfico mostrado na Fig. 4.7 denuncia um alargamento do espectro de difração de Bragg devido a reflexões simultâneas de planos adjacentes. À medida que o ângulo de incidência é aumentado para valores acima de $20^{\circ}$, parte do sinal incidente é refletida pelo próprio plano (111), mas há também reflexões devido a planos próximos a este. Isto significa que a faixa espectral de reflexão do plano (111) passa a incluir também comprimentos de onda relativos à reflexão de outros planos cristalinos [53]-[54].

No entanto, o alargamento espectral não é somente resultado das reflexões de planos adjacentes a (111), mas também recebe a influência da espessura finita da rede cristalina simulada [54]. A espessura finita da rede periódica induz um descasamento entre os meios na 
interface cristal-ar, contribuindo para aumentar a largura das faixas espectrais de refletância associadas ao plano (111).

Assim como o que ocorre no diagrama da Fig. 4.7, também foi observado na caracterização experimental um aumento da largura espectral para ângulos de incidência superiores a $20^{\circ}$. Entretanto, os valores de FWHM calculados numericamente são significativamente menores que aqueles encontrados nos experimentos para a amostra látex-300. Na Fig. 4.7, a largura espectral sofre um aumento de 3,7\% para, aproximadamente, $10 \%$ quando o ângulo de incidência varia de $2^{\circ}$ até $50^{\circ}$. No entanto, para este mesmo intervalo de variação angular, os experimentos mostraram uma elevação de $10 \%$ para $18 \%$ no valor de FWHM. Esta divergência entre os resultados práticos e numéricos provém da existência de defeitos no cristal fabricado, defeitos estes correspondentes à variação randômica da posição das opalas em relação ao que é esperado para uma rede FCC perfeita, conforme é observado na Fig. 3.1 (vide capítulo 3 - seção 3.1). 


\section{5 - CONCLUSÃO}

Os capítulos concernentes a este trabalho dedicaram-se a discutir uma abordagem numérica para o estudo de cristais fotônicos tridimensionais. Tal abordagem é fundamentada no método das diferenças finitas no domínio do tempo (FDTD), um método numérico explícito que possibilita a determinação das componentes de campo elétrico e magnético diretamente a partir das equações de Maxwell. Como o estudo de cristais fotônicos é realizado pela obtenção de informações no domínio da freqüência, a forma discreta da transformada de Fourier (DFT discrete Fourier transform) foi utilizada conjuntamente com o método FDTD para a obtenção de diagrama de bandas e espectros de refletância.

Por meio de uma aferição com resultados já apresentados na literatura, foi demonstrada a validade da aplicação do método FDTD ao estudo de cristais fotônicos tridimensionais. Através deste método, foi modelada uma rede cristalina infinita nas direções $x$ e $y$ e finita na direção $z$, o que necessitou de duas condições de contorno distintas: nas direções em que o cristal é considerado infinito, é aplicada a condição de contorno periódica e, na direção em que a rede cristalina possui tamanho finito, é aplicada PML. Esta modelagem objetivou implementar um algoritmo FDTD que pudesse retratar de forma mais realística as propriedades eletromagnéticas de um cristal fotônico tridimensional sem que, para isto, o algoritmo desenvolvido exigisse esforço computacional excessivo. Mesmo com esta modelagem, a obtenção de diagramas de bandas e espectros de refletância exigiu a utilização de um cluster de computadores para que o processamento fosse executado em tempo hábil.

A implementação do algoritmo FDTD teve como objeto de estudo cristais fotônicos tridimensionais de célula unitária FCC. Mais especificamente, as amostras de cristal fotônico fabricadas pelo Instituto de Química de Araraquara. Estes cristais são constituídos por opalas de 
látex imersas em ar, conferindo à estrutura um contraste de índice de refração de 0,59. Foram realizados cálculos de diagrama de bandas tanto para o cristal FCC perfeito quanto para a rede com fator de empacotamento igual a $54 \%$.

As simulações realizadas indicaram que o baixo contraste de índice de refração do cristal FCC formado por opalas látex impede a formação de um PBG ao longo de toda a zona de Brillouin. No entanto, para o cristal com fator de empacotamento de 54\%, foi possível obter um PBG completo.

Também foram calculados por meio do método FDTD comprimentos de onda de Bragg associados à família de planos cristalinos (111), os quais já haviam sido visualizados experimentalmente. Nestes cálculos, à medida que o ângulo de incidência era variado, a divergência entre os valores numéricos e experimentais evidenciou a influência das imperfeições das amostras fabricadas nas propriedades ópticas do cristal. Os cálculos FDTD também foram capazes de mostrar que a espessura finita da rede cristalina, conjuntamente com planos adjacentes a (111), tem forte influência no alargamento da faixa espectral de refletância.

Sob uma visão geral, este trabalho demonstrou que, apesar de o cristal FCC de látex não possuir um PBG completo, é possível obter bandas fotônicas proibidas ao longo de algumas direções de propagação, conforme foi evidenciado através da investigação de espectros de refletância relativos aos planos (111). Além disto, foi mostrado que o diagrama de bandas é dependente do fator de empacotamento do cristal. Estas investigações tornam a modelagem aqui desenvolvida uma apropriada ferramenta de simulação para futura otimização do cristal FCC de periodicidade tridimensional.

Como proposta para futuros trabalhos, cita-se a modelagem da variação randômica das opalas ao longo da estrutura cristalina, o que possibilita investigar sob um prisma mais realístico a influência de defeitos nas propriedades ópticas do cristal tridimensional. No entanto, conforme 
foi mencionado nesta dissertação, a realização de tal modelagem está diretamente atrelada à disponibilidade de uma infraestrutura computacional significativamente mais robusta, isto é, com elevada capacidade de processamento e armazenamento de dados, de modo que seja possível analisar um cristal com um número de opalas maior que o utilizado neste trabalho, que seja finito em todas as direções. 


\section{6 - REFERÊNCIAS}

[1] K. Inoue and K. Ohtaka, Photonic Crystals: Physics, Fabrication and Applications, Nova York: Springer Verlag, 2004.

[2] J. D. Joannopoulos, R. Meade and J. Winn, Photonic Crystals - Molding the Flow of Ligth, Princeton: Princeton University Press, 1995.

[3] E. Yablonovitch, "Inhibited spontaneous emission in solid-state physics and electronics", Physical Review Letters, vol. 58, No 20, pp. 2059-2062, 1987.

[4] S. John, "Strong localization of photons in certain disordered dielectric superlattices", Physical Review Letters, vol. 58, No 23, pp. 2486-2489, 1987.

[5] E. Yablonovitch and T. J. Gmitter, "Photonic band structure: the face-centered-cubic case", Physical Review Letters, vol. 63, No 18, pp. 1950-1953, 1989.

[6] Z. Zhang and S. Satpathy, "Electromagnetic wave propagation in periodic structures: Bloch wave solution of Maxwell's equations", Physical Review Letters, vol. 65, No 21, pp. 26502653, 1990.

[7] K. M. Ho, C. T. Chan and C. M. Soukoulis, "Existence of a photonic gap in periodic dielectric structures", Physical Review Letters, vol. 65, No 25, pp. 3152-3155, 1990.

[8] E. Yablonovitch, T. J. Gmitter and K. M. Leung, "Photonic band structure: the face-centeredcubic case employing nonspherical atoms", Physical Review Letters, vol. 67, No 17, pp. 2295-2299, 1991.

[9] E. Yablonovitch and T. J. Gmitter, "Donor and acceptor modes in photonic band structures", Physical Review Letters, vol. 67, No 24, pp. 3380-3383, 1991.

[10] E. Özbay, A. Abeyta, G. Tuttle, M. Tringides, R. Biswas, C. T. Chan, C. M. Soukoulis and K. M. Ho, "Measurement of a three-dimensional photonic band gap in a crystal structure made of dielectric rods", Physical Review B, vol. 50, No 3, pp. 1945-1949, 1994. 
[11] A. L. Rogach, N. A. Kotov, D. S. Koktysh, J. W. Ostrander and G. A. Ragoisha, "Electrophoretic deposition of latex-based 3D colloidal photonic crystals: a technique for rapid production of High-Quality opals", Chemistry Materials, vol. 12, No 9, pp. 2721-2726, 1996.

[12] I. I. Tarhan and G. H. Watson, "Photonic band structure of fcc colloidal crystals", Physical Review Letters, vol. 76, No 2, pp. 315-318, 1996.

[13] K. Busch and S. John, "Photonic band gap formation in certain self-organizing systems", Physical Review E, vol. 58, No 3, pp. 3896-3908, 1998.

[14] R. D. Meade, K. D. Brommer, A. M. Rappe and J. D. Joannopoulos, "Existence of a photonic band gap in two dimensions", Applied Physics Letters, vol. 61, No 4, pp. 495-497, 1992.

[15] S. Y. Lin, E. Chow, V. Hietala, P. R. Villeneuve and J. D. Joannopoulos, "Experimental demonstration of guiding and bending of electromagnetic waves in a photonic crystal", Science, vol. 282, No 5387, pp. 274-276, 1998.

[16] A. Chutinan and S. Noda, "Waveguides and waveguide bends in two-dimensional photonic crystal slabs", Physical Review B, vol. 62, No 7, pp. 4488-4492, 2000.

[17] P. R. Villeneuve, S. Fan and J. D. Joannopoulos, “Air-bridge microcavities", Applied Physics Letters, vol. 67, No 2, pp. 167-169, 1995.

[18] S. G. Johnson, S. H. Fan, P. R. Villeneuve and J. D. Joannopoulos, "Guided modes in photonic crystal slabs", Physical Review B, vol. 60, No 8, pp. 5751-5758, 1999.

[19] T. Niemi, L. Frandsen, K. Hede, A. Harpoth, P. I. Borel and M. Kristensen, "Wavelengthdivision demultiplexing using photonic crystal waveguides", IEEE Photonics Technology Letters, vol. 18, No 1, pp. 226-228, 2006.

[20] M. Davanço, A. Xing, J. W. Raring, E. L. Hu and D. J. Blumenthal, "Compact broadband photonic crystal filters with reduced back-reflections for monolithic InP-based photonic integrated circuits", IEEE Photonic Technology Letters, vol. 18, No 10, pp. 1155-1157, 2006. 
[21] H. M. Driel, "Ultrafast optical-switching of 2-D photonic crystals", International Conference on Transparent Optical Networks 2006 (ICTION 2006), vol. 2, pp. 83-85, 2006.

[22] A. Faraon, E. Waks, D. Englund, I. Fushman and J. Vuckovic, "Efficient photonic crystal cavity-waveguide couplers", Applied Physics Letters, vol. 90, pp. 1-3, 2007.

[23] T. Yoshie, O. B. Shchekin, H. Chen, D. G. Deepe and A. Scherer, "Quantum dot photonic crystal lasers", Electronics Letters, vol. 38, No 17, pp. 967-968, 2002.

[24] P. Bhattacharya, J. Sabarinathan, J. Topolancik, S. Chakravarty, P. C. Yu and W. Zhou, "Quantum dot photonic crystal light sources", Proceedings of IEEE, vol. 93, No 10, pp. 1825$1838,2005$.

[25] K. Nozaki, S. Kita and T. Baba, "Room temperature continuous wave operation and controlled spontaneous emission in ultrasmall photonic crystal nanolaser", Optics Express, vol. 15, No 12, pp. 7506-7514, 2007.

[26] N. Skivesen, A. Têtu and M. Kristensen, "Photonic crystal waveguide biosensor", Optics Express, vol. 15, No 6, pp. 3169-3176, 2007.

[27] M. Lee and P. M. Fauchet, "Two-dimensional silicon photonic crystal based biosensing platform for protein detection", Optics Express, vol. 15, No 8, pp. 4530-4535, 2007.

[28] S. Wong, M. Deubel, F. Willard, S. John, G. Ozzin, M. Wegener and G. Freymann, "Direct laser writing of three-dimensional photonic crystals with a complete photonic band gap in chalcogenide glasses", Advanced Materials, vol. 18, No 3, pp. 265-269, 2006.

[29] A. Hynnien, J. Thijssen, E. Vermolen, M. Dijkstra and A. Blaaderen, "Self-assembly route for photonic crystals with a bandgap in the visible region", Nature Materials, vol. 6, pp. 202205, 2007.

[30] A. Taflove and S. Hagness, Computational Electrodynamics: The Finite-difference TimeDomain Method, Boston: Artech House, 2005.

[31] C. Herman and O. Hess, "Modified spontaneous-emission rate in an inverse opal structure with complete photonic band gap", Journal of Optical Society of America, vol. 19, No 12, pp. 3013-3018, 2002. 
[32] Bertholdo, Roberto, "Preparação e caracterização de cristais fotônicos 3D baseados em sistemas coloidais de látex e sílica", tese de doutorado da Universidade Estadual Paulista, Instituto de Química, 2005.

[33] W. Axmann and P. Kuchment, "An efficient finite element method for computing spectra of photonic and acoustic band-gap materials", Journal of Computational Physics, vol. 150, pp. 468-481, 1999.

[34] J. B. Pendry, "Calculating photonic band structure", Journal of Physics: Condensed Matter, vol. 8, pp. 1085-1108, 1996.

[35] C. Kittel, Introduction to Solid State Physics, John Wiley \& Sons, 2005.

[36] K. Yee, "Numerical solution of initial boundary value problems involving Maxwell equations in isotropic media", IEEE Transactions on Antennas and Propagation,vol. AP-14, No 3, pp. 302-307, 1966.

[37] A. Asi, and L. Shafai, "Dispersion analysis of anisotropic inhomogeneous waveguides using compact 2D-FDTD”, Electronics Letters, vol. 28 ,No 15, pp. 1451-1452, July 1992.

[38] N. N. Rao, Elements of Engineering Electromagnetics, Prentice Hall, 2000.

[39] J. P. Berenger, "A perfect matched layer for the absorption of electromagnetic waves", Journal of Computational Physics, No 114, pp. 185-200, 1994.

[40] J. P. Berenger, "Three-dimensional perfect matched layer for the absorption of electromagnetic waves", Journal of Computational Physics, No 127, pp.363-379, 1996.

[41] S. D. Gedney, "An anisotropic perfectly matched layer-absorbing medium for the truncation of FDTD lattices", IEEE Transactions on Antennas and Propagation, vol. 44, No 12, pp. 1630-1639, December 1996.

[42] G. Liu and S. D. Gedney, "Perfectly matched layer media for an unconditionally stable threedimensional ADI-FDTD method", IEEE Microwave and Guided Wave Letters, vol. 10, No 7, pp. 261-263, July, 2000. 
[43] C. M. Furse and O. P. Gandhi, "Why the DFT is faster then the FFT for FDTD time-tofrequency domain conversions", IEEE Microwave and Guided Wave Letters, vol. 5, No 10, pp. 326-328, October, 1995.

[44] C. Hermann, "Three dimensional finite-difference time-domain simulations of photonic crystals", tese de doutorado da Universidade de Stuttgart, Faculdade de Matemática e Física, 2004.

[45] S. G. Johnson and J. D. Joannopoulos, "Three-dimensionally periodic dielectric layered structure with omnidirectional photonic band gap", Applied Physics Letters, vol. 77, No 22, pp. 3490-3492, 2000.

[46] S. Noda, "Recent progresses and future prospects of two and three-dimensional photonic crystals", Journal of Lightwave Technology, vol. 24, No 12, pp. 4554-4567, 2006.

[47] H. B. Sun, S. Matsuo and H. Misawa, "Three-dimensional photonic crystal structures achieved with two-photon-absorption photopolymerization of resin", Applied Physics Letters, vol. 74, No 6, pp. 786-788, 1999.

[48] M. Campbell, D. N. Sharp, M. T. Harisson, R. G. Denning and A. J. Turberfield, "Fabrication of photonic crystals for the visible spectrum by holography lithography", Nature, vol. 404, No 2, pp. 53-56, 2000.

[49] B. A. Parviz, D. Ryan and G. M. Whitesides, "Using self-assembly for the fabrication of nano-scale electronic and photonic devices", IEEE Transactions on Advanced Packaging, vol. 26, No 3, pp. 233-241, 2003.

[50] L. V. Azároff, Elements of X-ray Crystallography, McGraw-Hill, New York, 1968.

[51] M. Allard, E. H. Sargent, E. Kumacheva and O. Kalinina, "Characterization of internal order of colloidal crystals by optical diffraction", Optical and Quantum Electronics, vol. 34, pp. 2736, 2002.

[52] S. H. Fan and J. D. Joannopoulos, "Analysis of guided resonances in photonic crystal slabs", Physical Review B, vol. 65, No 23, pp. 1-8, 2002. 
[53] Martinez, Jesús Manzanares, "Modelisation de cristaux photoniques a base d'opales", tese de doutorado da Universidade de Montpellier, 2002.

[54] C. F. Bohren and D. R. Huffman, Absorption and Scattering of Light by Small Particles, Nova York: John Wiley and Sons, 1983. 